\title{
REPORT \\ OF THE \\ BUILDING 9207 AIR BAG TEST
}

December 1992

by

T. E. Huff

K E Fricke

W. D. Jones

Structural and Architectural Engineering Department

and the

Center for Natural Phenomena Engineering

Engineering Division

Oak Ridge Y-12 Plant

managed by

Martin Marietta Energy Systems, Inc.

Oak Ridge, Tennessee

for the

U.S. Department of Energy

under contract DE-AC05-84OR21400 
fI

It

$I^{\prime}$

I'

I) 


\section{DISCLAIMER}

This report was prepared as an account of work sponsored by an agency of the United States Government. Neither the United States Government nor any agency thereof, nor any of their employees, make any warranty, express or implied, or assumes any legal liability or responsibility for the accuracy, completeness, or usefulness of any information, apparatus, product, or process disclosed, or represents that its use would not infringe privately owned rights. Reference herein to any specific commercial product, process, or service by trade name, trademark, manufacturer, or otherwise does not necessarily constitute or imply its endorsement, recommendation, or favoring by the United States Government or any agency thereof. The views and opinions of authors expressed herein do not necessarily state or reflect those of the United States Government or any agency thereof. 


\section{DISCLAIMER}

Portions of this document may be illegible in electronic image products. Images are produced from the best available original document. 


\section{CONTENTS}

FIGURES

TABLES $\ldots \ldots \ldots \ldots \ldots \ldots \ldots \ldots \ldots \ldots \ldots \ldots \ldots \ldots \ldots \ldots \ldots \ldots \ldots \ldots \ldots \ldots$

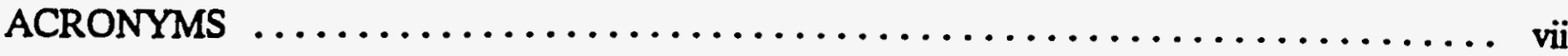

ACKNOWLEDGEMENTS $\ldots \ldots \ldots \ldots \ldots \ldots \ldots \ldots \ldots \ldots \ldots \ldots \ldots \ldots \ldots \ldots \ldots \ldots$ ix

EXECUTTVE SUMMARY $\ldots \ldots \ldots \ldots \ldots \ldots \ldots \ldots \ldots \ldots \ldots \ldots \ldots \ldots \ldots \ldots \ldots$

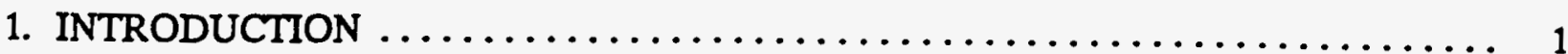

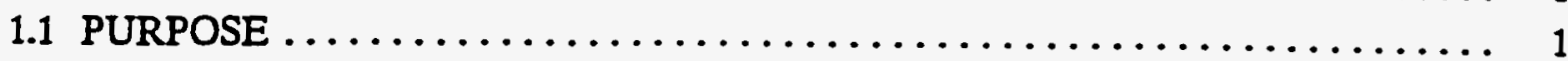

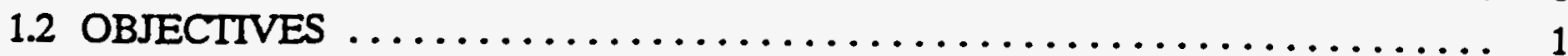

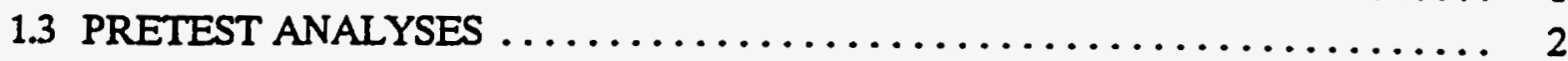

1.4 SUPPORTING TESTS ON THE AIR BAG WALI $\ldots \ldots \ldots \ldots \ldots \ldots \ldots, 2$

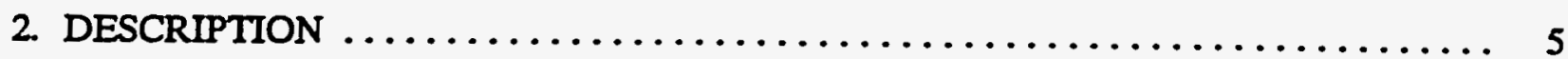

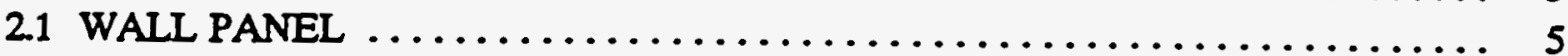

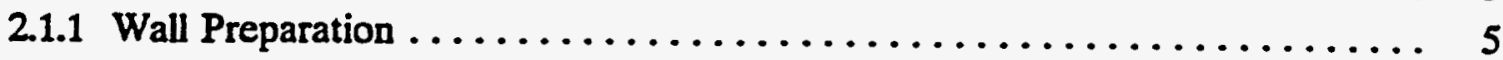

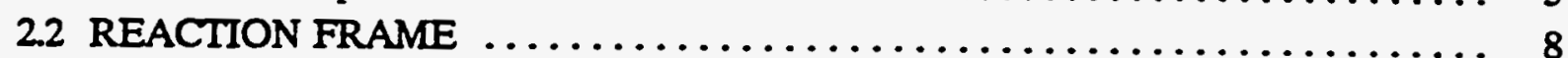

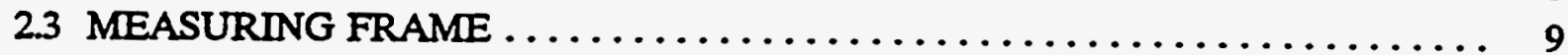

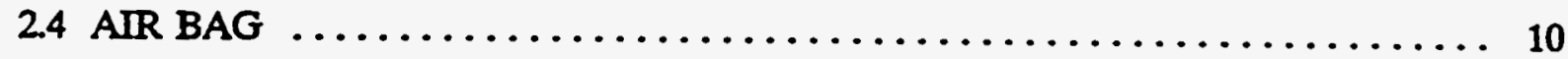

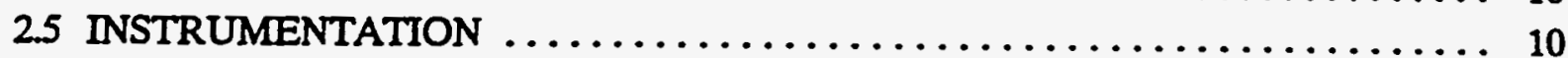

2.5 .1 LVDT's and Strain Gages ............................. 10

2.5 .2 Pressure Cushions ................................... 11

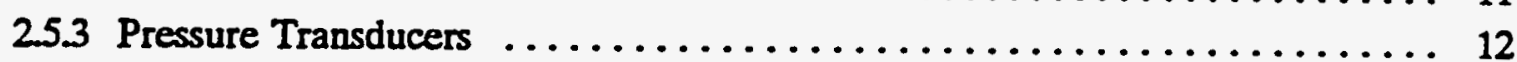

2.5 .4 Data Acquisition System ............................. 13

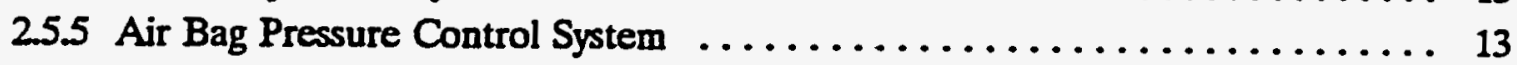

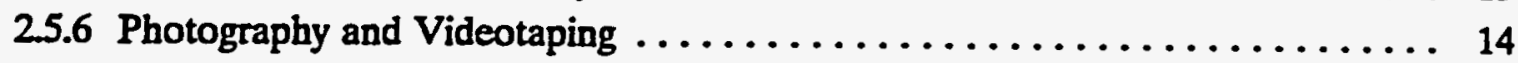

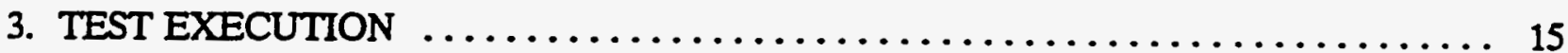

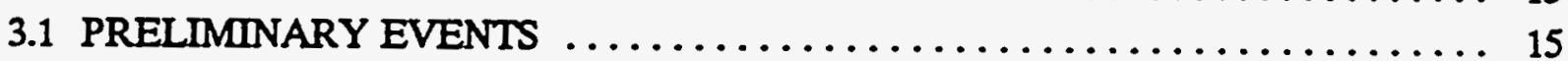

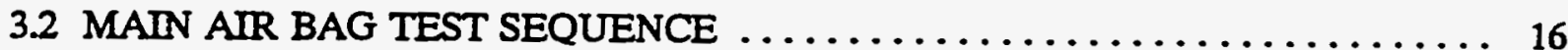




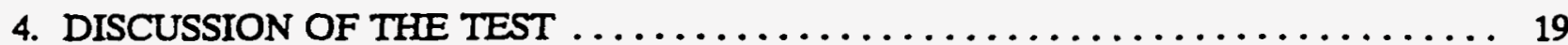

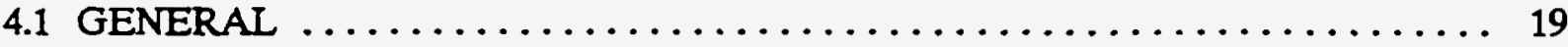

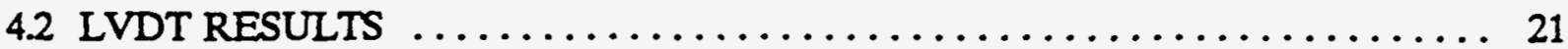

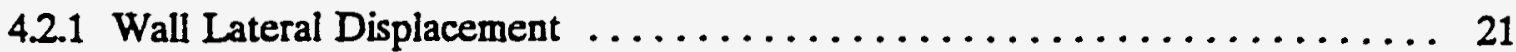

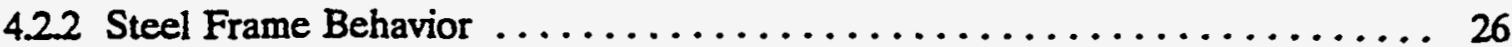

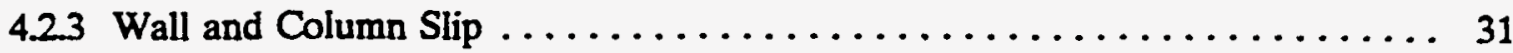

4.3 POST-TEST WALL SURVEY $\ldots \ldots \ldots \ldots \ldots \ldots \ldots \ldots \ldots \ldots \ldots \ldots \ldots \ldots \ldots \ldots$

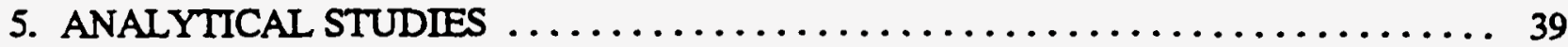

5.1 THEORY VS. EXPERIMENTAL RESULTS $\ldots \ldots \ldots \ldots \ldots \ldots \ldots \ldots \ldots \ldots$

5.1 .1 One-Way Arch Model . . . . . . . . . . . . . . . . . . . . 40

5.12 Propped-Cantilever Model $\ldots \ldots \ldots \ldots \ldots \ldots \ldots \ldots \ldots \ldots \ldots \ldots \ldots \ldots$

5.2 NATURAL FREQUENCY VERIFICATION $\ldots \ldots \ldots \ldots \ldots \ldots \ldots \ldots \ldots \ldots \ldots 44$

5.3 WIND AND SEISMIC LOADS $\ldots \ldots \ldots \ldots \ldots \ldots \ldots \ldots \ldots \ldots \ldots \ldots \ldots \ldots$

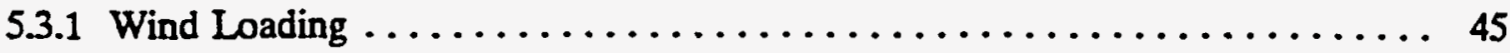

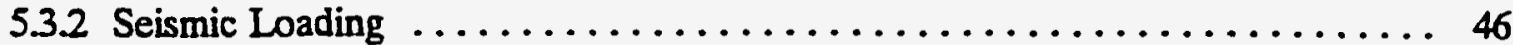

6. SUMMARY AND CONCLUSIONS $\ldots \ldots \ldots \ldots \ldots \ldots \ldots \ldots \ldots \ldots \ldots \ldots \ldots$

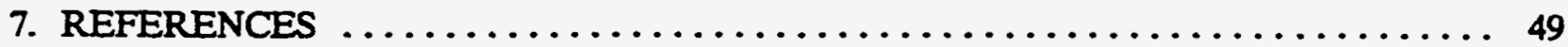

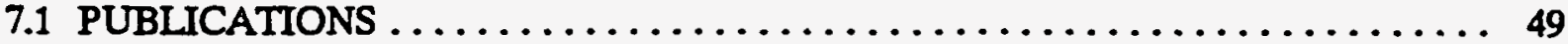

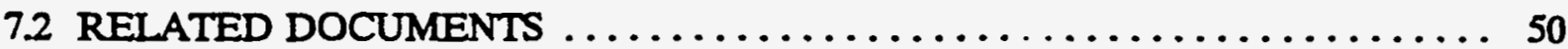




\section{FIGURES}

1. The west (air bag) face of the test wall. (Note the air bag reaction frame) . . . . . . . 6

2. Portions of the test wall with double-wythe construction $\ldots \ldots \ldots \ldots \ldots \ldots \ldots \ldots \ldots$

3. Two types of construction were found in the test wall. $\ldots \ldots \ldots \ldots \ldots \ldots \ldots \ldots \ldots$

4. The HCT block numbering scheme, shown here from the air bag (west) side, facilitated the placement identification and analysis of individual blocks $\ldots \ldots \ldots \ldots \ldots \ldots \ldots \ldots$

5. The block numbering scheme was mirrored on the hall (east) side of the test wall .....8

6. The reaction frame and air bag in place for the test $\ldots \ldots \ldots \ldots \ldots \ldots \ldots \ldots \ldots$

7. A measuring frame was built along the hall side of the test wall $\ldots \ldots \ldots \ldots \ldots \ldots$

8. The measuring frame, LVDTs, and cameras are in place $\ldots \ldots \ldots \ldots \ldots \ldots \ldots \ldots$

9. The block numbering schemes, placement of the LVDTs, and location of new blocks are shown here, on the east face of the wall $\ldots \ldots \ldots \ldots \ldots \ldots \ldots \ldots$

10. LVDTs were also placed on the steel beams framing the test wall to measure the twisting effect of the pressure exerted on them during air bag inflation $\ldots \ldots \ldots \ldots \ldots 12$

11. Location of strain gages, placed to measure possible deformation of the steel frame . . . . 12

12. Location of pressure cushions, placed to measure the uniformity of the applied loading

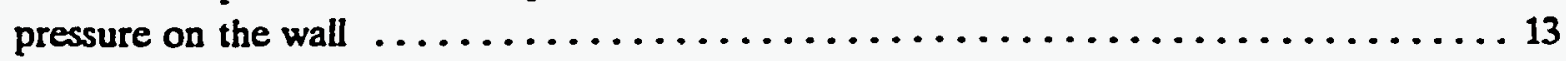

13. Pressure exerted by the air bag vs. the elapsed time of the test $\ldots \ldots \ldots \ldots \ldots \ldots$

14. Deflection of the test wall's center point (V5) vs. air bag pressure . . . . . . . . . 22

15. Deflection of the top $(V-1)$ and bottom $(V-10)$ of the test wall vs. air bag pressure ..... 22

16. Vertical displacement profile at midwidth of the test wall showing the out-of-plane

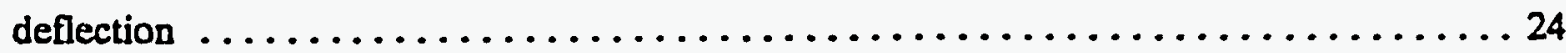

17. Horizontal displacement profiles of the second course of HCT blocks from the wall's

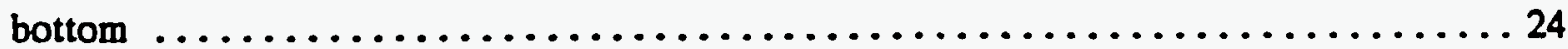

18. Horizontal displacement profile at midheight of the wall $\ldots \ldots \ldots \ldots \ldots \ldots \ldots \ldots \ldots$

19. Surface deflection of the test wall at 1.0 psi $\ldots \ldots \ldots \ldots \ldots \ldots \ldots \ldots \ldots \ldots \ldots \ldots \ldots$

20. Surface deflection of the test wall at maximum displacement $\ldots \ldots \ldots \ldots \ldots \ldots \ldots \ldots$

21. Surface deflection of the test wall after the test ended $\ldots \ldots \ldots \ldots \ldots \ldots \ldots \ldots \ldots 28$

22. Overhead quarter-span beam deflection vs. by the air bag pressure on the test wall ..... 30

23. Deflection or twisting of column $D 2$ vs. the air bag pressure $\ldots \ldots \ldots \ldots \ldots \ldots \ldots$

24. Deflection or twisting of column $\mathrm{D} 3$ vs. the air bag pressure $\ldots \ldots \ldots \ldots \ldots \ldots \ldots \ldots \ldots$

25. In-plane wall deflection at column $\mathrm{D} 2$ vs. the air bag pressure . . . . . . . . . . 34

26. In plane wall deflection at column $\mathrm{D} 3$ vs. the air bag pressure $\ldots \ldots \ldots \ldots \ldots \ldots \ldots$

27. The cracks in the loaded face of the test wall were mapped and categorized ........ 35

28. The cracks on the hallway side were similarly mapped and categorized ......... 35

29. Severe cracking of the HCTs blocks occurred near the bottom of the wall . . . . . . . 36

30. Separation or cracking of the face shell was identified in 13 HCT blocks that were not

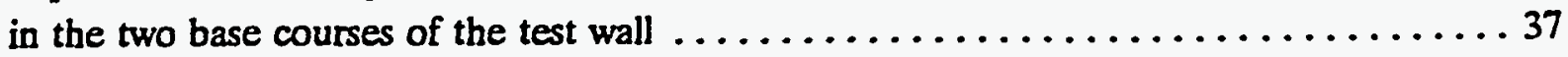

31. A typical example of the significant web cracks noted in Fig. $30 \ldots \ldots \ldots \ldots$ 


\section{FIGURES (cont.)}

32. The predicted out-of-plane wall load capacity compared to the experimentally

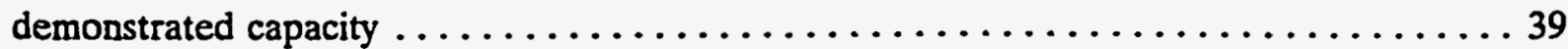

33. A one-way arch model was developed to predict a pressure-deflection curve $\ldots \ldots \ldots . \ldots 40$

34. Comparison of the one-way arch model with actual data from the air bag test .......41

35. The effect of normal stress on wall load deflection $\ldots \ldots \ldots \ldots \ldots \ldots \ldots \ldots \ldots \ldots$

36. The effect of wall offset on wall load deflection $\ldots \ldots \ldots \ldots \ldots \ldots \ldots \ldots \ldots \ldots \ldots$

37. The effect of elastic modulus on wall load deflection $\ldots \ldots \ldots \ldots \ldots \ldots \ldots \ldots \ldots \ldots$

38. The effect of spring stiffness on wall load deflection $\ldots \ldots \ldots \ldots \ldots \ldots \ldots \ldots \ldots$

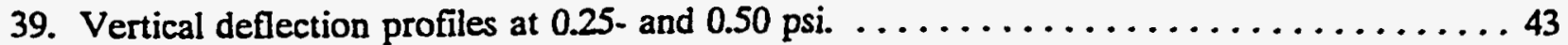

40. Vertical deflection profiles at 0.75 and $1.00 \mathrm{psi} . \ldots \ldots \ldots \ldots \ldots \ldots \ldots \ldots \ldots$

41. Vertical deflection profiles at $1.00 \mathrm{psi}$, maximum displacement, and unloaded. . . . . . 44

\section{TABLES}

1. Selected data records $\ldots \ldots \ldots \ldots \ldots \ldots \ldots \ldots \ldots \ldots \ldots \ldots \ldots \ldots \ldots \ldots \ldots$

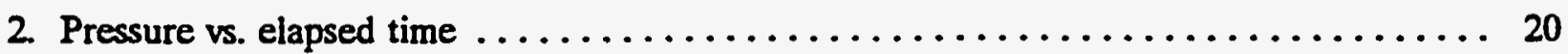

3. Wall deflections at mid-width $\ldots \ldots \ldots \ldots \ldots \ldots \ldots \ldots \ldots \ldots \ldots \ldots \ldots \ldots \ldots \ldots$

4. Wall deflection profile at the vertical centerline $\ldots \ldots \ldots \ldots \ldots \ldots \ldots \ldots \ldots \ldots \ldots$

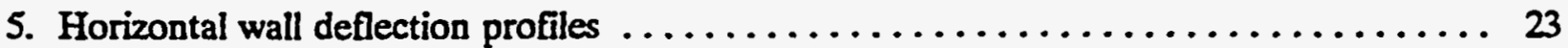

6. Wall surface deflections at 1.0 psi pressure $\ldots \ldots \ldots \ldots \ldots \ldots \ldots \ldots \ldots \ldots \ldots$

7. Maximum wall surface deflections after the "creep" loading stage ended ......... 25

8. Wall surface deflections after unloading (i.e., permanent set of the wall). . . . . . . 26

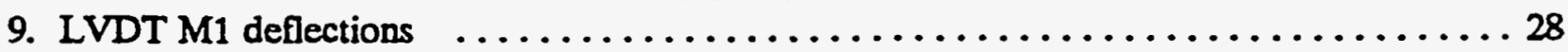

10. Out-of-plane deflections for overhead beam $(w 30 \times 108) \ldots \ldots \ldots \ldots \ldots \ldots$

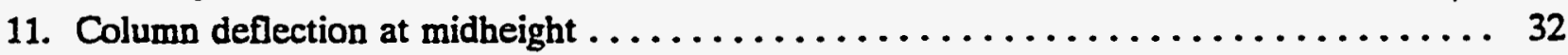

12. In-plane displacements between the steel frame and the wall $\ldots \ldots \ldots \ldots \ldots \ldots$ 


\section{ACRONYMS}

CNPE Center for Natural Phenomena Engineering

DAS data acquisition system

DOE U.S. Department of Energy

HCT hollow clay tile

HCTW hollow clay tile wall

HVAC heating, ventilation, and air conditioning

LVDT linear variable differential transformers

MMES Martin Marietta Energy Systems, Inc.

PGA peak ground acceleration

TS tubular steel

URM unreinforced masonry

V\&A Vibration and Acoustic Group 


$$
\text { - }
$$

Ii

. 


\section{ACKNOWLEDGEMENTS}

This work was performed at the Oak Ridge Y-12 Plant, Oak Ridge, Tennessee, managed by Martin Marietta Energy Systems, Inc. for the U.S. Department of Energy under contract DE-AC05-84OR21400. Many people at Energy Systems helped to make this test a success and should be recognized for their contributions. These include: Pat Adamson, the Project Manager; Manuel Duran, the Project Engineer during most of the pretest phase and who was directly involved in the engineering management and procurement phases; his replacement, Bob Fehling, served as coordinator for the last couple of months before and during the test; Ken Roberts, Construction Engineering, coordinated construction and site preparation with M-K Ferguson; Don Kelley, Ron Adamski, Jeff Broders, Dale Ballinger, Parker O'Shell, D. Howard, and A. R. Ellis, Stress Analysis Group of the Technical Services Division, coordinated wall instrumentation, testing, and data acquisition; Bill Flether, Instrument Engineering, was responsible for designing and operating the air bag control system; Clay Wynn prepared the air bag specifications, helped procure the air bag, and served as assistant control system operator during the test; Ted Morton and Ruth Tuft, Vibration and Acoustics Laboratory at the K-25 Site, and Jay Beeler and Bill Statum, Analysas Corporation, were responsible for providing photographic and video documentation of the test; and Jerry Hornyak, Mechanical Engineering at the K-25 Site, was responsible for preparing design drawings and for mapping the wall before and after the test. 
-

II

Jk

I

a.

E 


\section{EXECUTTVE SUMMARY}

As part of a major testing program currently underway at the Department of Energy's Oak Ridge Y-12 Plant, managed by Martin Marietta Energy Systems, Inc. (MMES), a full-scale air bag test was conducted on an in situ wall. The test program, supported and managed by the MMES Center for Natural Phenomena Engineering, is intended to study the behavior and strength of unreinforced hollow clay tile walls (HCTWs) in order to more accurately analyze and predict the strengths of the Y-12 buildings containing these type walls when subjected to seismic and high wind loadings.

An existing, unreinforced masonry (URM) infill wall was load tested out-of-plane using an air bag to more accurately analyze buildings containing HCTWs when subjected to seismic and high wind loadings. URM walls are typically assumed to have little or no strength resistance to out-of-plane loadings. However, it is believed that these infill walls do add substantial seismic resistance that should be taken into account in any "realistic" analysis of these facilities. Unfortunately, little information exists on the behavior of actual in situ infill walls subjected to out-of-plane loadings, therefore the air bag test was developed to provide additional data on the behavior of HCTWs.

The test wall was located on the ground foor of Building 9207 at the Y-12 Plant, a five story, steel frame structure built in 1945 and used for many years as a biology laboratory, but which has been essentially vacant during the past few years. The wall dimensions are 28-ft wide (centerline of column to centerline of column) $\times 12$-ft high (top of floor to underside of floor beam), and is constructed of HCT units, 12-in. $\times 12$-in. $\times$ 8-in. thick with the cores running horizontally, and with a running bond construction. The wall itself had apparently been modified on a number of occasions, a fact that slightly influenced the behavior of the wall during the test. Never previously subjected to large, out-of-plane and in-plane loadings, as best as it could be determined, the wall was not cracked before testing.

The air bag test lasted about $2 \frac{1}{2}$ hours. Wall and steel frame deflections and strains at 94 locations were automatically read and recorded at approximately two second intervals, producing about 4000 data records. Cracking of the wall was first noticed at a pressure level of about 0.28 psi. The air bag pressure reached a maximum of 1.0 psi approximately two hours into the test, after which the pressure fell and then fluctuated between $0.90 \mathrm{psi}$ and 0.96 psi over the next 26 minutes. During this time the linear variable differential transformers (LVDTs) indicated large displacements were taking place, even though major distress was not visible to either the wall or the frame. Finally, the test was terminated because the LVDTs measuring the behavior of the overhead steel beam indicated that large lateral displacements and possible rotations were occurring in that member. The maximum deflection of the center of the wall, just prior to unloading, was 1.68 in.

Test data were analyzed to provide insights into behavior. Crack patterns were mapped. The wall was taken down, block-by-block, to document details of construction. During the dismantling of the wall, the presence of wall sections composed of two 4-in.-thick blocks (double-wythe construction) were discovered in an area of the wall where a door had once existed and along the entire first course sitting on the floor.

The out-of-plane strength of the wall was found to be many times greater than that predicted by conventional theories that do not account for post-cracking mechanisms, especially the arching action of the wall within the steel frame, which provides a substantial increase in the predicted 
capacity. These methods predict "failure" of the wall at ground acceleration values ranging from $0.15 g$ to $0.25 \mathrm{~g}$. The maximum pressure obtained in the test correlates seismically to about an equivalent ground acceleration of $2.1 \mathrm{~g}$, and for winds to approximately a $208 \mathrm{mph}$ straight wind speed. Since the Oak Ridge area design ground accelerations range from $0.12 \mathrm{~g}$ to $0.32 \mathrm{~g}$, and the maximum straight design wind speed is about $80 \mathrm{mph}$, it can be stated that out-of-plane failure of infill walls similar to the one tested are highly unlikely due to either a high wind or a seismic event, even allowing for the amplification of the ground acceleration at higher elevations within a building reducing the overall margin.

This wall is probably typical of many of the other HCT URM infill walls found throughout the Y-12 Plant. Despite all the variable (and rather poor) construction encountered within this wall, it still demonstrated a remarkably high lateral-load capacity. A capacity more than sufficient to demonstrate the fact that this wall would not have failed (and fallen) from any expected out-of-plane loads that it would be subjected to in either a high wind or an earthquake. 


\section{INTRODUCTION}

As part of a major testing program now underway at the Department of Energy's (DOE) Oak Ridge Y-12 Plant, managed by Martin Marietta Energy Systems, Inc. (MMES), a full-scale air bag test was conducted in Building 9207. The test program, supported and managed by the MMES Center for Natural Phenomena Engineering (CNPE), is intended to determine the stiffness and strength of unreinforced hollow clay tile walls (HCTWs) in order to more accurately analyze and predict the response of buildings containing these types of walls, especially when subjected to seismic and high wind loadings.

The air bag test was a very large undertaking that started more than a year before the test was actually performed. Preparation for the test included the following activities:

- preparation of the wall and the adjacent building areas;

- design and field fabrication of test supporting structures;

- procurement of equipment and instrumentation;

- development of supporting test procedures and checklists;

- installation of over seventy linear variable differential transformers (LVDTs) and strain gages;

- development of computer programs for use in the data acquisition systems;

- extensive review into the existing engineering literature;

- discussions with researchers with prior experience performing air bag tests;

- coordination with the building operators;

- plant safety reviews; and

- dry runs of the test itself.

\subsection{PURPOSE}

The purpose of the air bag test was to determine an HCTW's out-of-plane capacity to resist wind and seismic loadings. This was accomplished by applying lateral pressure (using an air bag) to an existing wall. The result will be very useful to the overall objective of the HCTW Test Program of gaining a better understanding of how buildings with HCT infill walls respond to these types of loadings. The test also served the major purpose of demonstrating that unreinforced masonry (URM) infill walls are inherently stronger than would normally be predicted by conventional theory.

\subsection{OBJECTIVES}

The primary objectives of the air bag test were to

1. determine out-of-plane load capacity and load-deflection behavior of the wall,

2. determine the existing boundary conditions (connectivity of the wall to the steel frame), 
3. establish crack patterns,

4. obtain data for correlation with computer and analytical models in order to develop accurate behavioral models for use in future seismic analyses of buildings with similar wall construction,

5. demonstrate that this wall is capable of resisting larger out-of-plane loads than would be calculated by normal means, and

6. address DOE design and evaluation requirements for natural phenomena hazards.

\subsection{PRETEST ANALYSES}

Various methods are available for the prediction of the out-of-plane capacity of infill walls. These range in complexity from simple beam theory to rigorous mathematical treatments of the "arching action" mechanism. Arching action refers to the development of significant in-plane thrust loads when a specimen of significant thickness is subjected to out-of-plane loads. Simple beam models treat the wall as a flexural member, spanning either horizontally or vertically. Bending stresses are computed and compared to some multiple of code-based allowable stresses to obtain an estimate of ultimate capacity. Past evaluations of existing buildings at $Y-12$ have relied on this method.

Ultimate plate theory has also been proposed as a method for analysis. Seah $[1]^{1}$ developed yield-line formulas and compared predictions from these formulas with experimental results. They consistently underestimated actual capacities; the ratio of theoretical to experimental capacities ranged from 0.35 to 0.99 . Seah also developed a model which included the effects of arching action. The model was shown to be a good predictor of experimental capacity. Theoretical results ranged from 0.94 to 1.14 times experimental values. To simplify the analysis, Dawe and Seah [2], also proposed an empirical design formula that includes the effects of arching action. The primary parameters in the formula are the wall panel dimensions and the stiffness properties of the surrounding frame.

Chua [3] used Seah's arching action model to predict the ultimate load for the Building 9207 infill test wall, obtaining a value of $q_{u b}=2.0 \mathrm{psi}$. Chua also used the empirical formula developed by Dawe and Seah to estimate the ultimate load capacity of the wall and obtained $q_{u b}=1.4$ psi. Chua's analyses were performed prior to the actual test and his results were used in developing the 9207 air bag test, for example, in designing the reaction frame for supporting the pressures exerted by the inflating air bag.

\subsection{SUPPORTING TESTS ON THE AIR BAG WALL}

A couple of fairly simple field tests were performed on the wall in preparation for the air bag test. These tests determined (1) the approximate dead load existing on the wall, and (2) the low amplitude natural frequencies of the wall. The dead load was needed to make certain that, if the wall collapsed during the air bag test, the overhead steel beam was still capable of safely supporting the

\footnotetext{
${ }^{1}$ Numbers in [ ] refer to references listed in Sect. 7.1.
} 
additional loads it would be subjected to, even though the infill wall was not considered to be load bearing. In addition, the magnitude of the in situ compressive load on the wall might have a substantial impact on the lateral load results. The larger the dead load, the higher the lateral-load capacity. This data is needed to develop a finite element model of the wall and frame system. The natural frequency determination (both before the test and after the test) were identified for use in developing a more detailed, computer finite element model of the wall.

The existing compressive stress in the test wall was approximated using the flatjack method. This method is described by Noland et. al. [4]. A flatjack is an envelope-like bladder which may be pressurized with a fluid, such as oil, or air. When a slot is cut in the masonry wall, the compressive stresses, and hence the strains, that existed in the wall (at the slot) are relieved and the slot gap partially closes. A flatjack is inserted into the slot and pressurized until the original distance between a set of gage points (located and measured before cutting) above and below the slot are restored. The compressive stress in the wall is approximately equal to the internal flatjack pressure multiplied by factors that account for the physical characteristics of the jack, the bearing area of the jack in contact with the masonry, and the bearing area of the slot. The value of normal stress obtained in this manner is a good approximation of the normal stress that originally existed in the wall. The test results estimated the equivalent uniform load on the W30x108 overhead beam to be $2.7 \mathrm{kpf}$. A calculation based on the drawings and a field walkdown resulted in a value of $2.9 \mathrm{kpf}$. The:allowable uniform load for a W30x108 beam spanning $28 \mathrm{ft}$ is $169 \mathrm{kjps}$, or $6.0 \mathrm{kpf}$, well above the calculated values, so it was concluded that the beam could safely support the entire second floor load if the wall collapsed during the test.

Low amplitude impact hammer tests were performed before and after the air bag test to obtain natural frequencies. The lowest two natural frequencies and their corresponding mode shapes were obtained. The pretest natural frequencies corresponding to the undamaged wall were $14.43 \mathrm{~Hz}$ and $23.78 \mathrm{~Hz}$, while the post-test, damaged wall, natural frequencies were $12.97 \mathrm{~Hz}$ and $22.0 \mathrm{~Hz}$ The pretest data will be used in the development of a finite element model of the wall in its initial undamaged state. The post-test data gives the information for the wall after it has been tested with lateral loads, and is in a cracked and damaged condition. This will be useful in verifying how well the finite element model predicts the damaged state. 
$=$

두

$\boldsymbol{F}$

$I$

n

$\Sigma$

I 


\section{DESCRIPTION}

\subsection{WALL PANEL}

The wall panel is 28-ft wide and 12-ft high (floor to top of wall), mostly consisting of single-wythe unreinforced construction, made from HCT units, 12-in. $x$ 12-in. $x$ 8-in. thick (wall thickness) with the cores running horizontally, and using a running bond construction. The wall was located on the ground floor of Building 9207, along N-S column line " $D$ " between column lines " 2 " and " 3 ". The building is a five-story steel frame structure with reinforced concrete floor slabs. Built around 1945, it was used for many years as a biology laboratory, but has been essentially vacant during the past few years.

The wall was infilled between W14x142 columns with a W30x108 overhead beam and concrete floor slab beneath. The wall tiles were placed up against the column webs, but since the distance between the inside of the flanges (121/2 in.) exceeded the width of the wall ( 8 in.), the wall was not fully captured in the columns and rotation of the wall about the inside corner of the column flanges was possible. Figure 1 shows the wall from the air bag side (in the picture the reaction frame for the air bag is seen in front of the wall). The upper beam is oriented with the strong axis in the plane of the wall. The 2nd floor concrete floor slab was poured around the top flange of the overhead beam, providing continuous lateral support of the top flange. The main overhead beam has a W21x59 beam framing in at midspan on each web face. After the test was finished, the wall was carefully torn down, block-by-block. It was found that in an area where a door had once been, the wall construction consisted of two 4-in. HCT blocks in a double-wythe arrangement with a void collar joint between them. The location of all these double-wythe areas is shown in Fig. 2 Figure 3 is a cross-section of the wall showing the two types of construction that existed. Thus, the wall was not homogenous throughout.

\subsection{Wall Preparation}

The wall had apparently been modified on a number of occasions, a fact that had some bearing on its behavior during the test. A lintel beam, at about $7 \mathrm{ft}$ above the floor, indicated the location of a door that had been removed. The following actions were taken to prepare the wall and the surrounding area for the test:

1. Removing the lintel beam and refilling the hole with new HCT tiles.

2. Removing two HVAC ducts that went through the wall on either side of the lintel beam and refilling the holes with new HCT tiles. This was a major undertaking because the HVAC ducts were wrapped in asbestos, requiring asbestos removal procedures.

3. Rerouting a drain line on the air bag side of the wall that ran down it near to column $D-2$. This drain line was located in the area to be loaded by the air bag and was interfering with its installation. 


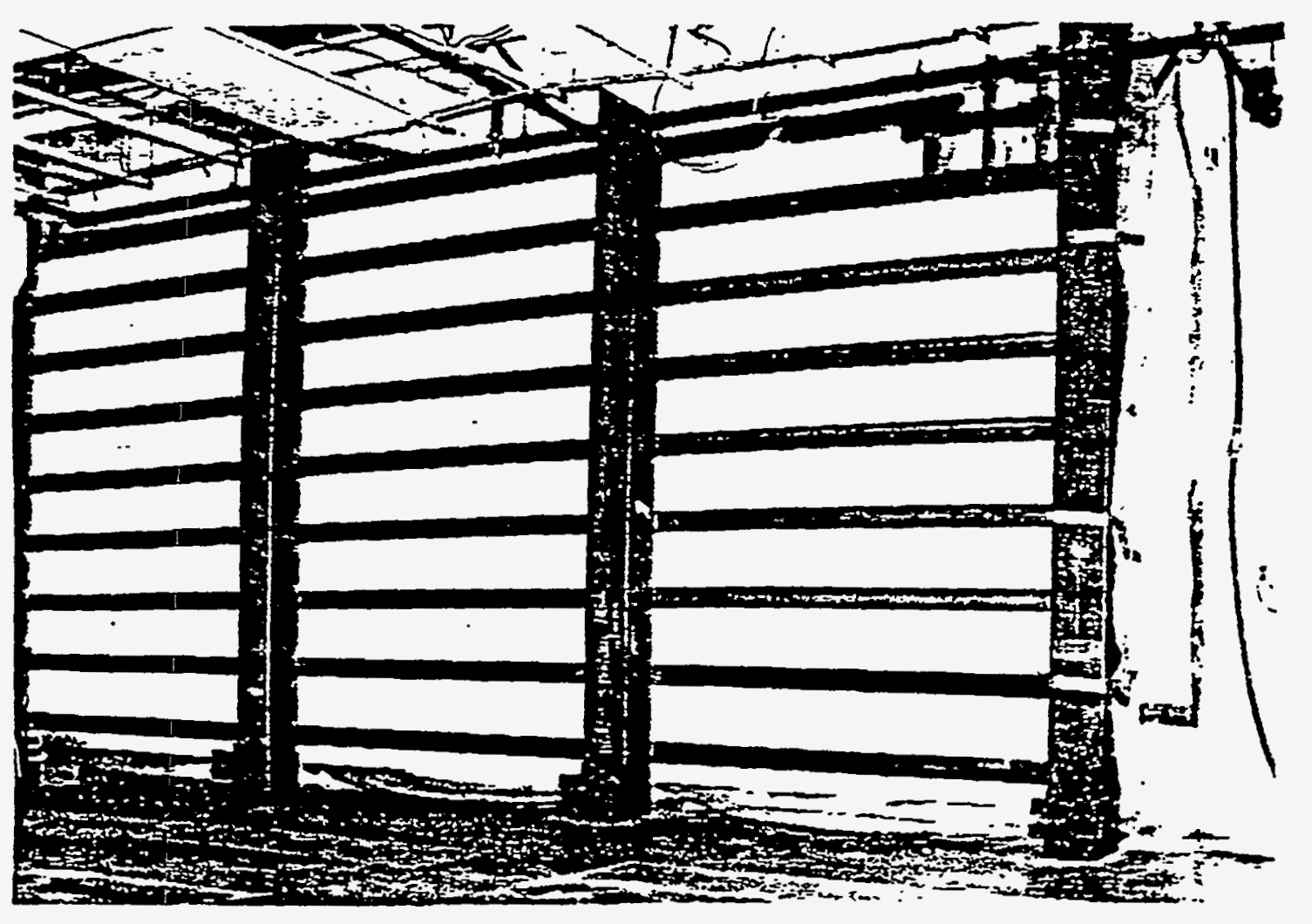

Fig. 9. The west or air bag face of the test wall. (Note the air bag reaction frame.)

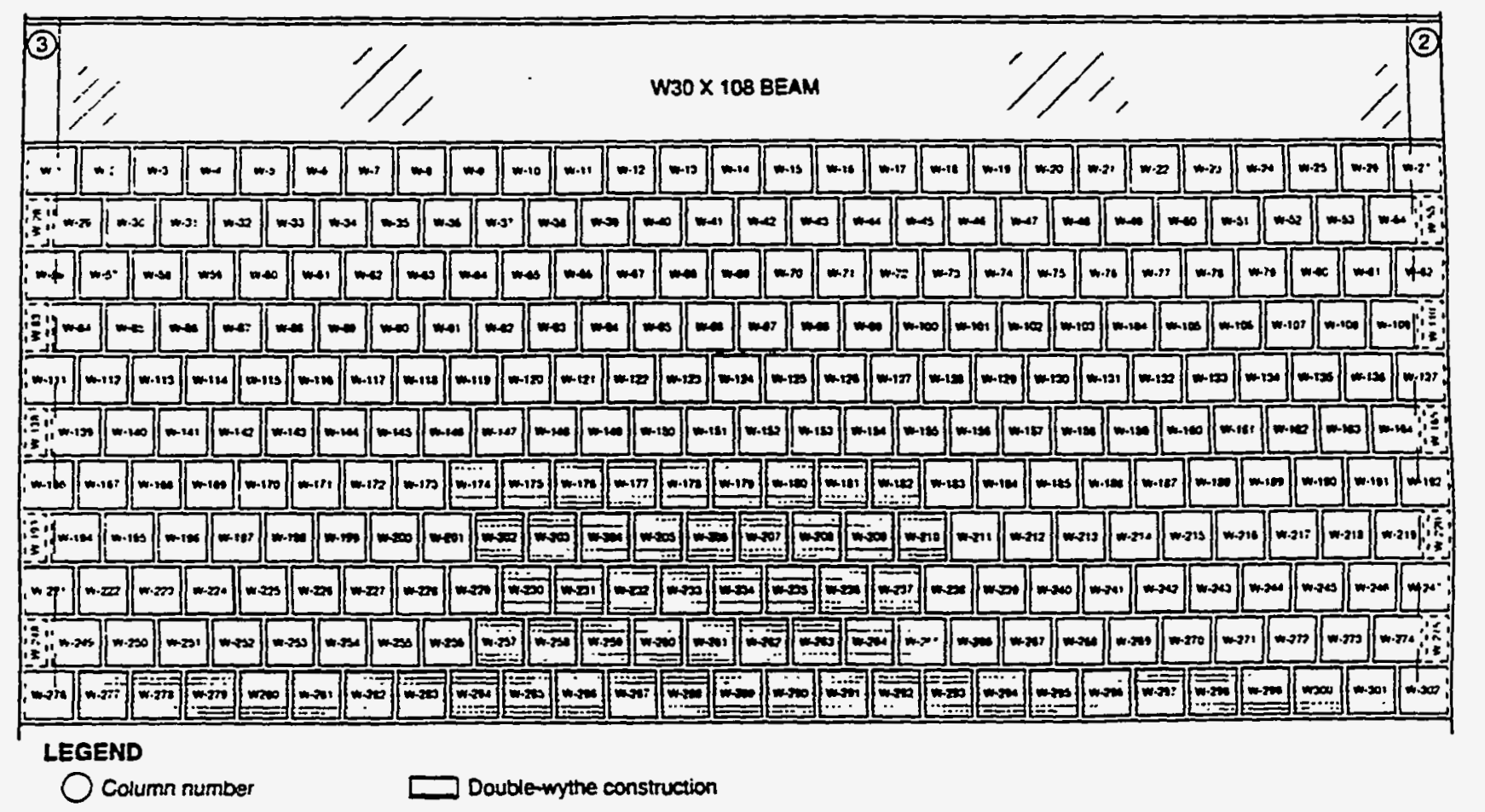

Fig. 2. Portions of the test wall with double-wythe construction. 
4. After cleaning and lightly painting the wall, identifying numbers were marked on the face of each block, on both sides of the wall. These numbers were used to make it easier to identify blocks, cracks, and crack patterns during the test. A block had the same number on each side, except that it was prefaced with a $W$ or with an $E$ to indicate that it was the west face or the east face of the wall. Figure 4 shows the west face of the wall with the numbered blocks. Figure 5 similarly shows the east (measuring frame) face.

5. Removing and replacing with whole blocks an area of the wall covering about $28 \mathrm{ft}^{2}$ that consisted of cut, half-blocks, and miscellaneous block pieces (some of which did not go through the complete wall thickness). These new "patches" are the darkened areas in Figs. 4 and 5.

6. Removing some of the dropped-ceiling

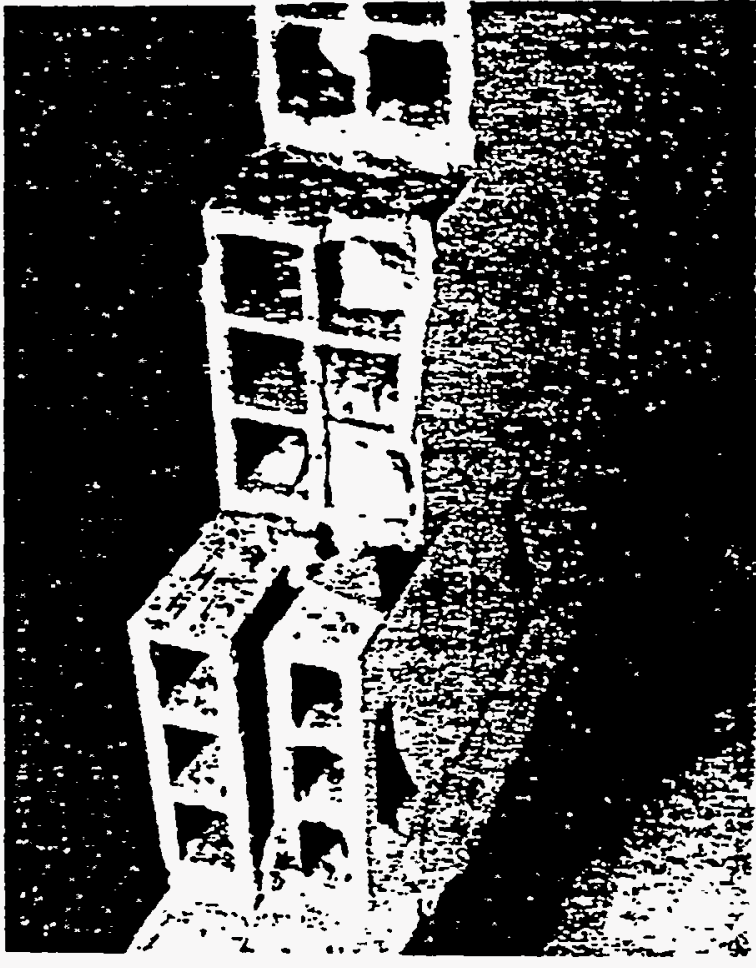

Fig. 3. Two types of construction were found in the test wall. panels located adjacent to the wall in order to be able to install the reaction frame beams and the air bag.

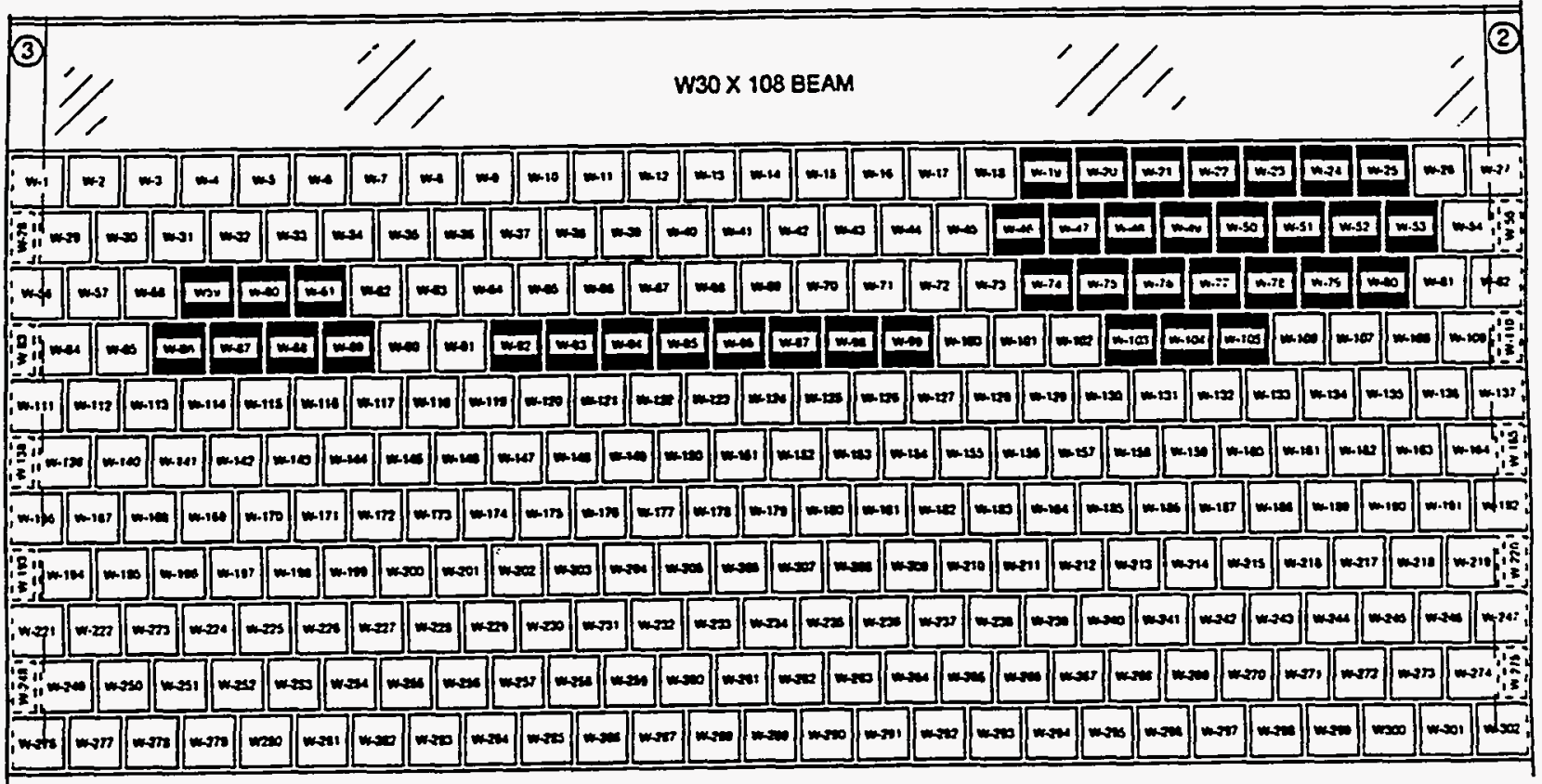

LEGEND

Column number

Now blocks and mortar

Fig. 4. The HCT block numbering scheme, shown here from the air bag (west) side, facilitated the placement identification and analysis of individual blocks. 


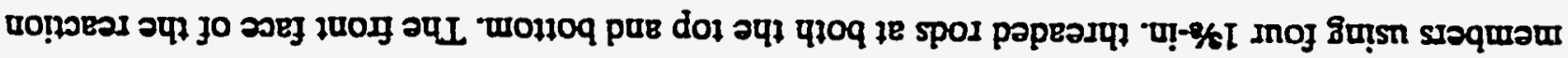

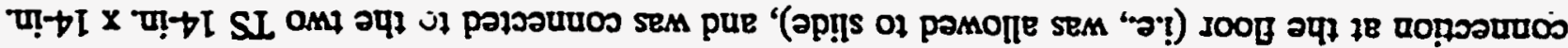

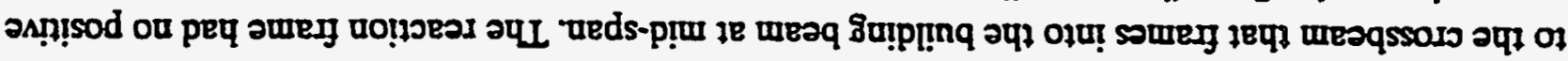

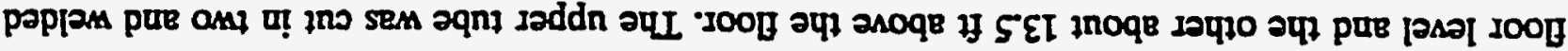

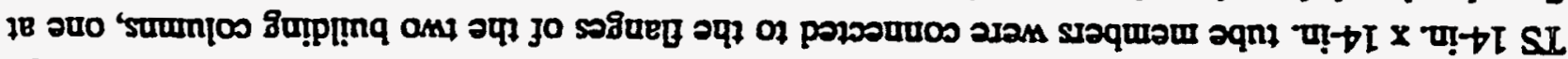

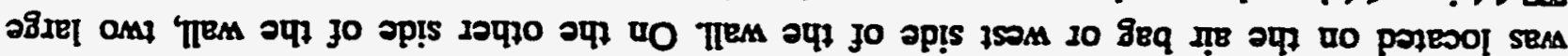

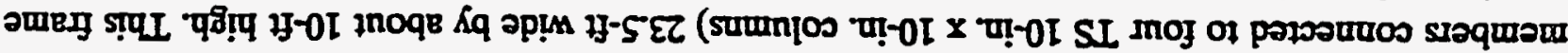

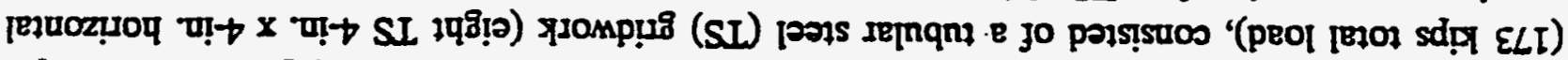

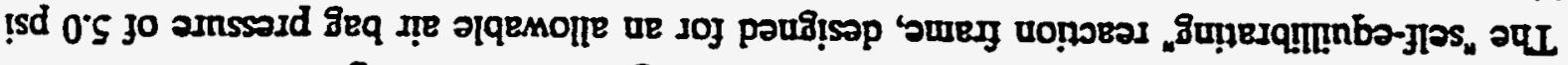

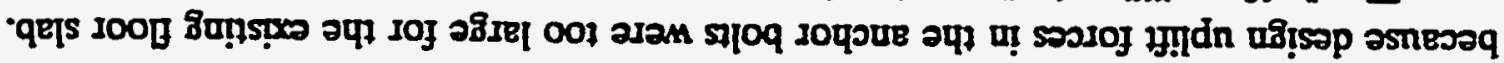

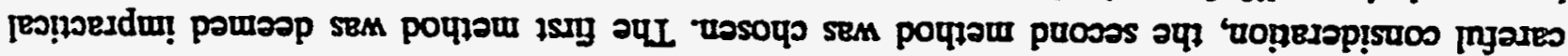

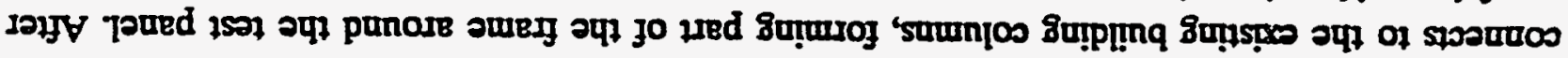

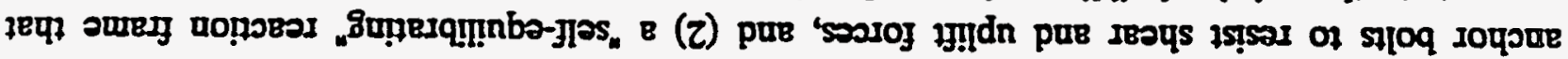

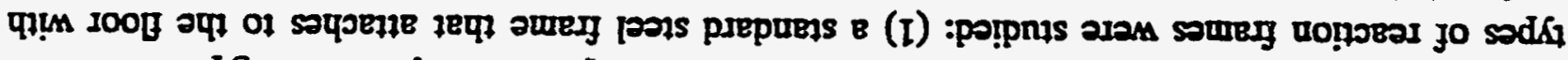

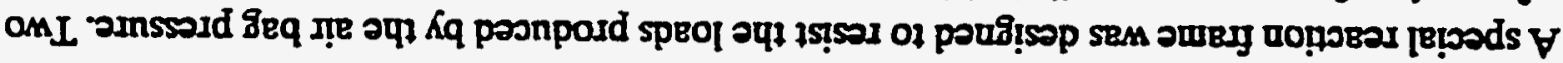

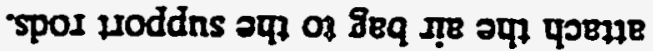
of posn әJan sinnșu

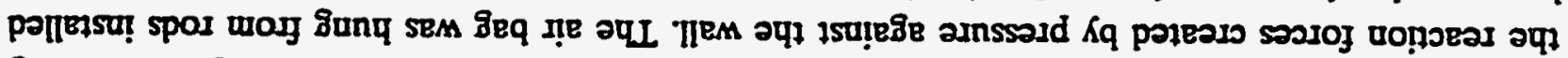

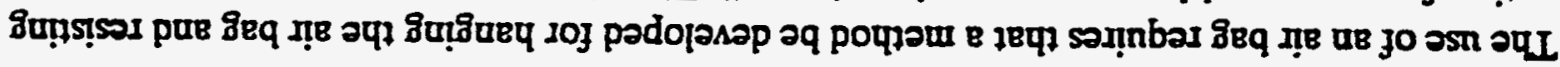

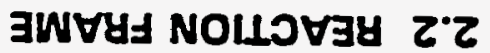

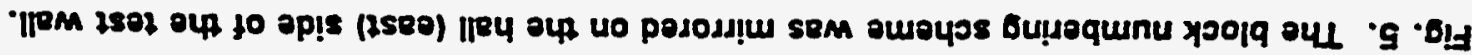

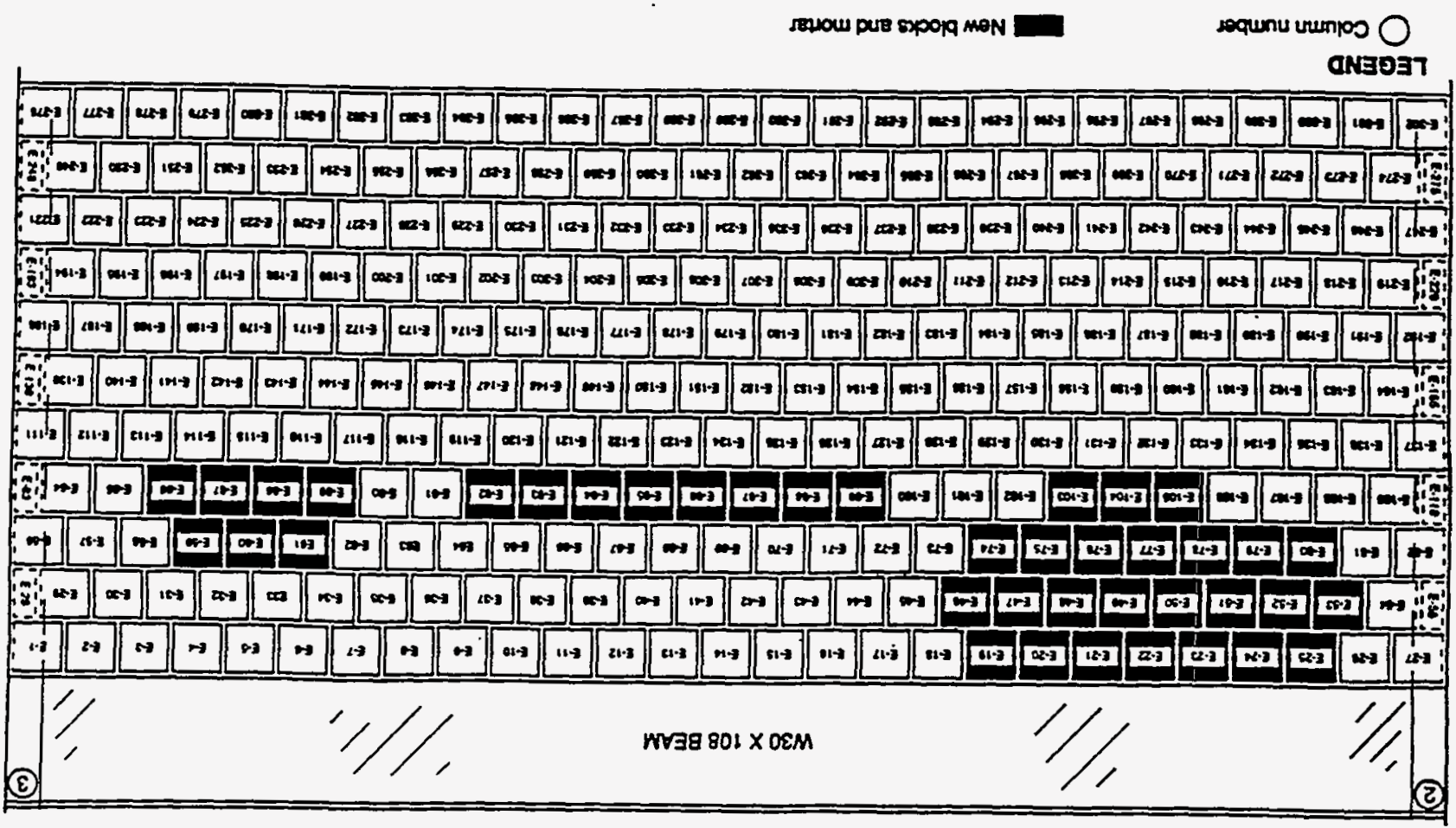


frame was covered with a 2-in.-thick sheet of plywood to form a solid surface for the air bag. Figure 6 shows a photograph of the reaction frame in place, with the plywood. The air bag can be seen sticking out the right edge of the reaction frame.

As air pressure is applied by the air bag, equal and opposite loads are transmitted by the air bag to the HCT wall and the reaction frame. The reaction frame tries to move away from the wall, but is resisted by the eight through rods in tension, which in turn transfer the load to the large tubes and then into the building columns. Analysis indicated that the columns were capable of withstanding these loads. Since the loads are applied to the column only at the top and the bottom, where either floor anchorage or additional steel framing exists, it was concluded that movement of the column at these points would not effect the test results.

\subsection{MEASURING FRAME}

During the test, measurement of the out-of-plane displacement of the wall and steel frame were to be recorded at numerous locations using LVDTs. In order to provide a platform (reference frame) to support the more than sixty LVDTs to be used to take these measurements, a semi-rigid tubular steel frame, called the measuring frame, was designed and fabricated. This frame was located and anchored in the hallway, approximately $3 \mathrm{ft}$ from the surface of the wall. Clear plastic panels were attached to the frame and holes drilled through them where LVDTs were to be located. The LVDTs were anchored in place with some small angles epoxied to the panels. The measuring frame is shown in Fig. 7, and the frame with some of the LVDTs in place is seen in Fig. 8.

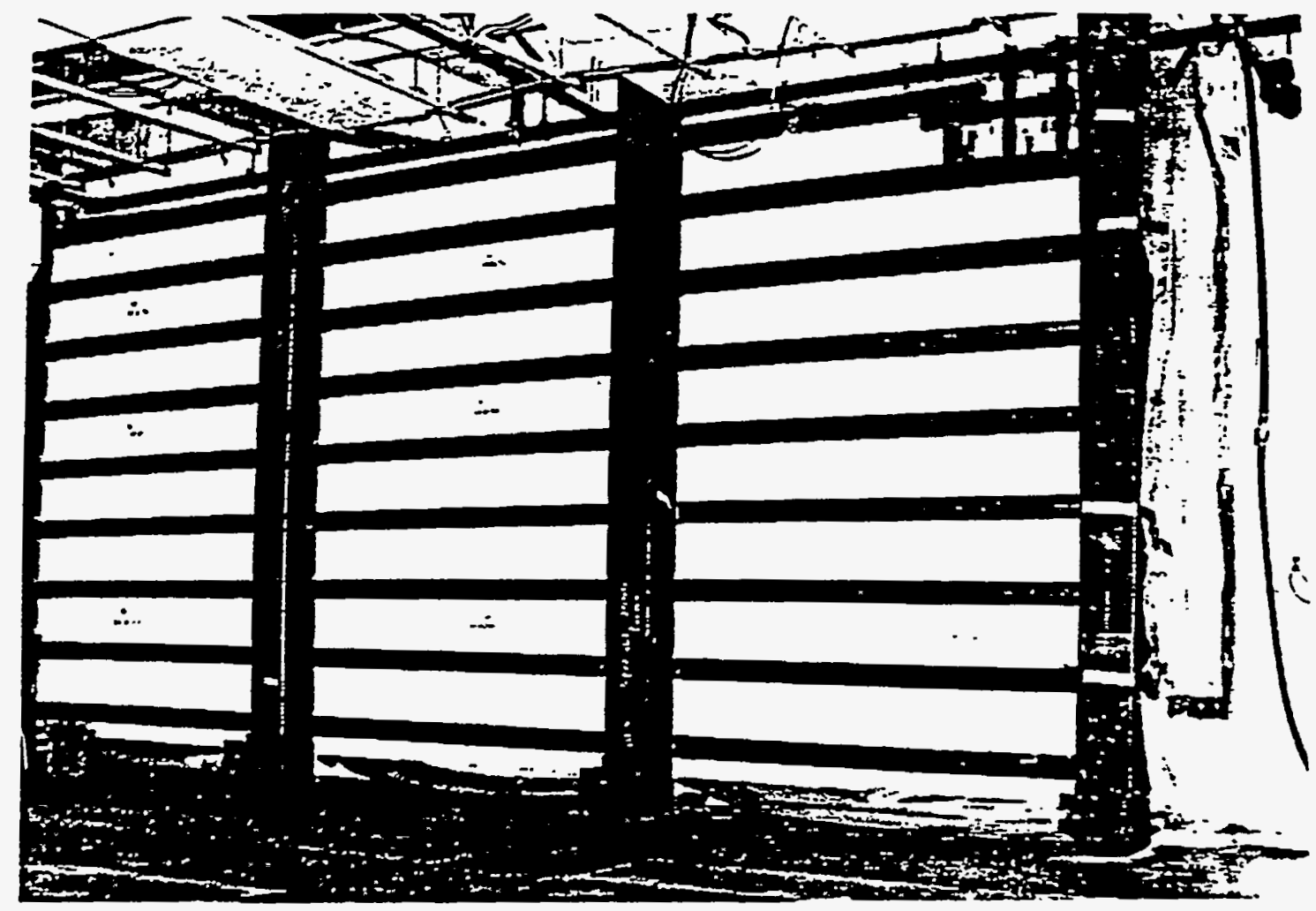

Fig. 6. The reaction frame and air bag in place for the test. 


\subsection{AIR BAG}

Three air bags were purchased, measuring (in the uninflated state) 24-ft, 8-in. long by 10-ft, 8 -in. wide. These air bags are made from 0.036-in.-thick vinyl coated fabric with polyester reinforcement. The bags had an extra lap of material, with grommet holes along the top edge, to allow the bag to hang from an overhead support system. Three hose couplings were provided with each bag: one for inflation, one for evacuation, and one for pressure measurements.

\subsection{INSTRUMENTATION}

\subsection{LVDT's and Strain Gages}

A total of seventy-three LVDTs were used to take measurements during the air bag test;

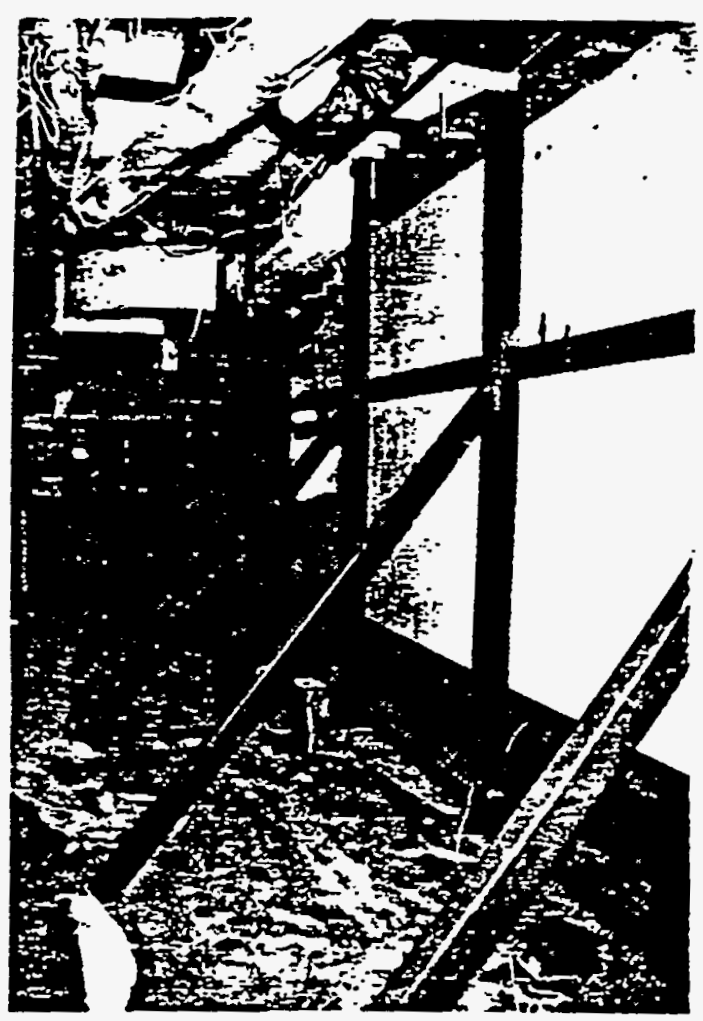

Fig. 7. A measuring frame was built along the hall side of the test wall.

- fifty-eight large displacement $( \pm 10$-in.) LVDTs measured out-of-plane motion of the wall;

- ten small displacement ( \pm 0.3 -in.) LVDTs measured the deformation of the steel frame, and

- five medium displacement ( \pm 1 -in.) LVDTs measured the relative in-plane motion (slip) between the steel frame and the wall.

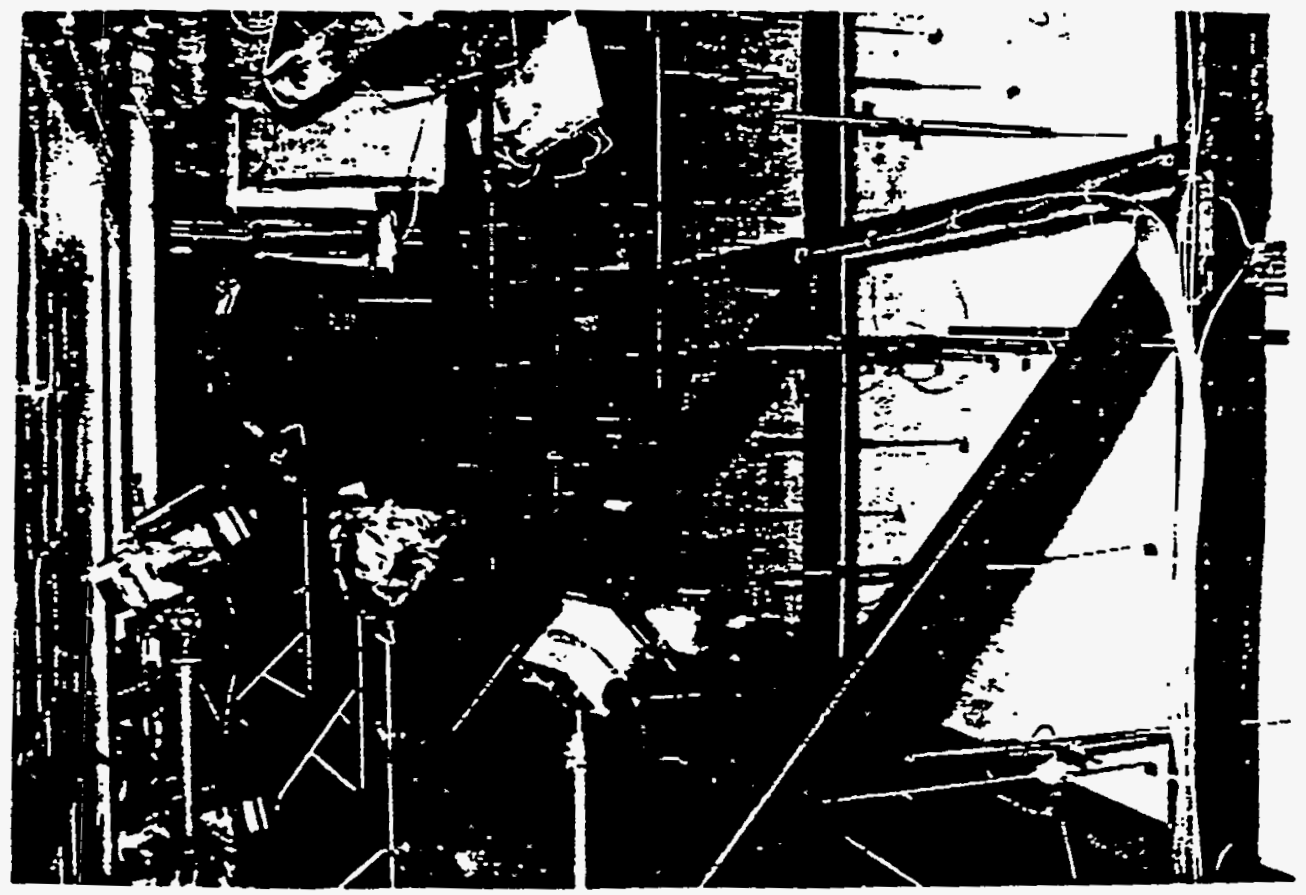

Fig. 8. The measuring frame, LVDTs, and cameras are in place. 
The large- and small-range LVDTs were supported directly by the measuring frame. Figure 9 shows the layout for the wall measuring LVDTs (labeled with the prefixes H,V,D, and S), and Fig. 10 shows the layout for the LVDTs measuring the deflection of the steel frame (labeled with the prefixes F and $\mathrm{M}$ ). The in-plane measuring LVDTs were attached between the steel and the wall and are shown in Fig. 10 identified with the I prefix. All the LVDTs were precalibrated in the laboratory prior to the test. The "M" LVDTs were specially monitored during the test and instrumented to allow stoppage of the test in the event that a specified, preset maximum deflection occurred.

Four single, uniaxial, micromeasurement foil-type strain gages $(\mathrm{Cl}-\mathrm{C4})$, with a 0.25 -in. gage length, were placed on the columns. Three gages (B1-B3) were placed on the overhead beam, at high stress locations as determined by analysis. The strain gages provided supplemental data to the LVDT measurements of the steel frame deformations and were located as shown in Fig. 11.

\section{Pressure Cushions}

Nine pressure cushions were mounted between the air bag and the test wall. A pressure cushion is a small, thin plastic and airtight enclosed bag, with one external lead, used to monitor externally applied pressure by measuring the internal pressure that is created. A plastic sheet was attached to the wall to decrease the amount of friction between the air bag and the HCT wall surface. The pressure cushions were attached to this plastic sheet in a 3 by 3 array, spaced 9-ft apart horizontally and 3-ft apart vertically. The middle pressure cushion was located at the center of the wall (Fig. 12). The air line from each cushion was carefully snaked out from behind the air bag to the control room where internal pressure was monitored and recorded. They were included in the instrumentation in an effort to monitor and measure (1) the differential pressure that exists, if any, between the air pressure inside the air bag and that which the wall actually sees ( $Q$ : How much pressure is required

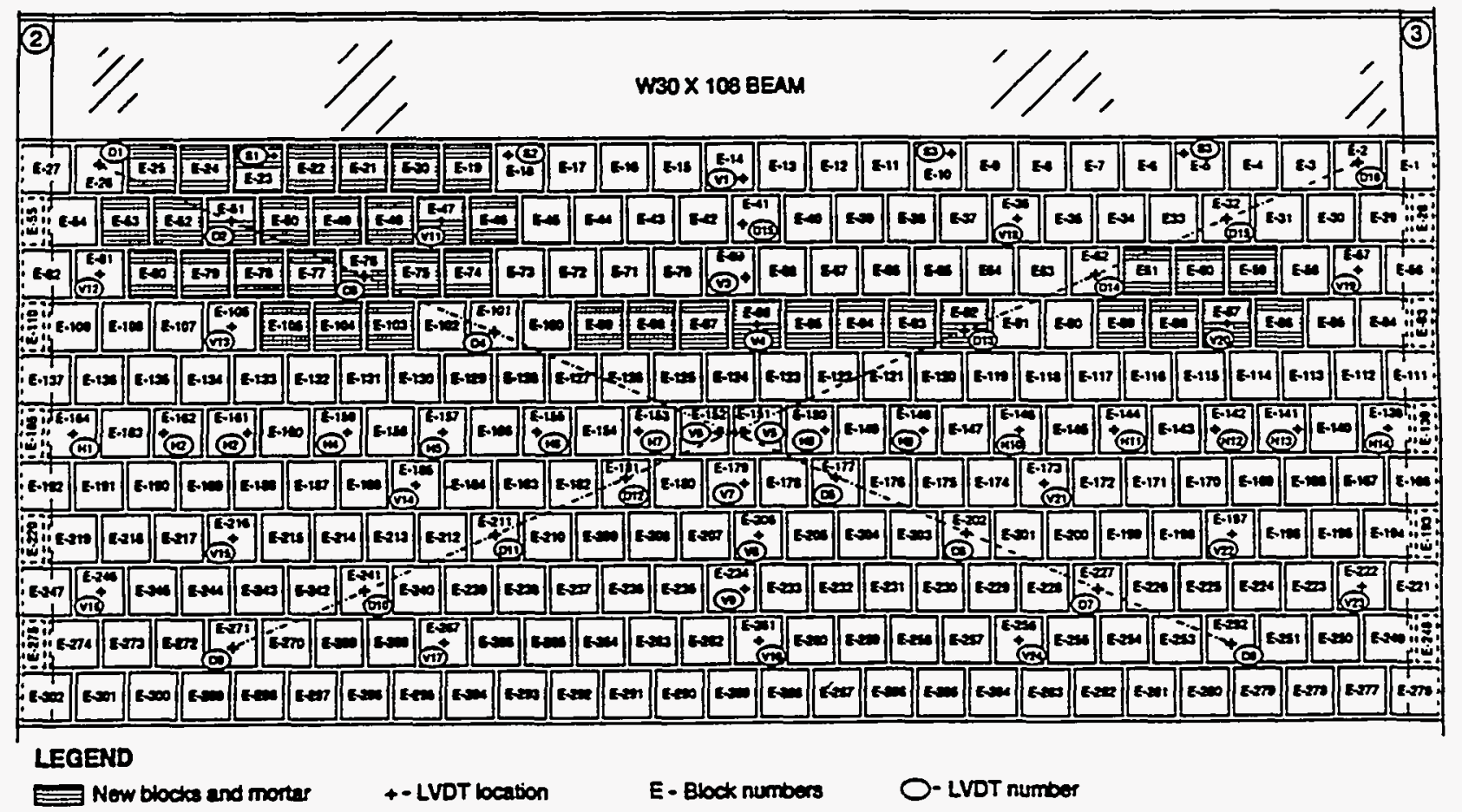

Fig. 9. The block numbering schemes, placement of the LVDTs, and location of new blocks are shown here, on the east face of the wall. 
to inflate the air bag to the point that it is in contact with the wall, and is this pressure negligible?), and (2) the uniformity of the applied loading pressure on the wall ( $Q$ : How well does the air bag mold itself to the contour of the deformed wall during the test?). However, their use was experimental in nature and it was decided not to use their measurements to determine a critical test condition. No practical experience with their use existed. Also, receipt of potentially questionable (and probably confusing) data was considered possible. However, it was felt that they might provide some useful data, so they were inciuded for informational purposes only.

\section{Pressure Trans-}

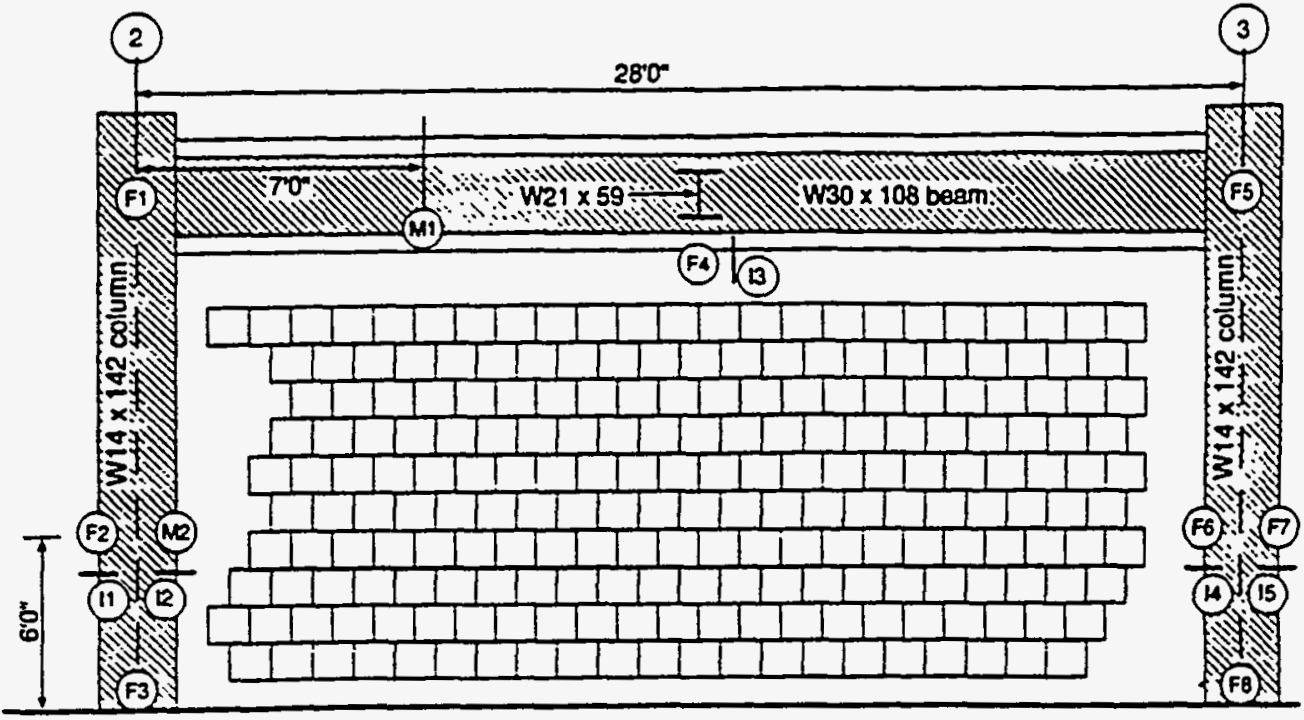

Fig. 10. LVDTs were also placed on the steel beams framing the test wall to measure the twisting effect of the pressure exerted on them during air bag inflation.

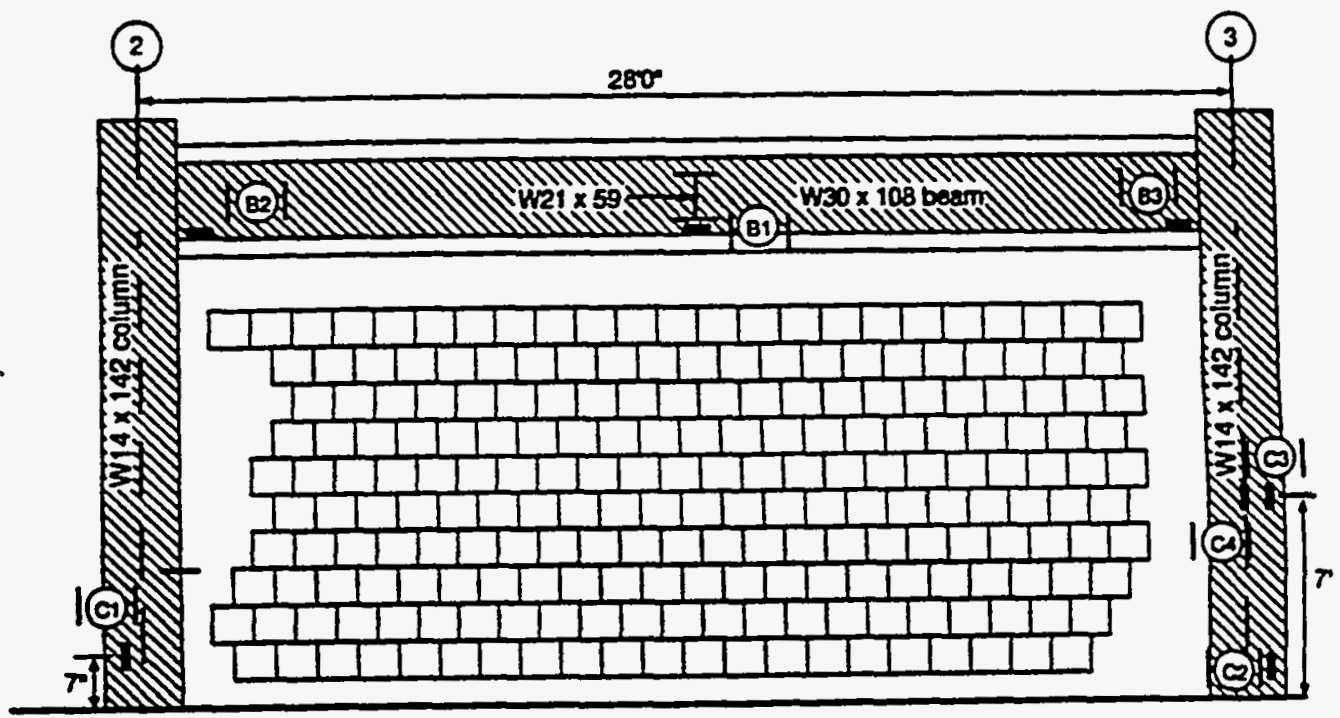

Fig. 11. Location of strain gages placed to measure possible deformation of the steel frame.

ducers

Two pressure transducers were used to monitor the pressure in the air bag during the test. One had an operating range from zero to about 1 psi, the other went up to about 5 psi. Since the test achieved only 1.007 psi, the 5 psi limit was post-test calibrated only to the 1 psi range. 
25.4 Data Acquisition System

The data acquisition system used a HewlettPackard model R332 Controller (computer) and five HP model 3497A relay multiplexer/analog to digital converters (scanners). The 3497As were setup to scan twenty channels each. The computer collected the digitized raw data (voltages) from the five scanners, stored it on a hard

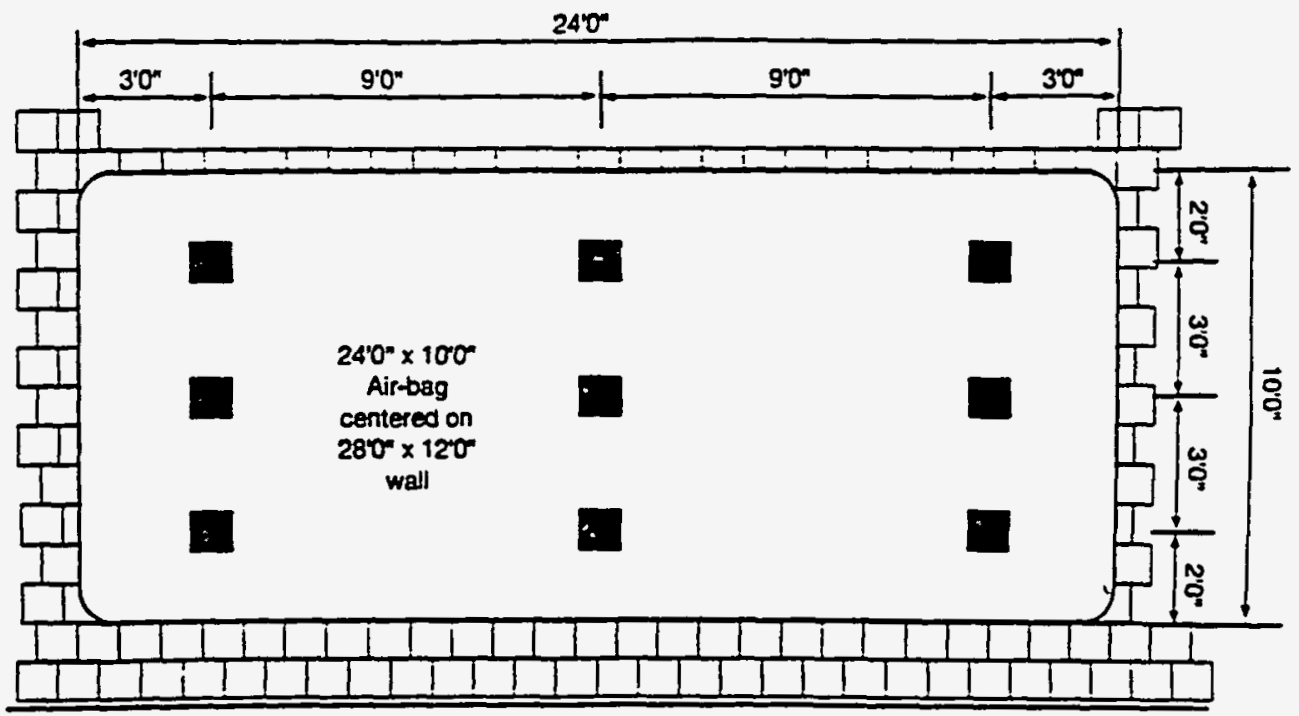

Fig. 12. Location of pressure cushions placed to measure the uniformity of the applied loading pressure on the wall.

disk, converted the

voltages to engineering units, and displayed it on a CRT (during the test). The instrumentation was scanned roughly every two seconds. The computer recorded the digitized voltages and scan times for later print-out, and also for data reduction purposes.

\subsection{Air Bag Pressure Control System}

A control system, called the control panel, for controlling air bag pressure was designed and fabricated in the Y-12 instrument shops. This system was built into a metal housing and contained all the necessary controls and gages for starting, monitoring, and stopping the flow of air into and out of the air bag.

Pressurized air was provided by the plant air system, at 90 psig, reduced to 5 psig with an air pressure regulating valve, and then input to the control panel. A pressure interlock prevented the air pressure from exceeding $5.0 \mathrm{psig}$. In addition to the bag's electronic pressure interlocks, inlet pressure was monitored by an indicating pressure switch to ensure that the 90 psig plant air was reduced to 5 psig. This switch would deactivate the supply solenoid valves and open the exhaust valves on any oversupply pressure. As additional backup, a pressure relief valve set at 7 psig was provided.

Under normal operating conditions, air bag pressure is manually operated under operator control. Two manually operated throttling valves exist for controlling air flow, a 0.5 -in. valve and a 0.25 -in. valve for finer flow control. These valves can either be used individually or in tandem. Pressure interlociss are always in control and will immediately override the operator to relieve the pressure in the event of an overpressure situation. Normally, the air pressure is steadily increased until either (1) the preset pressure limit is reached, (2) the On-Off switch is pushed to Off, (3) an emergency STOP button is pushed on the front panel, or (4) one of the LVDTs monitoring building steel deflections reaches a preset limit. Since pressure relief could occur in the event of a power loss, an uninterruptible power supply was provided. An air compressor was also available to serve as a 
back-up air supply in case the plant air failed during the test. The air control system and air bag were both subjected to a series of performance tests before installation at the Building 9207 test site.

\subsection{Photography and Videotaping}

Video and still photographic documentation was provided by the Vibration and Acoustic Group (V\&A) from the K-25 Site. Photographic lighting was installed to illuminate the wall and eliminate as much of the LVDT shadows as possible from each video camera's field of vision. The width of the hallway and the structural members of the measuring frame made it necessary to use one camera setup for each of the five bays of the measuring frame. Four bays had one camera each, fitted with wide-angle lenses, to provide as much detail as possible of the wall structure (there was some overlap between the coverage from one camera to the next). The last bay, closest to the control room, had two cameras, focused on the upper and lower halves of the wall respectively, because wide-angle lenses were not available for these cameras. The four wide-angle cameras came from the V\&A laboratory and the other two cameras were provided by Analysas Corporation through a subcontract with the Y-12 Photography Department. All cameras were operated on line voltage, using highdefinition, $120 \mathrm{~min}, 8 \mathrm{~mm}$ video cassettes. The first set of videotapes are approximately 105 -mins long; the second set are about 60-mins long. Date and time were recorded on all tapes during the test, except for one camera that lacked a date/time option. Each tape was labeled on the spot as it was removed from the camera. The tapes were indexed, and are stored, at the V\&A laboratory.

Video monitors were set up in the control room, one monitor per camera. This allowed the observers to monitor the entire wall during the test. The monitors were operated in real time, so that the observers could see what was actually occurring on the wall. The monitors were set up before the day of the test, and their performance was verified according to the checklist. A check was made to ensure that each monitor was connected to the appropriate camera. In addition to the video coverage, still photographs were taken during the test. A complete photographic record also exists of the construction and preparation of the test site. The prints and negatives have been numbered and indexed, and are available through CNPE. 


\section{TEST EXECUTION}

The air bag test was run on Saturday, October 5, 1991. The test was conducted in accordance with Procedure HCTP-21[5]. The complete test was previously estimated to take all morning and maybe part of the afternoon. A Saturday was chosen in order to avoid distraction by and interference with personnel working in and around the building, and to reduce the amount of peripheral noise (vibration, etc.) that could affect the test. The day for performing the test was approved by the Y-12 Plant Shift Superintendent, and it was verified that no other work (such as roofing) that might interfere with the test was being planned for that day, in or around the building.

\subsection{PRELIMINARY EVENTS}

On the morning of the test, the video camera floodlights were turned on shortly before 7:30 am to allow the LVDTs to reach a state of thermal equilibrium prior to starting preliminary testing. During a preliminary checkout the previous day, it was found that the floodlights for the video cameras caused the LVDT readings to drift until the ambient temperature had stabilized. However, turning a light off or on immediately affected the LVDTs in the vicinity. The drift decreased steadily with time.

Two preliminary low-level tests (part of the final checkout procedures) to approximately 0.554 -in. $\mathrm{H}_{2} \mathrm{O}$ (0.02 psi) air bag pressure were run prior to the actual test. These pretest runs served the purpose of verifying that the control system, the data acquisition system (DAS), and all associated instrumentation were functioning properly, and that the air bag was filling as expected. During these preliminary tests neither the video cameras nor the XY-plots were turned on. The first run began at 9:44 am and concluded at 10:10 am. The second preliminary test began at 10:19 am and was concluded at 10:25 am.

The main test started at 10:55 am. Air flow was begun using the faster flow valve. At 11:01 am, a sudden rise in the air bag pressure to about 0.058 psi was detected by the control instruments and the air was dumped from the bag. No damage was done to the bag or the wall. The reason for the pressure spike was not determined, but after rechecking the instruments and hoses, the test was resumed at 11:07 am, again using the high flow valve. After about two minutes, as the bag was approaching the surface of the wall, the air flow to the bag was switched from the fast to the slow flow valve. A problem with the DAS was noted and again the air was dumped (at 11:08 am). The problem occurred upon switching the DAS data scan rate from slow (about every minute during the initial fill of the bag) to fast (every two seconds once the air bag was near to the wall). To avoid this potential problem it was decided to scan at the faster rate from the beginning of the test. 


\subsection{MAIN AIR BAG TEST SEQUENCE}

A brief discussion of the events during the course of the air bag test is presented in this section. For locations of the cracking (such as E92 and E93) refer to Fig. 5. Obviously, cracking was not visible on the west side of the wall due to the air bag covering the wall. The crack pattern on that side was inspected after the test, with the air bag removed. LVDT V5, located in the geometric center of the wall (Fig. 9), was monitored closely during the test and is frequently mentioned in the discussion that follows. The pressure indicators on the control panel read in inches of water (in. $\mathrm{H}_{2} \mathrm{O}$ ) and are converted for this report into psi.

- 11:12:34 am (data record \#313), air flow to the air bag is restarted. Channel 1, measuring the pressure from the low-pressure gage, first indicates a nonzero pressure approximately two minutes into the test.

- 11:33 am, pressure is held constant at approximately 2.55 -in. $\mathrm{H}_{2} 0(0.092$ psi) while a spot check on the computer readings is performed. Loading is resumed at 11:42 am. No creep in the wall is evident during this hold.

- 11:49 am, the first sounds indicating possible cracking are audible. The pressure is $0.28 \mathrm{psi}$; LVDT V5 measures $0.066 \mathrm{in}$. A vertical crack in the mortar over block E93 is noted. When the pressure reaches 0.30 psi this crack extends to the vicinity of block E92.

- 0.49 psi, a horizontal crack above blocks E24 and E22, the top left beam interface (near Col. D2), is noted. IVDT V5 is measuring 0.104 in.

- 0.63 psi, the crack above blocks E93-E92 had extended to E94.

- $12.33 \mathrm{pm}\left(1 \mathrm{~h} 21 \mathrm{~m}\right.$ elapsed time of test), the pressure is held constant at 18 -in. $\mathrm{H}_{2} \mathrm{O}(0.65 \mathrm{psi})$ while the video camera tapes are changed out. Loading resumes at $12: 40 \mathrm{pm}$.

- 0.84 psi, a separation of the beam and mortar above E18 is noted. LVDT V5 measures 0.246 in.

- 0.86 psi, a crack in the vicinity of blocks E97 and E70 is observed to be growing.

- 0.96 psi, a stair-step cracking pattern develops in the vicinity of blocks E49 and E76.

- 1:12 pm, a pressure of 27.9-in. $\mathrm{H}_{2} \mathrm{O}$ (1.007 psi) is reached; LVDT V5 shows a deflection of 0.60 in. This, as it turns out, is the maximum pressure attained during the test. Almost immediately the pressure begins to fall and for the next 25 minutes, with air still flowing into the air bag, the pressure fluctuates between 0.92 to 0.99 psi. During this period there are obvious signs of wall movement, e.g., the deflection of LVDT V5 increases to $1.68 \mathrm{in}$. 
- 1:37:41 pm (record \#3983), with the XY-plot of the overhead steel beam and the LVDT V5 displacement showing definite nonlinear behavior, an air pressure dump is initiated and the test is terminated. About $\mathbf{3 0}$ seconds is needed to release the pressure from the wall. Data is read for a few more minutes after the pressure is at zero to allow the LVDTs to stabilize.

After the test, the wall was inspected on the hallway side for any visible damage. At this time it was still difficult to get close to the wall because of the LVDTs, and only a cursory inspection was made. The test site was closed up for the rest of the weekend, but on Monday, additional zero pressure measurements were taken of all the channels. 
$=$

II

It

1

$=$

I 


\section{DISCUSSION OF THE TEST}

\subsection{GENERAL}

More than 3600 data records were obtained from the main test on October 5, each having 96 channel measurements. For this report, only a few records have been chosen to represent the loading history. The records were selected in 0.05 psi increments and include those showing the maximum wall panel and steel frame deflections, applied pressure, and onset of nonlinear behavior. Table 1 lists the records used in preparing this report.

Table 1. Selected data records

\begin{tabular}{|c|c|c|c|c|c|}
\hline $\begin{array}{l}\text { Record } \\
\text { no. }\end{array}$ & Time & $\begin{array}{c}\text { Pressure } \\
\text { (psi) }^{1}\end{array}$ & $\begin{array}{l}\text { Record } \\
\text { no. }\end{array}$ & Time & $\begin{array}{c}\text { Pressure } \\
\text { (psi) }^{7}\end{array}$ \\
\hline 206 & $10: 15: 18$ & $2 e r 0^{2,3}$ & 2700 & 12:47:01 & 0.747 \\
\hline 766 & $11: 29: 40$ & 0.047 & 2834 & 12:52:19 & 0.798 \\
\hline 1126 & 11:43:13 & 0.097 & 2984 & 12:58:13 & 0.848 \\
\hline 1265 & 11:48:26 & 0.148 & 3140 & 13:04:21 & 0.899 \\
\hline 1371 & 11:52:25 & 0.198 & 3218 & 13:07:24 & 0.949 \\
\hline 1460 & $11: 55: 45$ & 0.249 & 3318 & $13: 11: 14$ & 1.000 \\
\hline 1541 & $11: 58: 48$ & 0.299 & 3344 & 13:12:14 & 1.007 \\
\hline 1614 & $12: 01: 34$ & 0.349 & 3348 & 13:12:23 & 1.004 \\
\hline 1686 & $12: 04: 17$ & 0.401 & 3525 & 13:19:14 & 0.978 \\
\hline 1759 & 12:07:06 & 0.451 & 3704 & $13: 26: 28$ & 0.993 \\
\hline 1998 & 12:16:11 & 0.498 & 3982 & 13:37:39 & $0.924^{5}$ \\
\hline 2111 & $12: 20: 29$ & 0.549 & 3983 & 13:37:41 & 0.845 \\
\hline 2241 & 12:25:27 & 0.599 & 3985 & 13:37:46 & 0.549 \\
\hline 2351 & $12: 29: 49$ & 0.650 & 3988 & 13:37:53 & 0.256 \\
\hline 2592 & 12:42:38 & 0.697 & 4026 & 13:40:36 & 0 \\
\hline \multicolumn{6}{|c|}{$\begin{array}{l}\text { NOTES: } \\
\text { 'Pressures based on data channel } 1 \text { using } 27.7 \text { in. } \mathrm{H}_{2} \mathrm{O}=1.0 \text { psi. The pressures } \\
\text { using Channel } 39 \text { are slightly lower. } \\
2 \text { Record \#206 was used for the data zeros, though record \#227, also a set of zeros, } \\
\text { is actually at a later time; the difference is quite small. } \\
3 \text { The actual starting point of the test was at time } 11: 12: 34 \text { (record \#313). Data } \\
\text { channel } 1 \text { first Indicated a nonzero pressure at time } 11: 13: 59 \text { (record \#350). } \\
4 \text { Maximum air bag pressure level. } \\
5 \text { Maximum displacement of the center of the wall. Started to off-load immediately. }\end{array}$} \\
\hline
\end{tabular}

A complete copy of all the data records obtained (including the data from the day before and the data taken two days after the test) are available in both hard copy and electronic forms. The raw data and the reduced data for each data point exists. To summarize the test results, Table 2 presents 
the pressure versus time-history data for the test, which is also plotted in Fig. 13. From the figure, it can be seen that the pressure loading rate for the first 30 minutes was $0.003 \mathrm{psi} / \mathrm{min}$. and about $0.010 \mathrm{psi} / \mathrm{min}$. for the next 90 minutes. The maximum air bag pressure attained during the test was 1.007 psi.

Table 2. Pressure vs. elapsed time

\begin{tabular}{cc||cc}
\hline $\begin{array}{c}\text { Elapsed Time } \\
\text { (minutes) }\end{array}$ & $\begin{array}{c}\text { Pressure } \\
\text { (psi) }\end{array}$ & $\begin{array}{c}\text { Elapsed Time } \\
\text { (minutes) }\end{array}$ & $\begin{array}{c}\text { Pressure } \\
\text { (psi) }\end{array}$ \\
\hline 00.00 & 0.000 & 93.03 & 0.748 \\
15.68 & 0.047 & 98.33 & 0.798 \\
29.23 & 0.098 & 104.23 & 0.849 \\
34.45 & 0.148 & 110.37 & 0.899 \\
38.43 & 0.199 & 113.42 & 0.950 \\
& & & \\
41.7 & 0.249 & 117.25 & 1.000 \\
44.82 & 0.300 & 118.25 & 1.007 \\
47.58 & 0.350 & 118.40 & 1.004 \\
50.30 & 0.401 & 125.25 & 0.979 \\
53.12 & 0.451 & 132.48 & 0.993 \\
& & & \\
62.20 & 0.498 & 143.67 & 0.924 \\
66.50 & 0.549 & 143.70 & 0.845 \\
71.47 & 0.599 & 143.78 & 0.549 \\
75.83 & 0.650 & 143.90 & 0.256 \\
88.65 & 0.697 & 146.62 & 0.0 \\
\hline
\end{tabular}

NOTE: Time $0.00=11: 13: 59$, first contact with the wall. The period of the test during which the air bag was inflating was ignored.

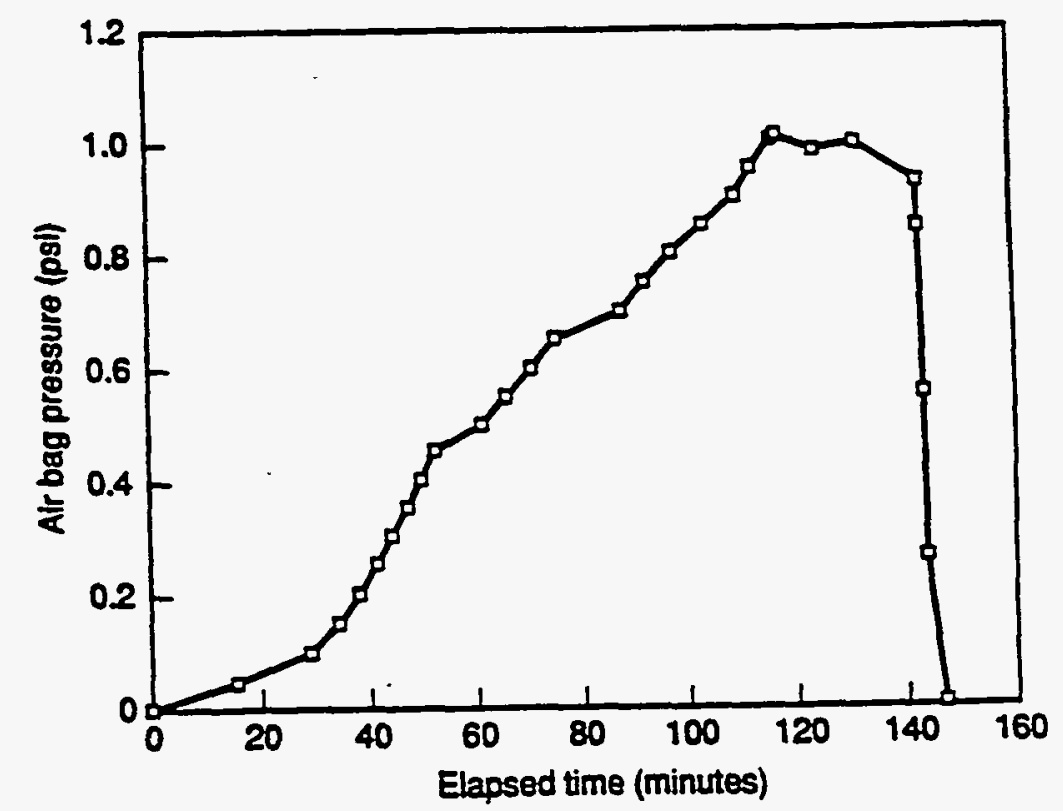

Fig. 13. Pressure exerted by the air bag vs. the elapsed time of the test. 


\subsection{LVDT RESULTS}

\subsection{Wall Lateral Displacement}

Table 3 presents pressure versus lateral deflection data from the top, middle, and bottom LVDTs (V1, V5, and V10 respectively) along the vertical centerline of the wall (see Fig. 9). Figure 14 plots the data for LVDT V5, located at the geometric center of the wall. A drastic change in the load-deflection behavior occurred at a pressure of 1.007 psi. The behavior up to this point could not be described as linear, per se, but at 1.007 psi, the stiffness of the wall at this location virtually went to zero. The deflection at LVDT V5 was $0.60 \mathrm{in}$. when the pressure first reached $1.007 \mathrm{psi}$. However, while the load slowly decreased to 0.92 psi the LVDT V5 deflection increased to 1.68 in. After removal of the load on the wall, LVDT V5 had a permanent set of 0.69 in.

Table 3. Wall deflections at mid-width

\begin{tabular}{cccc}
\hline $\begin{array}{c}\text { Airbag } \\
\text { pressure } \\
\text { (psi) }\end{array}$ & $\begin{array}{c}\text { LVDT V1 } \\
\text { ch. \#11 } \\
\text { (in.) }\end{array}$ & $\begin{array}{c}\text { LVDT V5 } \\
\text { ch. \#15 } \\
\text { (in.) }\end{array}$ & $\begin{array}{c}\text { LVDT V10 } \\
\text { ch. \#20 } \\
\text { (in.) }\end{array}$ \\
\hline 0.000 & 0.00000 & 0.00000 & 0.00000 \\
0.047 & 0.00676 & 0.00875 & 0.00272 \\
0.098 & 0.01465 & 0.01845 & 0.00563 \\
0.148 & 0.02469 & 0.02835 & 0.00873 \\
0.199 & 0.03155 & 0.03960 & 0.01230 \\
0.249 & 0.04291 & 0.05392 & 0.01559 \\
0.300 & 0.05502 & 0.06959 & 0.02019 \\
0.350 & 0.06413 & 0.08420 & 0.02469 \\
0.401 & 0.07587 & 0.09967 & 0.02948 \\
0.451 & 0.08939 & 0.11649 & 0.03446 \\
& & & \\
0.498 & 0.10441 & 0.14196 & 0.04404 \\
0.549 & 0.11887 & 0.16128 & 0.05117 \\
0.599 & 0.13803 & 0.18714 & 0.06056 \\
0.650 & 0.15417 & 0.21434 & 0.06873 \\
0.697 & 0.17755 & 0.25183 & 0.08112 \\
0.748 & 0.19455 & 0.27970 & 0.09051 \\
0.798 & 0.21840 & 0.31786 & 0.10291 \\
0.849 & 0.24582 & 0.36255 & 0.11774 \\
0.899 & 0.27211 & 0.41301 & 0.13408 \\
0.950 & 0.29840 & 0.46396 & 0.14939 \\
& & & \\
1.000 & 0.34290 & 0.56440 & 0.18075 \\
1.007 & 0.35492 & 0.59958 & 0.19849 \\
1.004 & 0.35746 & 0.60900 & 0.20807 \\
0.979 & 0.45098 & 0.89475 & 0.42055 \\
0.993 & 0.55679 & 1.19310 & 0.63313 \\
0.924 & 0.71407 & 1.68214 & 1.05603 \\
0.845 & 0.67088 & 1.59381 & 1.03491 \\
0.549 & 0.55426 & 1.36265 & 0.93566 \\
0.256 & 0.40356 & 1.02480 & 0.76580 \\
0.000 & 0.25774 & 0.69310 & 0.55914 \\
\hline & & & \\
\hline
\end{tabular}


The load versus deflection curve for LVDT's V1 and V10 is shown in Fig. 15. LVDT V1 (see Fig. 9) is located about 12 in. from the top and LVDT V10 about 18 in. from the bottom of the wall, along the vertical centerline. The maximum deflection at the bottom of the wall exceeded that near the top by $50 \%$, and the permanent set at the bottom was more than double that at the top, although early in the test the opposite behavior was taking place. When the pressure reached the maximum value of $1.007 \mathrm{psi}$, the deflection at the top was larger than that at the bottom. This crossover indicates that a compression failure occurred near the bottom, allowing the bottom part of the wall to slide (more) freely. This deformation was also quite evident after the test and is visible in the wall cracking sketches that are discussed later.

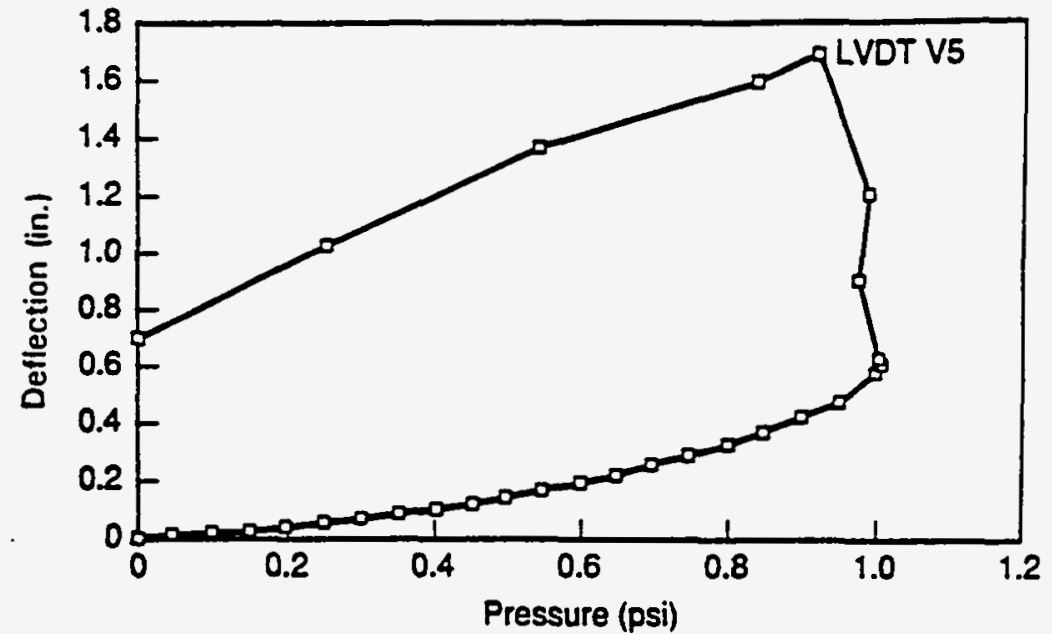

Fig. 14. Deflection of the test wall's center point (V5) vs. air bag pressure.

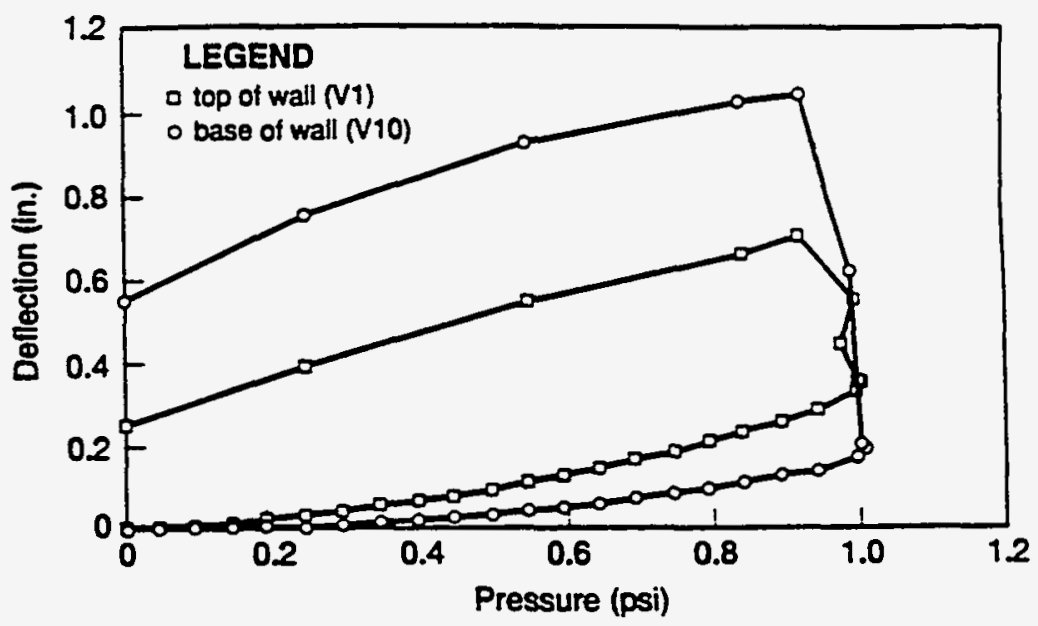

Fig. 15. Deflection of the top (V-1) and bottom $(V-10)$ of the test wall vs. air bag pressure.

\section{Deflection Profiles}

To obtain a more complete picture of the overall response of the wall during the test, horizontal and vertical profiles were developed. Table 4 presents the deflection data at four pressure levels along a vertical profile of the wall cut at midwidth. The horizontal deflection profiles are presented in Table 5 for two horizontal elevations, 18 in. above the floor and at midheight of the wall. These tables present the shape of the wall at the specified locations; at four pressures. $(0.25 \mathrm{psi}$, $0.50 \mathrm{psi}, 0.75 \mathrm{psi}$, and $1.00 \mathrm{psi}$ ); after the loading plateau that terminated with the air dump (creep); and after the pressure was totally removed from the wall. The corresponding plots are given in Figs. 16-18. These are "snapshots" of a slice through the wall at these given stages, and can bear further discussion. 
Table 4. Wall deflection profile at the vertical centerline

\begin{tabular}{|c|c|c|c|c|c|c|c|}
\hline \multirow{3}{*}{$\begin{array}{c}\text { LVDT } \\
\text { no. }\end{array}$} & \multirow{3}{*}{$\begin{array}{l}\text { Distance } \\
\text { above floor } \\
\text { (in.) }\end{array}$} & \multicolumn{6}{|c|}{$\begin{array}{c}\text { Displacement } \\
\text { (inches) }\end{array}$} \\
\hline & & \multicolumn{4}{|c|}{$\begin{array}{l}\text { Pressure level } \\
\text { (psi) }\end{array}$} & \multicolumn{2}{|c|}{ Test stage } \\
\hline & & 0.25 & 0.50 & 0.75 & 1.00 & Creep & Zero load \\
\hline$V_{10}$ & 20.75 & 0.016 & 0.044 & 0.091 & 0.198 & 1.056 & 0.536 \\
\hline v9 & 33.25 & 0.028 & 0.076 & 0.151 & 0.327 & 1.315 & 0.588 \\
\hline V8 & 44.25 & 0.039 & 0.104 & 0.201 & 0.432 & 1.531 & 0.628 \\
\hline$\sqrt{7}$ & 56.12 & 0.046 & 0.121 & 0.239 & 0.532 & 1.652 & 0.641 \\
\hline v5 & 67.75 & 0.054 & 0.142 & 0.280 & 0.600 & 1.682 & 0.641 \\
\hline$V_{4}$ & 94.75 & 0.057 & 0.146 & 0.296 & 0.617 & 1.513 & 0.548 \\
\hline v3 & 106.63 & 0.055 & 0.139 & 0.278 & 0.566 & 1.284 & 0.450 \\
\hline v2 & 117.00 & 0.051 & 0.123 & 0.238 & 0.472 & 1.023 & 0.343 \\
\hline V1 & 130.00 & 0.043 & 0.104 & 0.195 & 0.355 & 0.714 & 0.236 \\
\hline
\end{tabular}

Table 5. Horizontal wall deflection profiles

\begin{tabular}{|c|c|c|c|c|c|c|c|}
\hline \multirow{3}{*}{$\begin{array}{c}\text { LVDT } \\
\text { no. }\end{array}$} & \multirow{3}{*}{$\begin{array}{l}\text { Distance } \\
\text { from col. D2 } \\
\text { (in.) }\end{array}$} & \multicolumn{6}{|c|}{$\begin{array}{l}\text { Displacement } \\
\text { (inches) }\end{array}$} \\
\hline & & \multicolumn{4}{|c|}{$\begin{array}{c}\text { Pressure level } \\
\text { (psi) }\end{array}$} & \multicolumn{2}{|c|}{ Test stage } \\
\hline & & 0.25 & 0.50 & 0.75 & 1.00 & Creep & After unioad \\
\hline \multicolumn{8}{|c|}{ At midhoight of wall } \\
\hline $\begin{array}{l}H 1 \\
H 3 \\
H 6 \\
\text { V5 } \\
H 9 \\
H 11 \\
H 13 \\
H 14\end{array}$ & $\begin{array}{c}11.7 \\
54.2 \\
122 \\
171 \\
213 \\
259 \\
301 \\
324\end{array}$ & $\begin{array}{l}0.003 \\
0.024 \\
0.042 \\
0.054 \\
0.049 \\
0.029 \\
0.012 \\
0.004\end{array}$ & $\begin{array}{l}0.009 \\
0.062 \\
0.117 \\
0.142 \\
0.120 \\
0.072 \\
0.032 \\
0.008\end{array}$ & $\begin{array}{l}0.022 \\
0.126 \\
0.250 \\
0.280 \\
0.230 \\
0.140 \\
0.060 \\
0.018\end{array}$ & $\begin{array}{l}0.041 \\
0.237 \\
0.506 \\
0.564 \\
0.457 \\
0.273 \\
0.113 \\
0.031\end{array}$ & $\begin{array}{l}0.086 \\
0.643 \\
1.523 \\
1.682 \\
1.279 \\
0.719 \\
0.264 \\
0.060\end{array}$ & $\begin{array}{l}0.022 \\
0.271 \\
0.660 \\
0.693 \\
0.498 \\
0.269 \\
0.100 \\
0.020\end{array}$ \\
\hline \multicolumn{8}{|c|}{ At 18 in. from floor } \\
\hline $\begin{array}{l}\text { D9 } \\
\text { V17 } \\
\text { V10 } \\
\text { V24 } \\
\text { D8 }\end{array}$ & $\begin{array}{c}50.1 \\
99.7 \\
171 \\
236 \\
285\end{array}$ & $\begin{array}{l}0.009 \\
0.003 \\
0.016 \\
0.010 \\
0.006\end{array}$ & $\begin{array}{l}0.018 \\
0.020 \\
0.044 \\
0.027 \\
0.014\end{array}$ & $\begin{array}{l}0.035 \\
0.068 \\
0.090 \\
0.055 \\
0.024\end{array}$ & $\begin{array}{l}0.074 \\
0.186 \\
0.180 \\
0.118 \\
0.049\end{array}$ & $\begin{array}{l}0.545 \\
1.153 \\
1.056 \\
0.459 \\
0.204\end{array}$ & $\begin{array}{l}0.286 \\
0.612 \\
0.560 \\
0.241 \\
0.101\end{array}$ \\
\hline
\end{tabular}

Figure 16-Vertical profile

The bottom of the wall is shown at the bottom of the figure. Note that up to the point where the maximum pressure was reached, displacement at the top of the wall was larger than that near the bottom; but at maximum deflection and after unload, the reverse was true. 
Figure 17-Horizontal deflection profile near bottom

The horizontal displacement profile of the lower set of HCT blocks indicates that, throughout the test, the displacement was larger towards the south column, D2 (bottom of figure). Also, note that the maximum deflection did not occur at the center of the wall.

Figure 18-Horizontal deflection profile at midheight

The maximum displacement occurs, as expected, near the center of the wall. Again, the permanent set exceeds the displacement that occurred at the maximum pressure level, except near the ends of the wall.

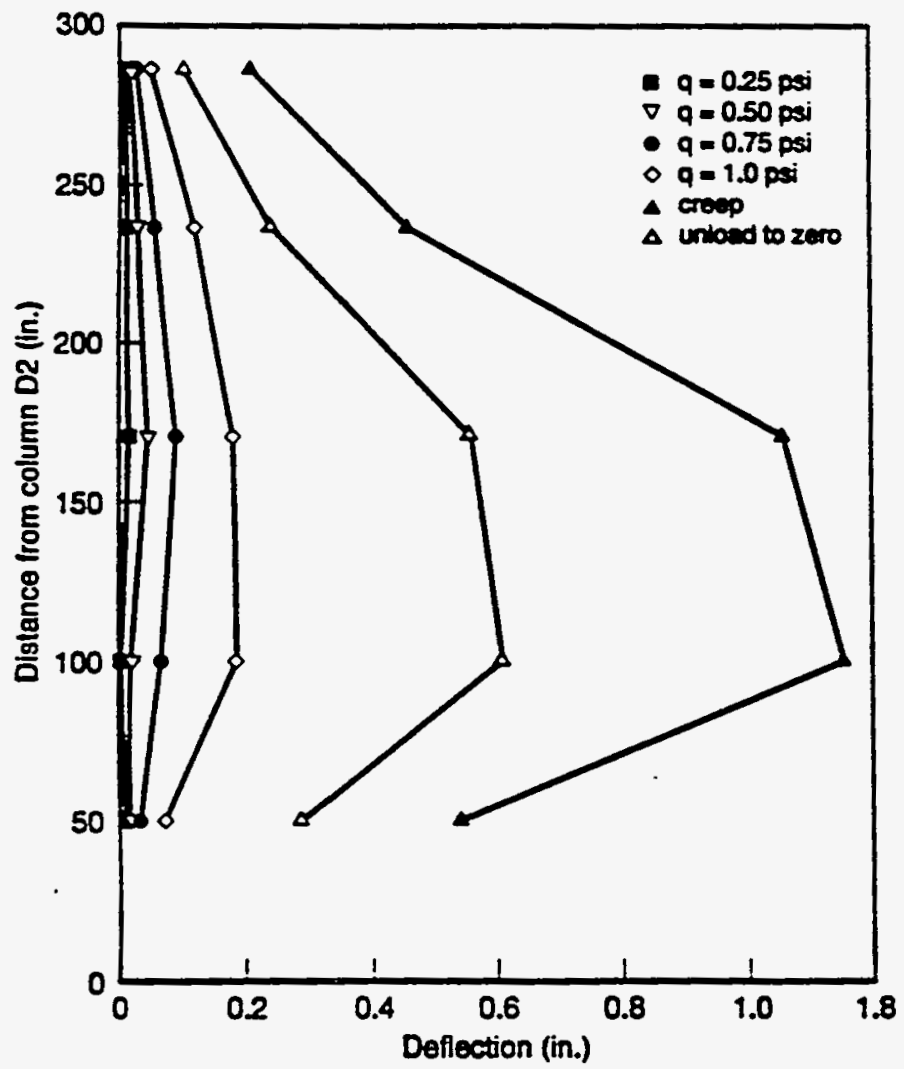

Fig. 17. Horizontal displacement profiles of the second course of HCT blocks from the wall's bottom.

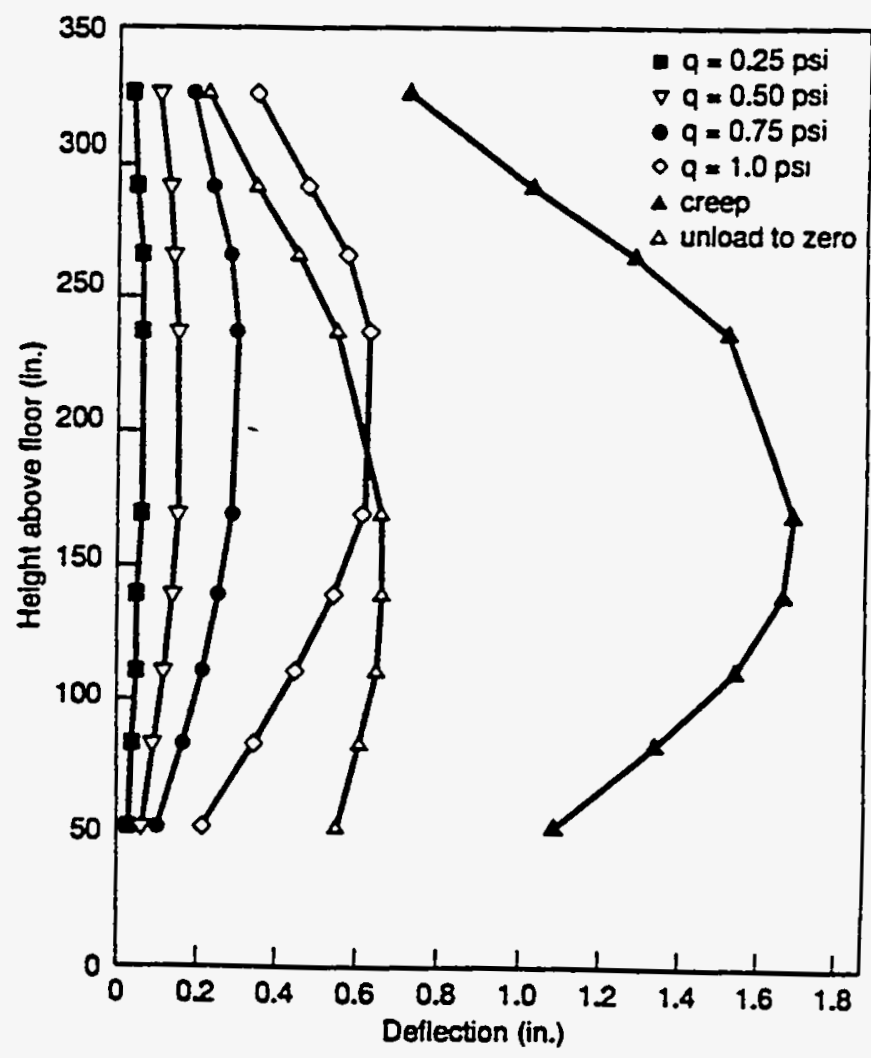

Fig. 16. Vertical displacement profiles at midwidth of the test wall showing out-of-plane deflection.

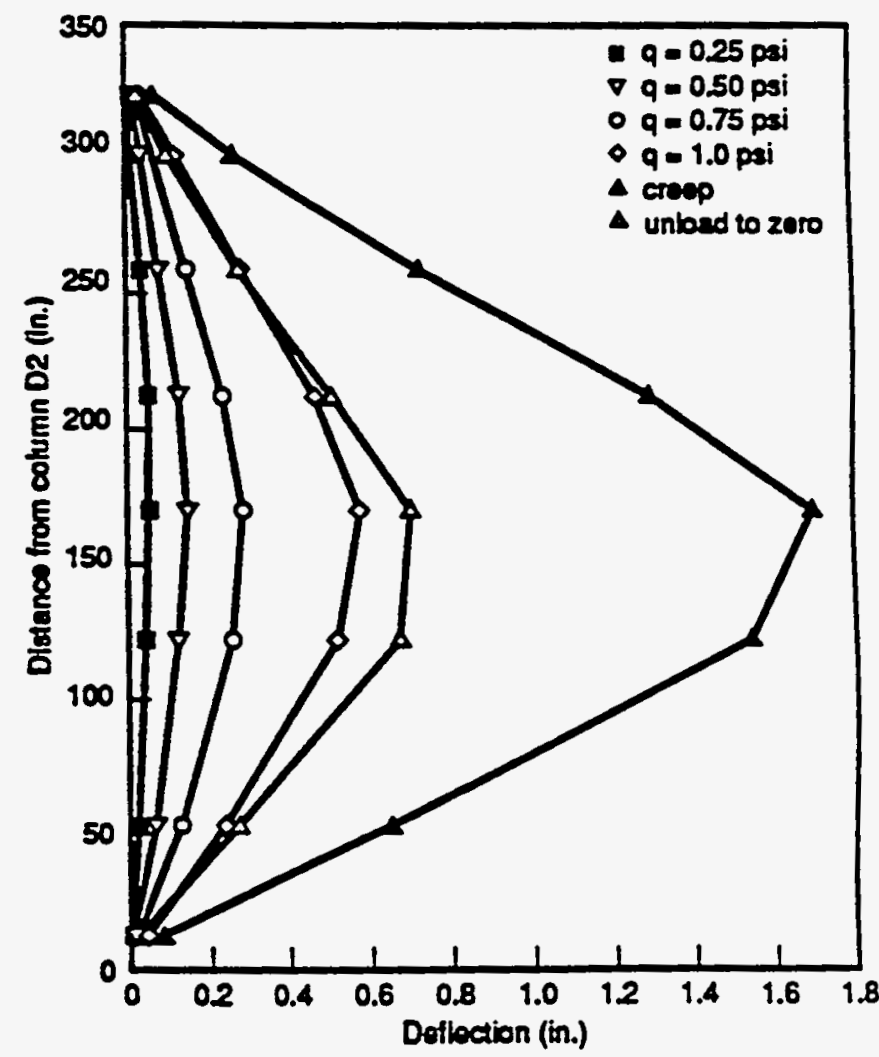

Fig. 18. Horizontal displacement profiles at midheight of the wall. 
The nonlinear pressure-deflection relationship for of out-of-plane loading on this infill wall is evident from these plots. Deflections nearly tripled when pressure values fluctuated only slightly once 1.007 psi was reached. Skewness of the horizontal profile (Fig. 17) near the bottom of the wall is probably an indication of the lower normal stresses occurring when the top blocks on the south half of the wall were replaced. (See the darkened HCT blocks at the top left of wall in Fig. 5.) "Crossover" of the 1.0 psi and unloaded vertical profiles (Fig. 16) is an indication of major damage at the bottom of the wall.

\section{Deflected Surface Plots}

Tables 6, 7, and 8 show selected data used in plotting the deflected shape of the wall. Figure 19 is a perspective showing the wall in an unloaded state; Fig. 20 is a perspective showing the surface deflected shape at maximum displacement; and Fig. 21 shows the surface deflection at maximum displacement viewed from above.

Table 6. Wall surface deflections at 1.0 psi pressure

\begin{tabular}{|c|c|c|c|c|c|c|c|}
\hline \multirow{2}{*}{$\begin{array}{l}\text { Vert. dist. from } \\
\text { wall center } \\
\text { (in.) }\end{array}$} & \multicolumn{7}{|c|}{$\begin{array}{l}\text { Horizontal distance from wall center } \\
\text { (in.) }\end{array}$} \\
\hline & -150 & -117 & -68 & $\mathbf{0}$ & 68 & 117 & 150 \\
\hline & \multicolumn{7}{|c|}{ LVDTs used in surface plot } \\
\hline \multirow[t]{2}{*}{$\begin{array}{r}50 \\
0 \\
50\end{array}$} & $\begin{array}{l}\text { D1 } \\
\text { H1 } \\
\text { V16 }\end{array}$ & $\begin{array}{l}S 1 \\
H 3 \\
D 9\end{array}$ & $\begin{array}{l}\text { V11 } \\
\text { H5 } \\
\text { V17 }\end{array}$ & $\begin{array}{l}\text { V2 } \\
\text { V5 } \\
\text { V10 }\end{array}$ & $\begin{array}{l}\text { V18 } \\
\text { H10 } \\
\text { V24 }\end{array}$ & $\begin{array}{l}\text { S4 } \\
\text { H12 } \\
\text { D8 }\end{array}$ & $\begin{array}{l}\text { D16 } \\
\text { H14 } \\
\text { V23 }\end{array}$ \\
\hline & \multicolumn{7}{|c|}{$\begin{array}{l}\text { Lateral displacement } \\
\text { (in.) }\end{array}$} \\
\hline $\begin{array}{r}50 \\
0 \\
50\end{array}$ & $\begin{array}{l}0.050 \\
0.043 \\
0.042\end{array}$ & $\begin{array}{l}0.182 \\
0.249 \\
0.082\end{array}$ & $\begin{array}{l}0.385 \\
0.458 \\
0.207\end{array}$ & $\begin{array}{l}0.472 \\
0.600 \\
0.199\end{array}$ & $\begin{array}{l}0.357 \\
0.402 \\
0.127\end{array}$ & $\begin{array}{l}0.163 \\
0.196 \\
0.054\end{array}$ & $\begin{array}{l}0.052 \\
0.032 \\
0.031\end{array}$ \\
\hline
\end{tabular}

Table 7. Maximum wall surface deflections after the "creep" loading stage ended

\begin{tabular}{|c|c|c|c|c|c|c|c|}
\hline \multirow{2}{*}{$\begin{array}{l}\text { Vert. dist. from } \\
\text { wall center } \\
\text { (in.) }\end{array}$} & \multicolumn{7}{|c|}{$\begin{array}{l}\text { Horizontal distance from wall center } \\
\text { (in.) }\end{array}$} \\
\hline & -150 & -117 & -68 & 0 & 68 & 117 & 150 \\
\hline \multirow{3}{*}{$\begin{array}{r}50 \\
0 \\
50\end{array}$} & \multicolumn{7}{|c|}{ LVDTs used in surface plot } \\
\hline & $\begin{array}{l}D 1 \\
H 1 \\
\text { V16 }\end{array}$ & $\begin{array}{l}S 1 \\
H 3 \\
D 9\end{array}$ & $\begin{array}{l}\text { V11 } \\
H 5 \\
\text { V17 }\end{array}$ & $\begin{array}{l}\text { V2 } \\
\text { V5 } \\
\text { V10 }\end{array}$ & $\begin{array}{l}\text { V18 } \\
\text { H10 } \\
\text { V24 }\end{array}$ & $\begin{array}{l}S 4 \\
H 12 \\
D 8\end{array}$ & $\begin{array}{l}\text { D16 } \\
\text { H14 } \\
\text { V23 }\end{array}$ \\
\hline & \multicolumn{7}{|c|}{$\begin{array}{l}\text { Loteral displacement } \\
\text { (in.) }\end{array}$} \\
\hline $\begin{array}{r}50 \\
0 \\
50\end{array}$ & $\begin{array}{l}0.098 \\
0.086 \\
0.169\end{array}$ & $\begin{array}{l}0.353 \\
0.642 \\
0.545\end{array}$ & $\begin{array}{l}0.840 \\
1.256 \\
1.157\end{array}$ & $\begin{array}{l}1.023 \\
1.682 \\
1.056\end{array}$ & $\begin{array}{l}0.742 \\
0.996 \\
0.460\end{array}$ & $\begin{array}{l}0.310 \\
0.463 \\
0.205\end{array}$ & $\begin{array}{l}0.085 \\
0.060 \\
0.099\end{array}$ \\
\hline
\end{tabular}


Table 8. Wall surface deflections after unloading (i.e., permanent set of the wall).

\begin{tabular}{|c|c|c|c|c|c|c|c|}
\hline \multirow{2}{*}{$\begin{array}{l}\text { Vert. dist. from } \\
\text { wall center } \\
\text { (in.) } \\
\end{array}$} & \multicolumn{7}{|c|}{$\begin{array}{l}\text { Horizontal distance from wall center } \\
\text { (in.) }\end{array}$} \\
\hline & -150 & -117 & -68 & 0 & 68 & 117 & 150 \\
\hline & \multicolumn{7}{|c|}{ LVDTs used in surface plot } \\
\hline $\begin{array}{r}50 \\
0 \\
50\end{array}$ & $\begin{array}{l}\text { D1 } \\
\text { H1 } \\
\text { V16 }\end{array}$ & $\begin{array}{l}\text { S1 } \\
\text { H3 } \\
\text { D9 }\end{array}$ & $\begin{array}{l}\text { V11 } \\
\text { H5 } \\
\text { V17 }\end{array}$ & $\begin{array}{l}\text { V2 } \\
\text { V5 } \\
\text { V10 }\end{array}$ & $\begin{array}{l}\text { V18 } \\
H 10 \\
\text { V24 }\end{array}$ & $\begin{array}{l}\mathrm{S} 4 \\
\mathrm{H} 12 \\
\mathrm{DB}\end{array}$ & $\begin{array}{l}\text { D16 } \\
\text { H14 } \\
\text { V23 }\end{array}$ \\
\hline-50 & \multicolumn{7}{|c|}{$\begin{array}{l}\text { Lateral displacement } \\
\text { (in.) }\end{array}$} \\
\hline $\begin{array}{r}50 \\
0 \\
-50\end{array}$ & $\begin{array}{l}0.030 \\
0.022 \\
0.080\end{array}$ & $\begin{array}{l}0.131 \\
0.271 \\
0.286\end{array}$ & $\begin{array}{l}0.317 \\
0.551 \\
0.612\end{array}$ & $\begin{array}{l}0.369 \\
0.693 \\
0.559\end{array}$ & $\begin{array}{l}0.268 \\
0.389 \\
0.241\end{array}$ & $\begin{array}{l}0.105 \\
0.176 \\
0.101\end{array}$ & $\begin{array}{l}0.030 \\
0.020 \\
0.050\end{array}$ \\
\hline
\end{tabular}

\section{Steel Frame Behavior}

The load-deflection behavior of the HCT-infilled steel frame (consisting of the W30 overhead beam and the two W14 columns) is described here.

Ten LVDTs were used, (shown in Fig. 10 marked F1-F8 and M1 and M2), to measure and monitor the lateral displacement behavior of the steel frame during the test. LVDT M1 was located on the leading edge of the bottom flange of the W30 beam, one-fourth of the distance between columns D2 and D3. LVDT F4 was located on the W30 web at midspan, just below the bottom flange of the W21 beam. LVDTs F1 and F8 were placed on the column top flange along the centerline of the W30 beam. LVDTs F2, M2, F6, and F7 were located at the leading edges of the top surface of the column flanges. LVDTs F3 and F8 were placed about 18 in. above the bottom of the two columns. Placing instrumentation any lower was not possible because of the interference of the reaction frame's lower horizontal tube member, located at the bottom of the wall.

\section{0x108 Beam}

Tables 9 and 10 present the lateral deflection data for the overhead W30 beam. Table 9 presents the load-deflection data for LVDT M1, plotted in Fig. 22. This LVDT was designated as one of the "critical monitoring" LVDTs because it provided the direct response of the overhead beam. If this LVDT indicated a displacement greater that 0.07 in. away from the wall, then the test was to be automatically stopped by the control system. However, shortly after the test started it became obvious that the LVDT was not performing as expected because (1) it was showing negative displacements, indicating that the beam flange was moving in the direction opposite to the loading (twisting of the beam due to arching action?), and (2) the displacements were huge (as large as 3 in.) as reported on the X-Y plotter. Since the automatic shutoff would never be triggered because of the negative value (a positive value was input to the control system), and since the large displacements were simply not possible, the test was allowed to proceed with constant monitoring of the beam visually and looking for nonlinear behavior of the beam reflected in the X-Y plotter. After the test 


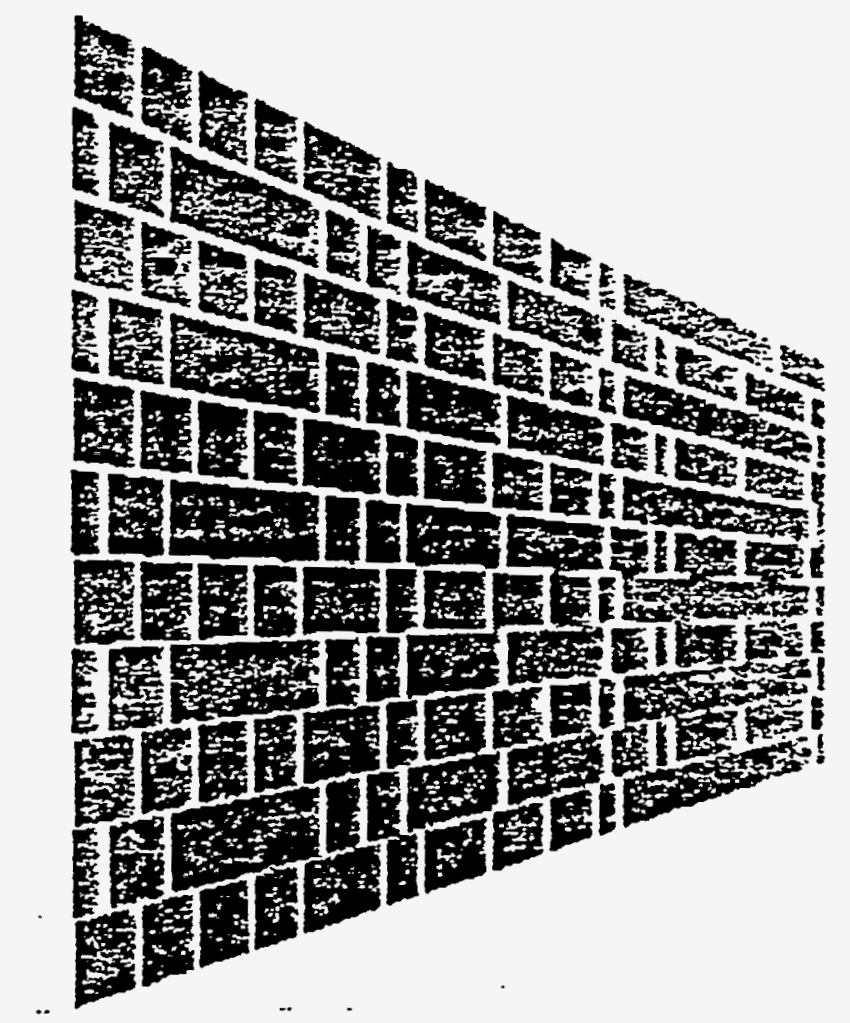

Fig. 19. Perspective showing test wall in an unloaded state.

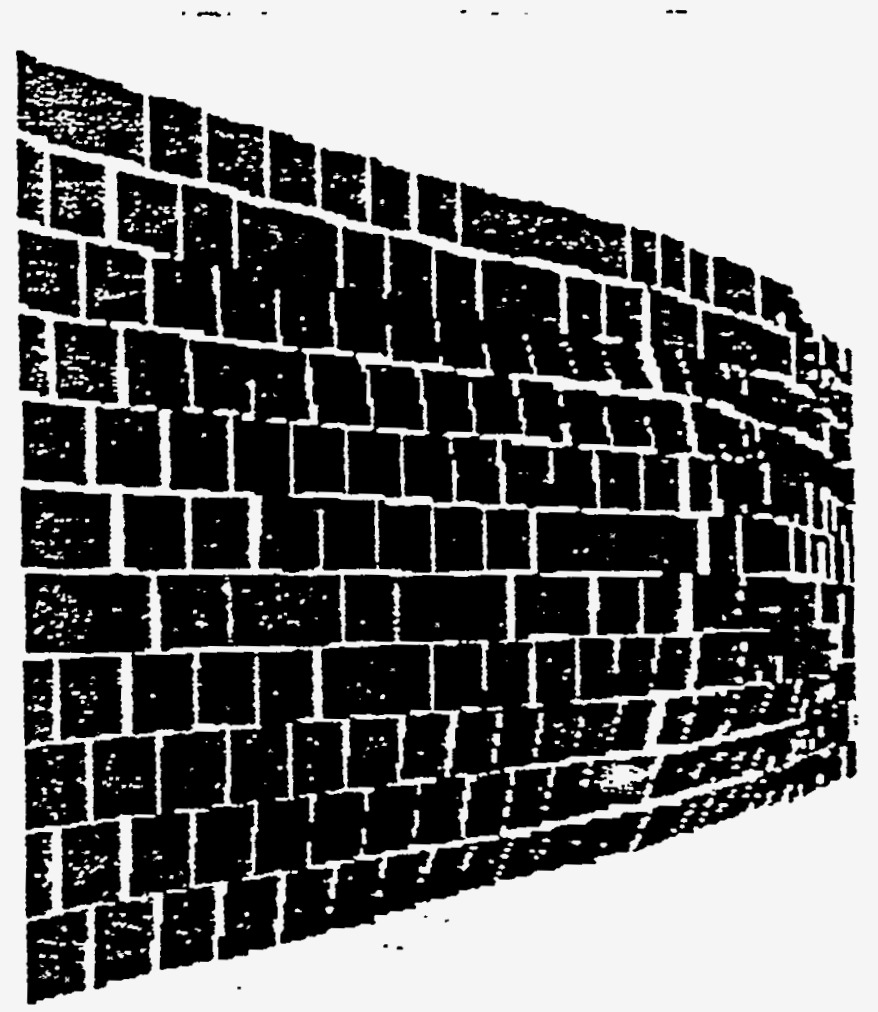

Fig. 20. Perspective of the deflected shape of the test wall surface at maximum displacement. 


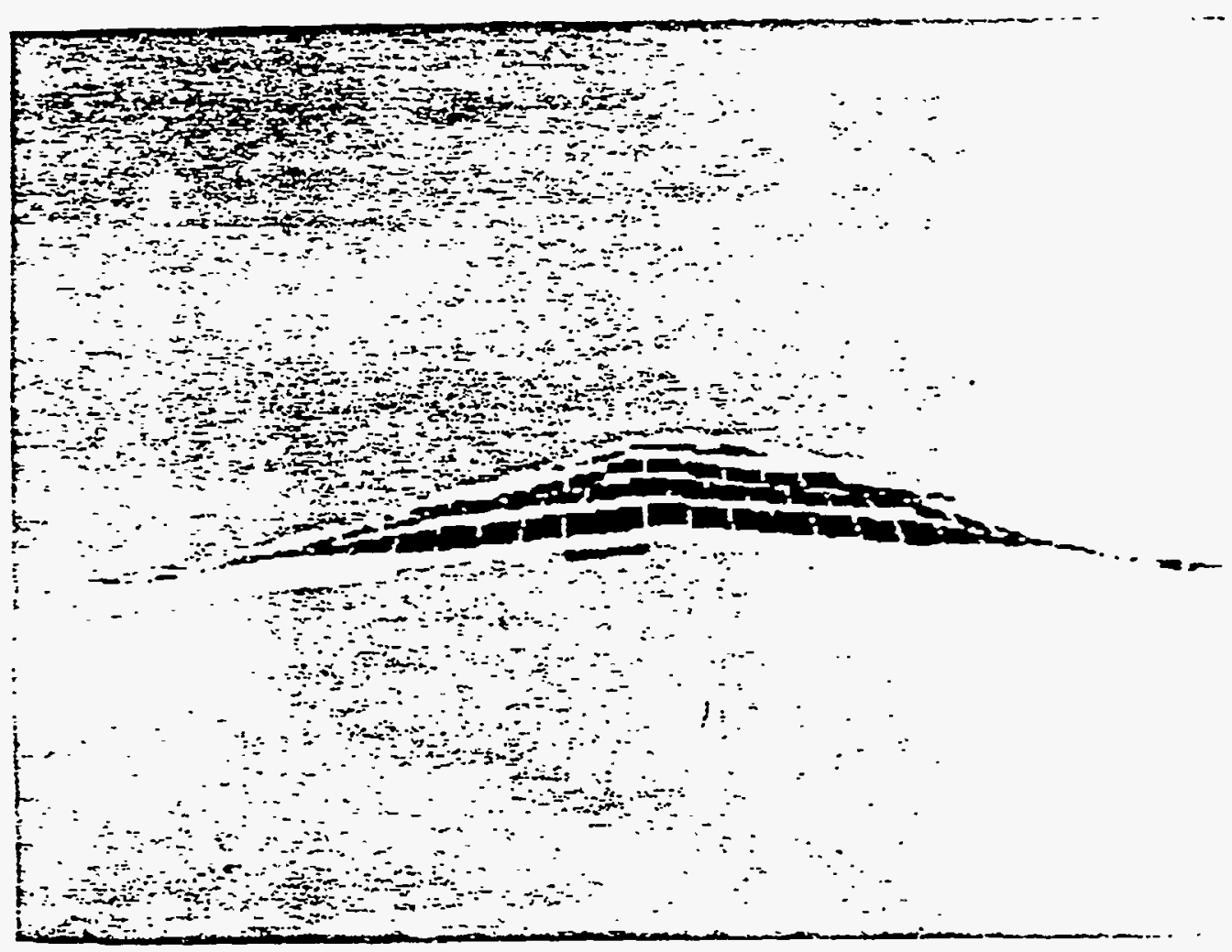

Fig. 21. Perspective showing the surface deflection at maximum displacement viewed from above.

Table 9. LVDT M1 deflections

\begin{tabular}{lc|cc}
\hline $\begin{array}{c}\text { Air bag } \\
\text { pressure } \\
\text { (psi) }\end{array}$ & $\begin{array}{c}\text { LVDT M1 } \\
\text { ch. \#87 } \\
\text { (in.) }\end{array}$ & $\begin{array}{c}\text { Air bag } \\
\text { pressure } \\
\text { (psi) }\end{array}$ & $\begin{array}{c}\text { LVDT M1 } \\
\text { ch. \#87 } \\
\text { (in.) }\end{array}$ \\
\hline 0.000 & 0.0000 & 0.748 & 0.1439 \\
0.047 & 0.0592 & 0.798 & 0.1536 \\
0.098 & 0.0029 & 0.849 & 0.1645 \\
0.148 & 0.0671 & 0.899 & 0.1759 \\
0.199 & 0.0718 & 0.950 & 0.1869 \\
& & & \\
0.249 & 0.0765 & 1.000 & 0.2047 \\
0.300 & 0.0812 & 1.007 & 0.2094 \\
0.350 & 0.0865 & 1.004 & 0.2102 \\
0.401 & 0.0920 & 0.979 & 0.2440 \\
0.451 & 0.0982 & 0.993 & 0.2811 \\
& & & \\
0.498 & 0.1054 & 0.924 & 0.3303 \\
0.549 & 0.1119 & 0.845 & 0.3087 \\
0.599 & 0.1194 & 0.549 & 0.2638 \\
0.650 & 0.1268 & 0.256 & 0.2026 \\
0.697 & 0.1359 & 0.000 & 0.1426 \\
\hline
\end{tabular}


Table 10. Out-of-plane defiections for overhead beam (W30x108)

\begin{tabular}{|c|c|c|c|}
\hline $\begin{array}{l}\text { Air bag } \\
\text { pressure } \\
\text { (psi) }\end{array}$ & $\begin{array}{l}\text { LVDT F1 } \\
\text { ch. \#89 } \\
\text { (in.) }\end{array}$ & $\begin{array}{l}\text { LVDT F4 } \\
\text { ch. \#76 } \\
\text { (in.) }\end{array}$ & $\begin{array}{c}\text { LVDT F5 } \\
\text { ch. } \# 77 \\
\text { (in.) }\end{array}$ \\
\hline $\begin{array}{l}0.000 \\
0.047 \\
0.098 \\
0.148 \\
0.199\end{array}$ & $\begin{array}{l}0.0000 \\
0.0004 \\
0.0005 \\
0.0005 \\
0.0005\end{array}$ & $\begin{array}{r}0.0000 \\
-0.0012 \\
-0.0042 \\
-0.0064 \\
-0.0103\end{array}$ & $\begin{array}{l}0.0000 \\
0.0007 \\
0.0006 \\
0.0004 \\
0.0003\end{array}$ \\
\hline $\begin{array}{l}0.249 \\
0.300 \\
0.350 \\
0.401 \\
0.451\end{array}$ & $\begin{array}{l}0.0004 \\
0.0003 \\
0.0002 \\
0.0002 \\
0.0001\end{array}$ & $\begin{array}{l}-0.0125 \\
-0.0150 \\
-0.0191 \\
-0.0230 \\
-0.0270\end{array}$ & $\begin{array}{l}0.0003 \\
0.0003 \\
0.0006 \\
0.0007 \\
0.0010\end{array}$ \\
\hline $\begin{array}{l}0.498 \\
0.549 \\
0.599 \\
0.650 \\
0.697\end{array}$ & $\begin{array}{r}0.0000 \\
-0.0002 \\
-0.0003 \\
-0.0005 \\
-0.0012\end{array}$ & $\begin{array}{l}-0.0324 \\
-0.0368 \\
-0.0411 \\
-0.0465 \\
-0.0540\end{array}$ & $\begin{array}{l}0.0014 \\
0.0015 \\
0.0019 \\
0.0019 \\
0.0023\end{array}$ \\
\hline $\begin{array}{l}0.748 \\
0.798 \\
0.849 \\
0.899 \\
0.950\end{array}$ & $\begin{array}{l}-0.0015 \\
-0.0019 \\
-0.0024 \\
-0.0028 \\
-0.0031\end{array}$ & $\begin{array}{l}-0.0603 \\
-0.0668 \\
-0.0729 \\
-0.0821 \\
-0.0890\end{array}$ & $\begin{array}{l}0.0023 \\
0.0026 \\
0.0028 \\
0.0032 \\
0.0036\end{array}$ \\
\hline $\begin{array}{l}1.000 \\
1.007 \\
1.004 \\
0.979 \\
0.993\end{array}$ & $\begin{array}{l}-0.0034 \\
-0.0034 \\
-0.0033 \\
-0.0032 \\
-0.0033\end{array}$ & $\begin{array}{l}-0.0998 \\
-0.1026 \\
-0.1028 \\
-0.1206 \\
-0.1409\end{array}$ & $\begin{array}{l}0.0042 \\
0.0043 \\
0.0043 \\
0.0043 \\
0.0053\end{array}$ \\
\hline $\begin{array}{l}0.924 \\
0.845 \\
0.549 \\
0.256 \\
0.000\end{array}$ & $\begin{array}{l}-0.0022 \\
-0.0018 \\
-0.0013 \\
-0.0011 \\
-0.0008\end{array}$ & $\begin{array}{l}-0.1646 \\
-0.1529 \\
-0.1253 \\
-0.0872 \\
-0.0485\end{array}$ & $\begin{array}{l}0.0053 \\
0.0049 \\
0.0038 \\
0.0027 \\
0.0012\end{array}$ \\
\hline
\end{tabular}

it was found that (1) the negative value was caused by a sign error in the calibration factor input for that LVDT (and a few others, as it turned out), and (2) the X-Y plotter was on the wrong scale (the measurement stored in the computer was correct, just the plotted value was wrong).

The deflection value at maximum pressure $(0.21 \mathrm{psi})$ was two-thirds the value indicated by LVDT V1 (0.35 psi) and slightly less than half the value at the point of maximum displacement, indicating that there was a possible slip between the top of the wall and the overhead beam. (However, note that M1 and V1 are not directly in line with each other.) The overhead beam, according to data from LVDT M1, exhibited the same behavior as the wall after the maximum pressure was reached, i.e., increasing displacement under level or slightly decreasing load, even after the block-steel beam bond failed. This is due to the fact that in-plane thrust is a primary source of 
loading felt by the beam. The in-plane thrust loads continue to increase as long as the wall continues to deflect, regardless of the air bag pressure.

Table 10 presents the lateral deflection data at each end and in the center of the overhead beam. The end displacements are very small (two orders of magnitude smaller than the displacements measured by $M 1$ ), and also have opposite signs, indicating one moved towards the hallway while the other went in the opposite direction. The center deflections of the beam, measured by $F 4$ where the W21 frames in, is about half as large as those measured by M1 and also indicated negative movement. These displacement anomalies have not yet been explained satisfactorily.

\section{Column Behavior}

Figures 23 (column D2) and 24 (column D3) show the pressure deflection curves for the IVDTs measuring the midheight column lateral deflections. The actual data are presented in Table 11. As expected, the LVDTs located on the edge of the columns nearest the wall (M2 and F6) showed positive displacement (away from the wall) while those located on the trailing edge of the column flanges (F2 and F7) showed negative displacement, indicating that both columns were rotating or twisting. Since the positive displacement exceeded the negative displacement, some bending of the flanges was also taking place. Again, noniinear behavior was noted after the point of maximum pressure. Midspan column flange displacements (flange tip on the test wall) when a pressure of 1.007 psi was initially attained were 0.013 in. for column D2 (South coiumn) and 0.017 in. for column D3 (North column). Both are very small in comparison to the wall center deflection of 0.6 in., as would be expected. Based on this observation, the net wall deflection could be taken as

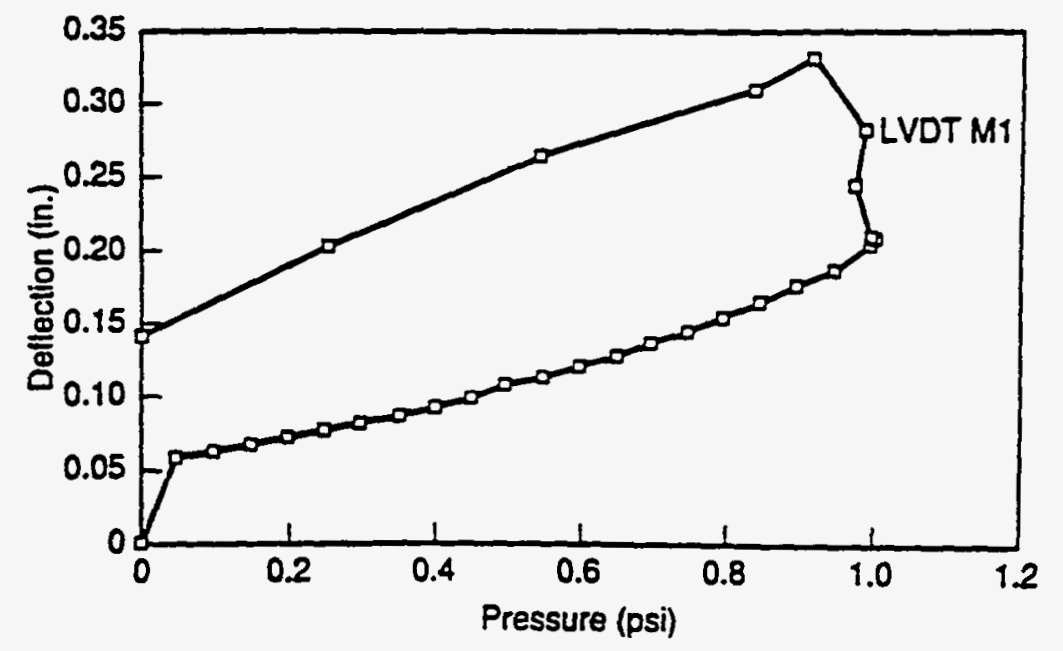

Fig. 22. Overhead quarter-span beam deflection vs. air bag

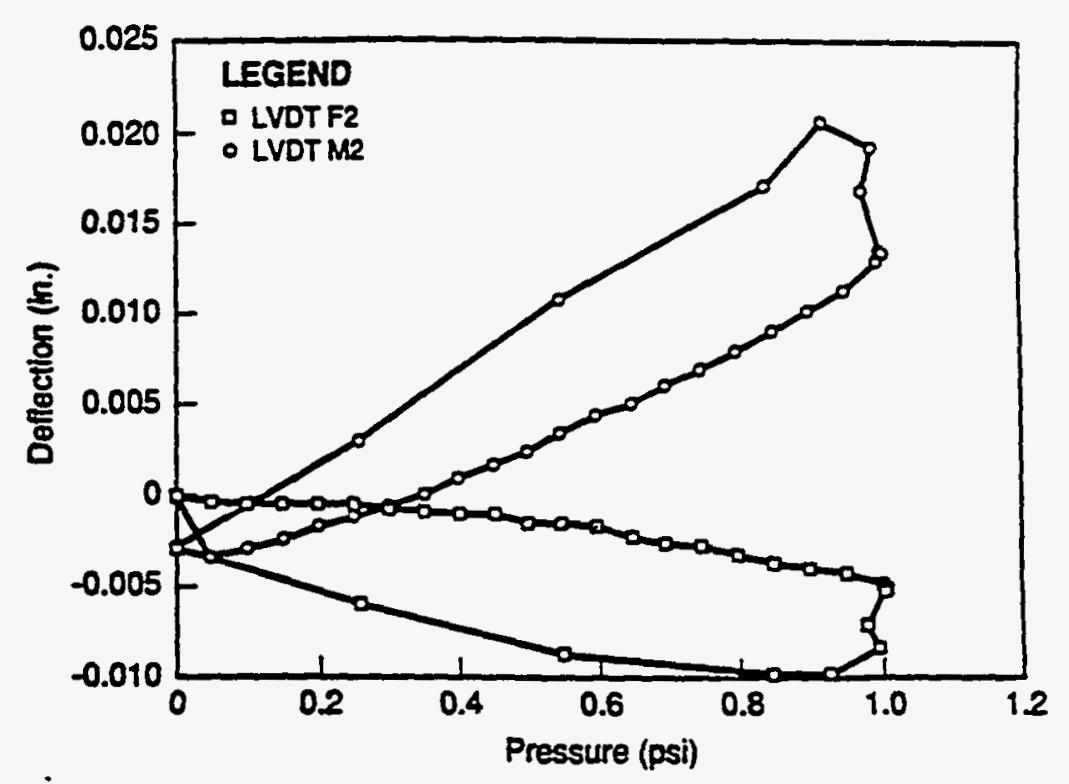

Fig. 23. Deflection or twisting of column D2 vs. the air bag pressure. pressure on the test wall. 
0.585 in. (97.5\% of the recorded value). Adjustment of wall displacement values was considered unnecessary.

\subsubsection{Wall and Column Slip}

As previously indicated, a set of LVDTs were placed to measure the relative in-plane displacements between the steel frame and the infill wall, and to measure the continuation of the wall on the back side of the columns. These are shown in Fig. 10 with the "I" designation. LVDTs 12,13 , and I4 measured the motion of the infill wall. LVDTs I1 and I5 measured motion with respect to the continuation wall portions. Table 12 presents the data for these five LVDTs, and Figs. 25 and 26 show the pressure versus deflection curves for the four LVDTs attached to the columns. For the two LVDTs placed on the far edge of the columns-away from the infill wall being tested-the displacement at maximum pressure was about 0.005 in, with a maximum displacement of 0.010 in. The in-plane displacement on the infill side was almost twice as great at column D2 as at column D3 (compare I2 and I4).

Note the difference in the behavior of the two columns. The deflections at both edges of column D2 were the same up through about 0.65 psi, after which the infill side showed a much larger displacement; the two LVDTs on column D3 followed each other rather closely up to the maximum pressure, after which the infill side displacement took off However, the overall motions were still small, and because of the method of attachment, it is not clear how much of these displacements are due to pure sliding and how much are a consequence of column rotation and lateral displacement of the infill wall. 
Table 11. Column deflection at midheight

\begin{tabular}{|c|c|c|c|c|}
\hline $\begin{array}{l}\text { Airbag } \\
\text { pressure } \\
\text { (psi) }\end{array}$ & $\begin{array}{l}\text { LVDT M2 } \\
\text { ch. } \# 88 \\
\text { (in.) }\end{array}$ & $\begin{array}{l}\text { LVDT F2 } \\
\text { ch. } \$ 90 \\
\quad \text { (in.) }\end{array}$ & $\begin{array}{l}\text { LVDT F6 } \\
\text { ch. \#78 } \\
\text { (in.) }\end{array}$ & $\begin{array}{c}\text { LVDT F7 } \\
\text { ch. \#79 } \\
\text { (in.) }\end{array}$ \\
\hline 0.000 & 0.0000 & 0.0000 & 0.0000 & 0.0000 \\
\hline 0.047 & -0.0034 & -0.0003 & 0.0010 & 0.0005 \\
\hline 0.098 & -0.00029 & -0.0004 & 0.0016 & 0.0003 \\
\hline 0.148 & -0.0024 & -0.0005 & 0.0020 & 0.0001 \\
\hline 0.199 & -0.0017 & -0.0005 & 0.0024 & 0.0001 \\
\hline 0.249 & -0.0011 & -0.0005 & 0.0030 & -0.0003 \\
\hline 0.300 & -0.0005 & -0.0007 & 0.0033 & -0.0006 \\
\hline 0.350 & 0.0001 & -0.0000 & 0.0040 & -0.0008 \\
\hline 0.401 & 0.0000 & -0.0010 & 0.0043 & -0.0011 \\
\hline 0.451 & 0.0017 & -0.0010 & 0.0046 & -0.0014 \\
\hline 0.498 & 0.0024 & -0.0015 & 0.0058 & -0.0018 \\
\hline 0.549 & 0.0034 & -0.0015 & 0.0064 & -0.00020 \\
\hline 0.599 & 0.0044 & -0.0017 & 0.0071 & -0.00024 \\
\hline 0.650 & 0.0050 & -0.0022 & 0.0079 & -0.0030 \\
\hline $0 . \circledast 7$ & 0.0050 & -0.0026 & 0.0001 & -0.0036 \\
\hline 0.748 & 0.0000 & -0.0028 & 0.0100 & -0.0042 \\
\hline 0.798 & 0.0079 & -0.0032 & 0.0111 & -0.0048 \\
\hline 0.849 & 0.0090 & -0.0037 & 0.0124 & -0.0054 \\
\hline 0.809 & 0.0101 & -0.0040 & 0.0132 & -0.0002 \\
\hline 0.950 & 0.0113 & -0.0043 & 0.0143 & -0.0068 \\
\hline 1.000 & 0.0129 & -0.0049 & 0.0161 & -0.0081 \\
\hline 1.007 & 0.0134 & -0.0051 & 0.0167 & -0.0084 \\
\hline 1.004 & 0.0135 & -0.0052 & 0.0168 & -0.0085 \\
\hline 0.979 & 0.0169 & -0.0071 & 0.0210 & -0.0112 \\
\hline 0.993 & 0.0193 & -0.0084 & 0.0252 & -0.0139 \\
\hline 0.924 & 0.0207 & -0.00088 & $0.02 \pi$ & -0.0165 \\
\hline 0.845 & 0.0172 & -0.0008 & 0.0052 & -0.0154 \\
\hline 0.549 & 0.0108 & -0.0087 & 0.0201 & -0.0127 \\
\hline 0.256 & 0.0050 & -0.0060 & 0.0136 & -0.0088 \\
\hline 0.000 & 0.0027 & -0.0028 & 0.0082 & -0.0052 \\
\hline
\end{tabular}


Table 12. In-plane displacements between the steel frame and the wall

\begin{tabular}{|c|c|c|c|c|c|}
\hline $\begin{array}{l}\text { Air bag } \\
\text { pressure } \\
\text { (psi) }\end{array}$ & $\begin{array}{l}\text { LVDT } 11 \\
\text { ch. } \# 91 \\
\text { (in.) }\end{array}$ & $\begin{array}{l}\text { LVDT } 12 \\
\text { ch. } \# 92 \\
\text { (in.) }\end{array}$ & $\begin{array}{l}\text { LVDT } 13 \\
\text { ch. } \# 93 \\
\text { (in.) }\end{array}$ & $\begin{array}{l}\text { LVDT } 14 \\
\text { ch. } \# 94 \\
\text { (in.) }\end{array}$ & $\begin{array}{c}\text { LVDT } 15 \\
\text { ch. } \$ 95 \\
\text { (in.) }\end{array}$ \\
\hline 0.000 & 0.0000 & 0.0000 & 0.0000 & 0.0000 & 0.0000 \\
\hline 0.047 & 0.0002 & 0.0001 & -0.0000 & 0.0001 & 0.0001 \\
\hline 0.098 & 0.0004 & 0.0003 & -0.0000 & 0.0002 & 0.0002 \\
\hline 0.148 & 0.0006 & 0.0004 & 0.0001 & 0.0004 & 0.0003 \\
\hline 0.190 & 0.0008 & 0.0006 & 0.0001 & 0.0005 & 0.0004 \\
\hline 0.249 & 0.0010 & 0.0008 & 0.0001 & 0.0006 & 0.0006 \\
\hline 0.300 & 0.0012 & 0.0000 & 0.0000 & 0.0007 & 0.0008 \\
\hline 0.350 & 0.0014 & 0.0012 & 0.0000 & 0.0008 & 0.0010 \\
\hline 0.401 & 0.0017 & 0.0014 & 0.0000 & 0.0009 & 0.0012 \\
\hline 0.451 & 0.0019 & 0.0017 & -0.0001 & 0.0011 & 0.0013 \\
\hline 0.498 & 0.0022 & 0.0020 & -0.0001 & 0.0014 & 0.0016 \\
\hline 0.549 & 0.0025 & 0.0024 & -0.0002 & 0.0016 & 0.0018 \\
\hline 0.599 & 0.00028 & 0.0020 & -0.0002 & 0.0019 & 0.0020 \\
\hline 0.650 & 0.0031 & 0.0033 & -0.0003 & 0.0021 & 0.0024 \\
\hline 0.697 & 0.0035 & 0.0040 & -0.0004 & 0.0026 & 0.0028 \\
\hline 0.748 & 0.0038 & 0.0046 & -0.0004 & 0.0030 & 0.0030 \\
\hline 0.798 & 0.0041 & 0.0054 & -0.0005 & 0.0033 & 0.0034 \\
\hline 0.849 & 0.0045 & 0.0053 & -0.0006 & 0.0039 & 0.0038 \\
\hline 0.899 & 0.0049 & 0.0074 & -0.0007 & 0.0045 & 0.0043 \\
\hline 0.950 & 0.0053 & 0.0084 & -0.0009 & 0.0050 & 0.0047 \\
\hline 1.000 & 0.0059 & 0.0104 & -0.0010 & 0.0051 & 0.0056 \\
\hline 1.007 & 0.0061 & 0.0111 & -0.0010 & 0.0065 & 0.0058 \\
\hline 1.004 & 0.0002 & 0.0113 & -0.0010 & 0.0065 & 0.0059 \\
\hline 0.979 & 0.0079 & 0.0192 & -0.0011 & 0.0097 & 0.0076 \\
\hline 0.993 & 0.0003 & 0.0278 & -0.0013 & 0.0133 & 0.0095 \\
\hline 0.924 & 0.0108 & 0.0418 & -0.0012 & 0.0208 & 0.0114 \\
\hline 0.845 & 0.0100 & 0.0406 & -0.0010 & 0.0197 & 0.0106 \\
\hline 0.549 & 0.0081 & 0.0376 & -0.0007 & 0.0176 & 0.0091 \\
\hline 0.256 & 0.0047 & 0.0320 & -0.0004 & 0.0143 & 0.0008 \\
\hline 0.000 & 0.0016 & 0.0266 & -0.0002 & 0.0108 & 0.0044 \\
\hline
\end{tabular}




\subsection{POST-TEST WALL}

\section{SURVEY}

Upon completion of the test, all new visible cracks on both sides of the wall were mapped and documented (Before starting the test, existing visible cracks were sketched so as to not confuse them with cracks formed during the test.) Many cracks that became visible during the test closed when the load was removed, making them difficult to trace, but careful inspection of the wall generally revealed the more important ones. After the wall was mapped and photographed, it was removed, block-byblock, in order to study the condition of individual blocks. During wall removal, the double-wythe section of the wall (previously described in Sect. 2.1) was discovered.

Figures 27 and 28 show the post-test crack patterns on each wall face. Cracking through the tile units at the bottom (Fig. 29) is an indication of the compressive failure mode discussed in Sect. 4.2.1. The severity of compressive stresses was greater at the bottom of the wall than at the top. Mortar cracks were found to exist at the wall-beam interface in a 9-ft area adjacent to column D2 (top right of Fig. 27), but the same pattern did not occur at the other end. This would further substantiate

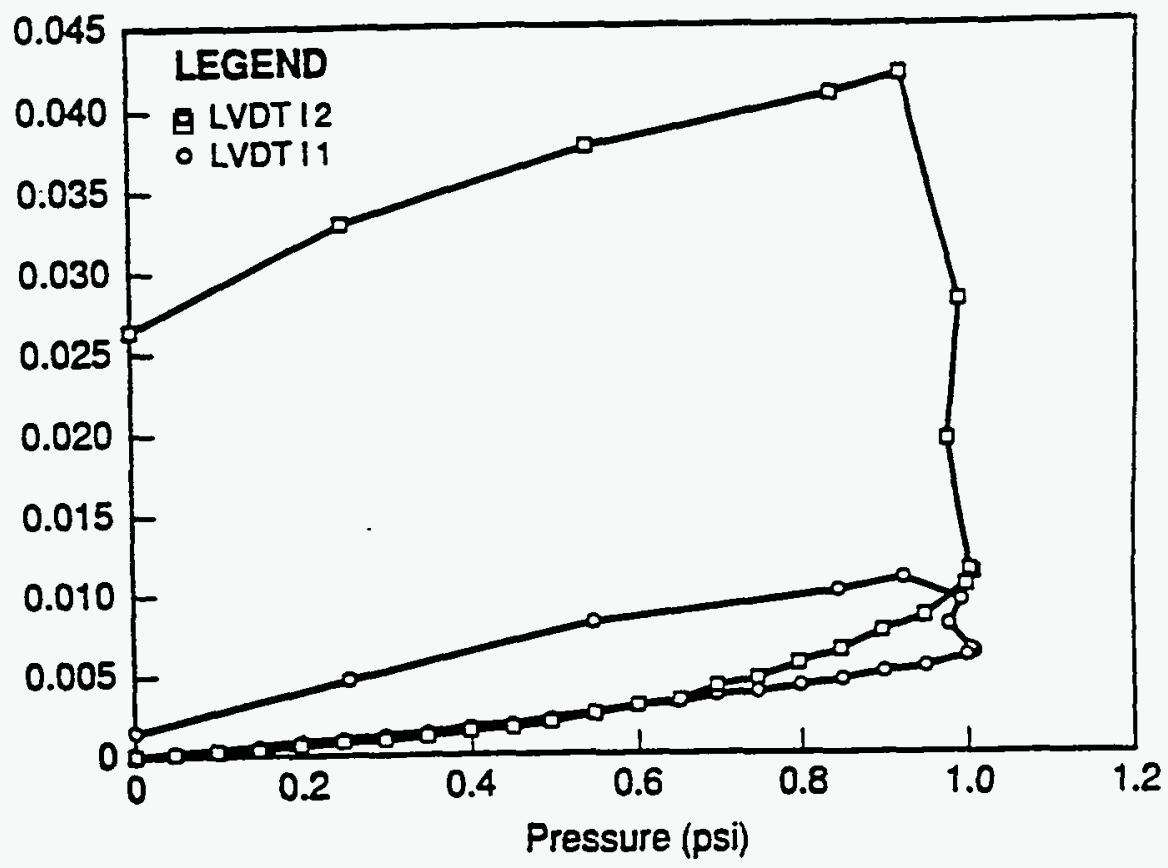

Fig. 25. In-plane wall deflection at column D2 vs. the air bag pressure.

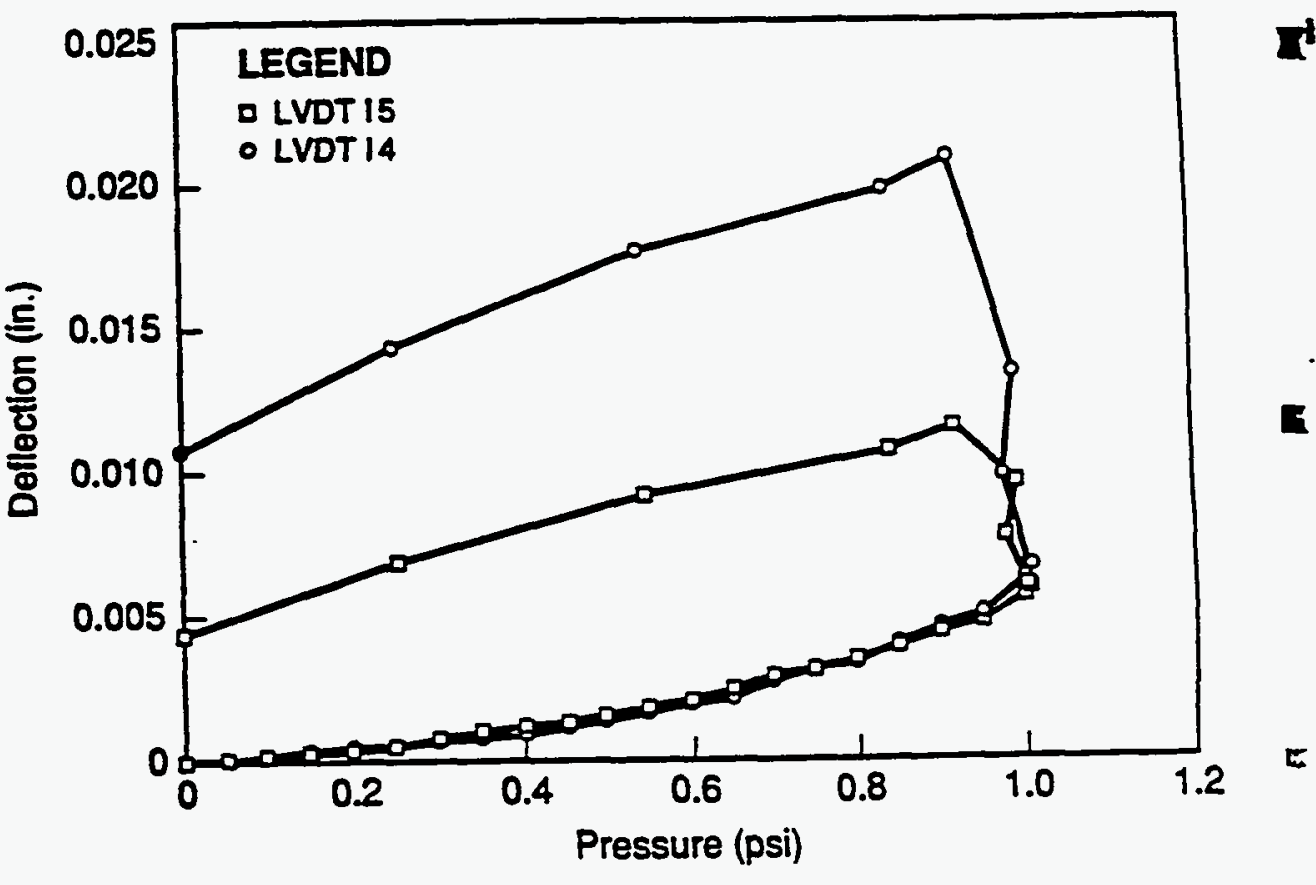

Fig. 26. In-plane deflection at column D3 vs. the air bag pressure. 


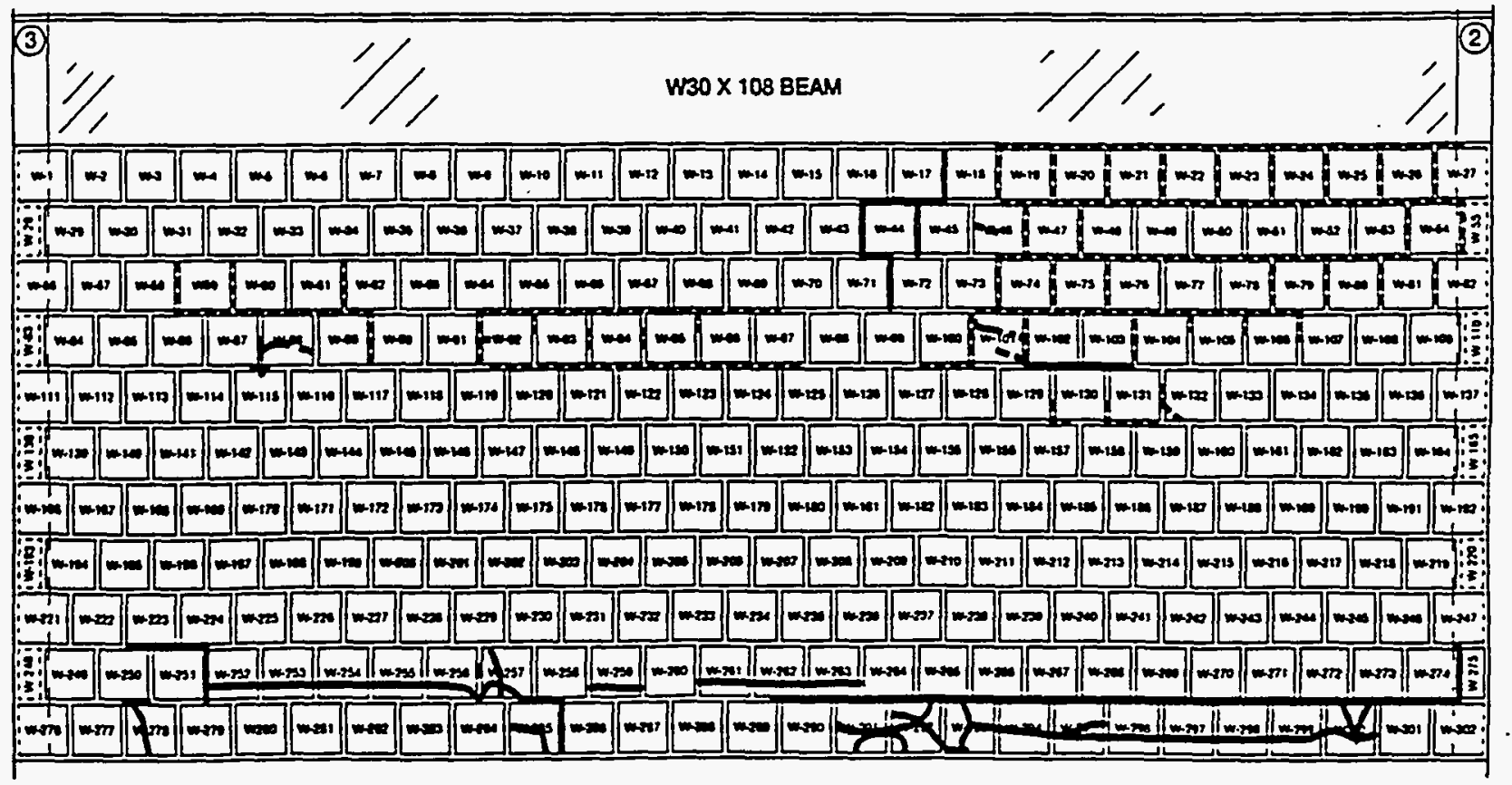

\section{LEGEND}

Colurm number

-.eve. Haitine Cradk-Visible with Rastlight and close inspection

-n.-. Significant Crack-Visible with nomal lightng at a distance of 24" -27

- Major Crack - Visible with normal lighting and showng separation of the mortar or cracking of the block itself

Fig. 27. The cracks in the loaded face of the test wall were mapped and categorized.

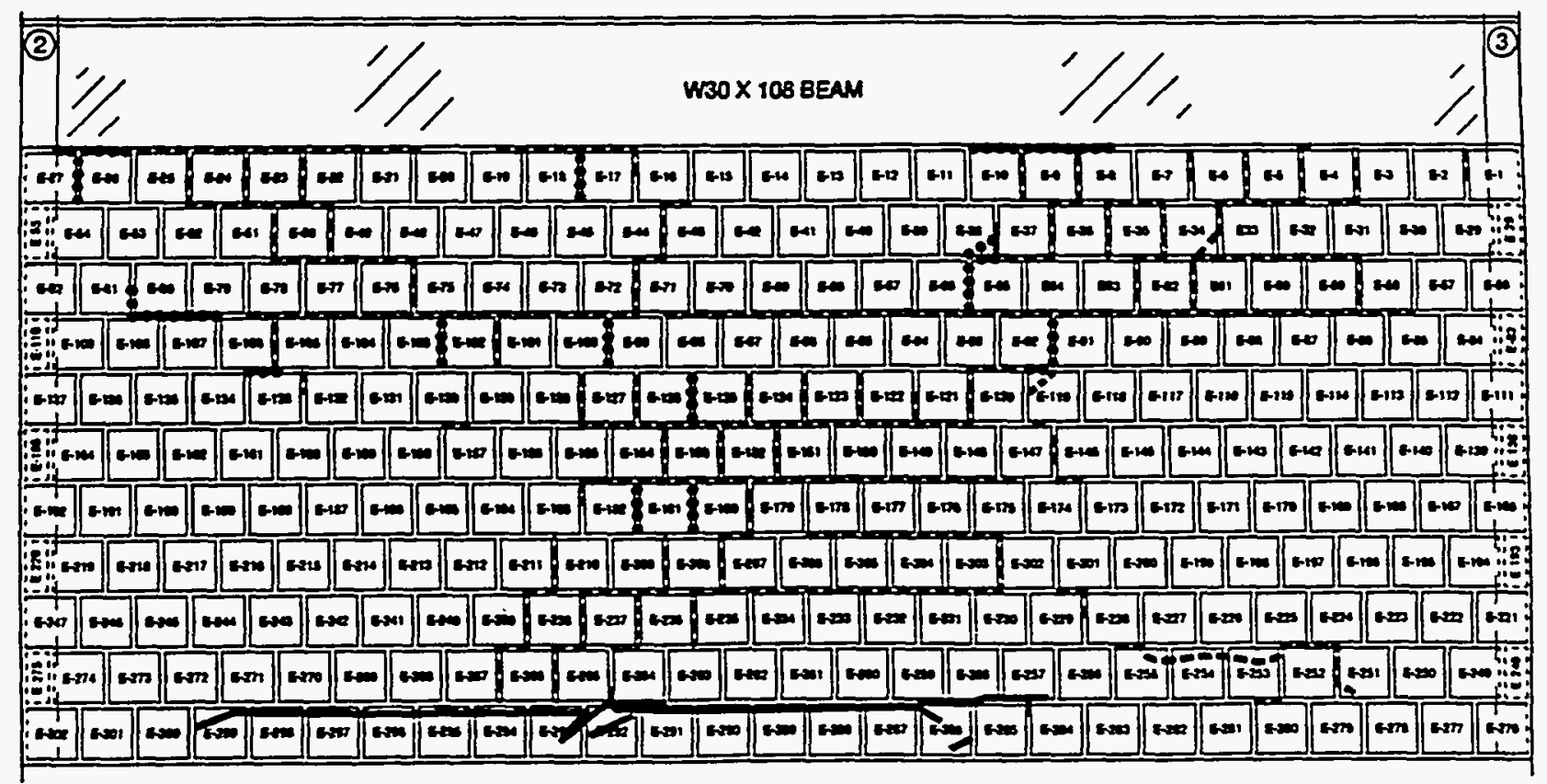

\section{LEGEND}

Column number

c.ove. Hairine Crack-Visible with flashight and close inspection

-..-. Significant Crack-Visiblo with nomal lighting of a distance of $24^{\prime \prime}-27$

Major Crack - Visible with normal lighting and showing separation of the mortar or crecking of the block itself

Fig. 28. The cracks on the hallway side were similarly mapped and categorized. 
comments in Sect. 4.2.1 regarding the "off-loading" of gravity loads to the north half of the wall and the resulting effective gap on the south half.

These double-wythe areas were constructed using two 4-in.thick tile units, side-by-side, with a 1.5-in. gap between. The doublewythe arca of the wall is shown in Fig. 2. It is not clear just what alfect the double-wythe section had on the lateral load capacity of the wall. The maximum wall displaccment of 1.68 in., was less than the 4-in. tilc thickness, however it is considerably larger than the face shcll thickness, but this is also true for the 8-in. units.

In addition to the above comments, the following observations were made during wall removal:

1. Most of the 4-in. tile units were found to be significantly damaged. Cracking of the webs was common. The reaction frame may have partly added to the cracking in the bottom course. Holes were drilled or punched in the bottom course of blocks in four locations so that the steel rods used in the reaction frame could be passed through the wall; this reduced the effective area of the face shell, resulting in local stress concentrations, and in some instances probably produced some local damage to the face shell.

2. Several 8-in. blocks displayed significant cracking of the webs. These blocks are identified in Fig. 30 and a typical case is shown in Fig. 31.

3. The bottom course of the wall was placed into a "keyway" in the floor slab. This keyway, coupled with the mortar bed joint placed underneath the first course, acted in such a manner as to resist rotation of this lower course of tiles. No such connection existed along the top surface of the wall underneath the steel W30 beam, though some mortar was pushed into the gap between the underside of the W30 and the top of the wall. 


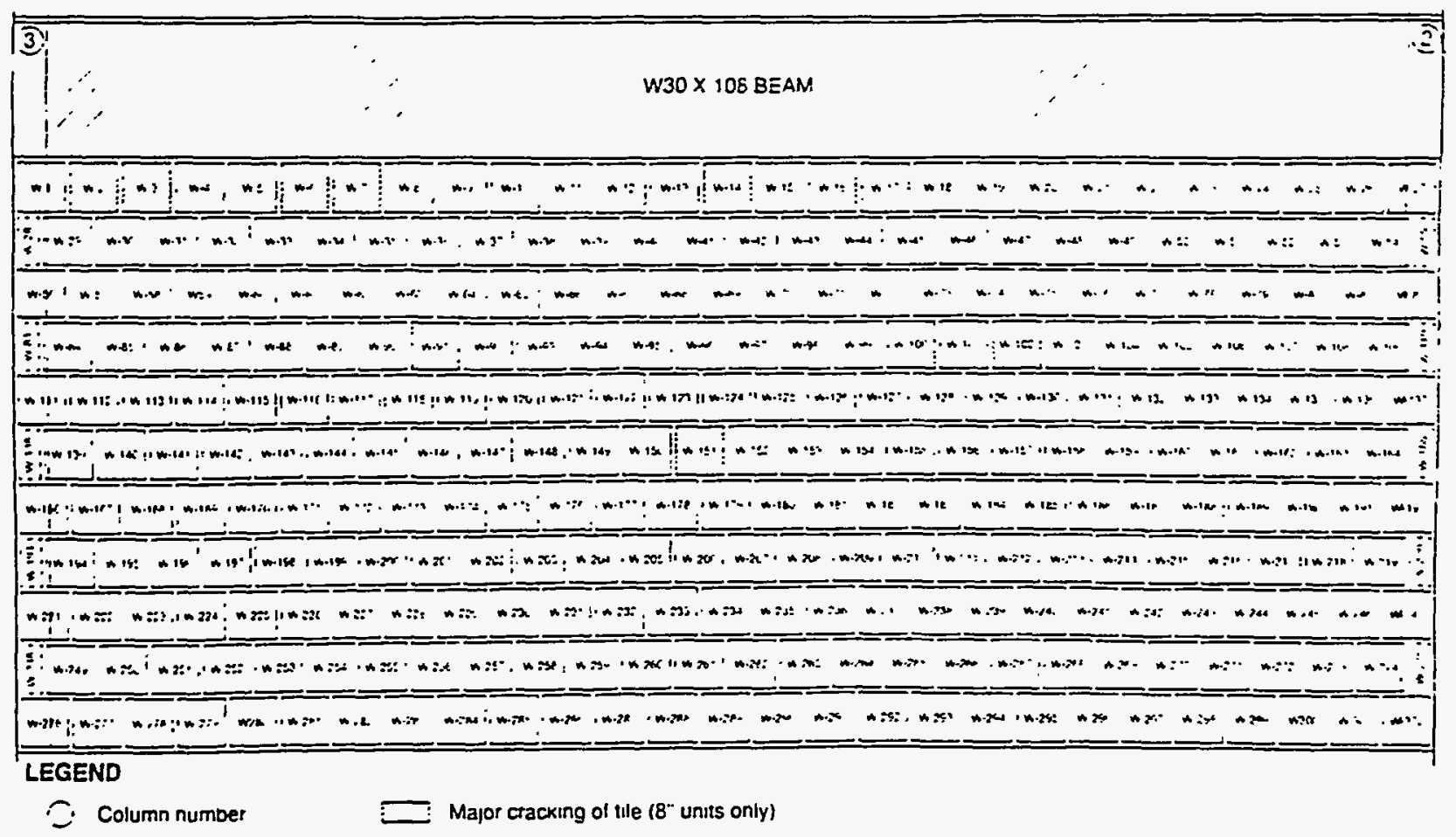

Fig. 30. Separation or cracking of the face shell was identified in 13 HCT blocks that were not in the two base courses of the test wall.

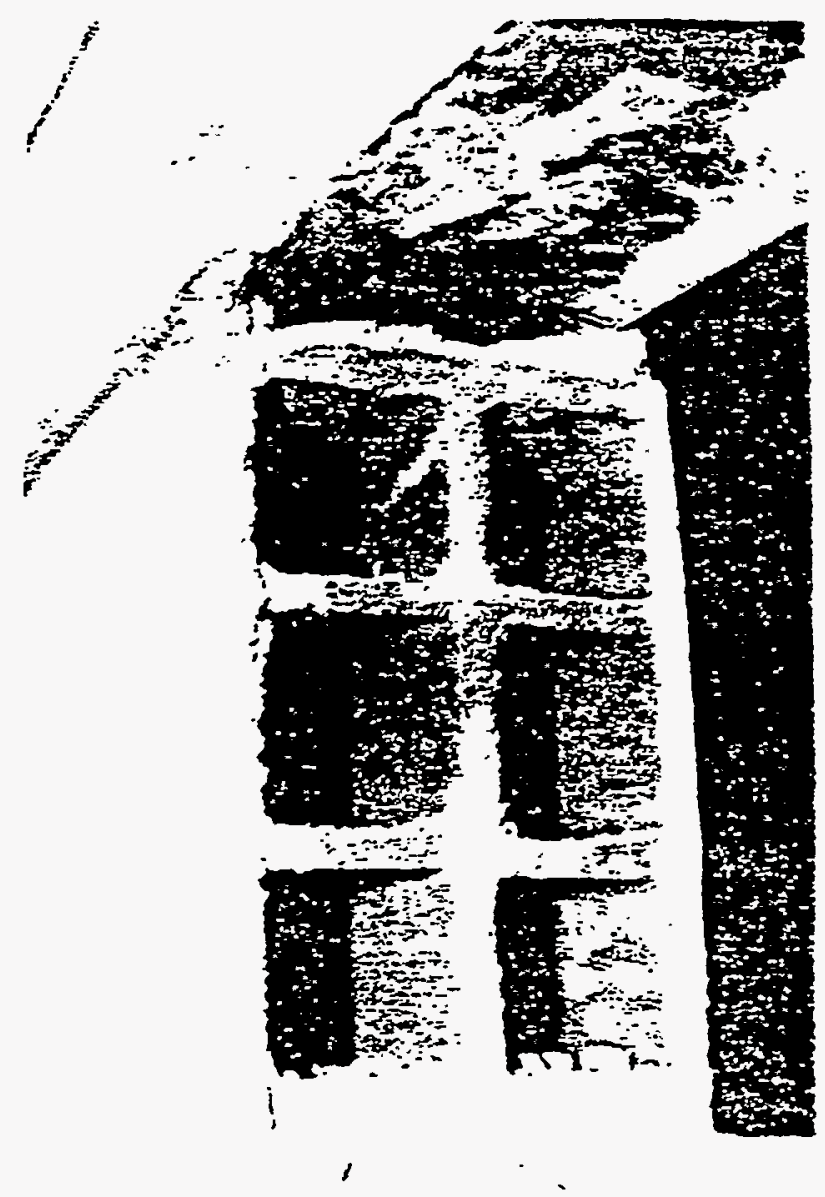

Fig. 31. A typical example of the significant web cracks noted in Fig. 30. 



\section{ANALYTICAL STUDIES}

\subsection{THEORY VS. EXPERIMENTAL RESULTS}

The maximum pressure achieved during the test (1.007 psi) is compared to the predicted values, after the partial load area effect is taken into consideration. Pretest calculations [9] estimated the ultimate capacity, assuming a uniform load over the entire wall area ( $28 \mathrm{ft} \times 12 \mathrm{ft}$ ), to be $2.0 \mathrm{psi}$. The capacity was estimated at 2.3 psi for a loading area equal to $24 \mathrm{ft} \times 10 \mathrm{ft}$. Thus, the partial loading effect is estimated to be 0.87 (2.0/2.3). The bag pressure multiplied by 0.87 produces an estimate of the equivalent, uniform full-area load obtained by the test;

$$
q_{\mathrm{s}}=0.87 \times 1.01=0.88 \mathrm{Lb} / \mathrm{in}^{2} .
$$

This value, taking into account the reduced test area, will be used as the experimental result for comparison with theoretical predictions.

An analytical pressure versus deflection curve was obtained before the test, based on work done by Chua [3], and was discussed in Sect. 1.3. Figure 32 shows the results of Chua's analysis compared to the test result (adjusted). The large discrepancy in the two is probably the result of several factors, including the following:

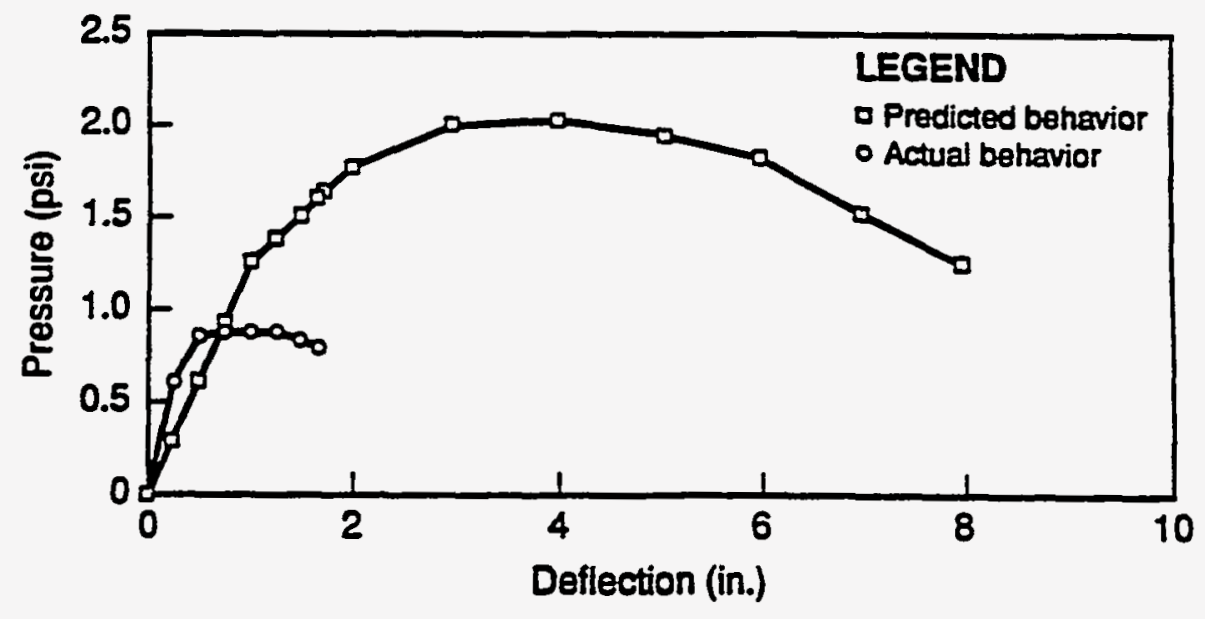

Fig. 32. The predicted out-of-plane wall load capacity compared to the experimentally demonstrated capacity.

1. The analytical model employed assumed no stiffness contribution from the 2nd floor slab, which must, in reality, carry in-plane loads along with the overhead beam.

2. The analytical model had no provision for the inclusion of normal stress effects.

3. The analytical model required the input of wall properties, specifically the compressive strength and elastic modulus of the wall. The benefit of prism test resuits was not available for input to the model and values had to be assumed.

4. Chua's model made no provision for the fact that the test wall was offset from the centerline of the overhead beam and the columns. 


\subsubsection{One-Way Arch Model}

In an effort to resolve the difference between the theoretical and experimental results, a simple one-way arch was developed. The model, shown in Fig. 33, was used to predict a load versus deflection curve for the test wall in Building 9207. The following assumptions were made in developing the one-way arch model:

1. Wall compression due to in-plane loads (that result from arching of the wall and the normal load), is concentrated over the face shell web thickness.

2. Net section material properties are used $\left(f^{\prime}\right.$. and $E_{2}$ ).

3. In-plane spring stiffness is calculated at the midspan of the overhead beam, resulting in a minimum value for spring stiffness.

4. Top and bottom (wallbeam and/or wall-floor)

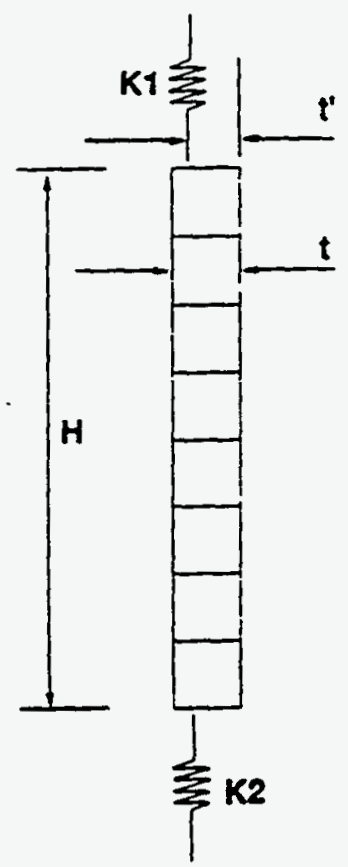

Fig. 33. A one-way arch model was developed to predict a pressure deflection curve. interfaces each carry onehalf of the out-of-plane shear load.

5. A hinge is formed at midheight and at each end (top and bottom).

The modulus of elasticity was taken as $3,000 \mathrm{ksi}$, and the ultimate compressive strength as 725 psi, both based on prism tests. The uniform dead load, $2.7 \mathrm{kips} / \mathrm{ft}$, was discussed in Sect. 1.4. The spring constants in the model were calculated using the centerline deflection of the W30 overhead beam, acting compositely with the second floor slab.

The parameters necessary to establish load versus deflection relationships are the following:

$$
\begin{aligned}
& H=\text { wall height (inches) } \\
& L=\text { wall length (inches) } \\
& t=\text { wall thickness (inches) } \\
& t^{\prime}=\text { portion of the wall under the beam flange (inches) } \\
& q=\text { applied pressure (psi) } \\
& T=\text { in-plane load (lbs) } \\
& k_{1}=\text { in-plane spring stiffness at the top (lbs/inch) } \\
& k_{2}=\text { in=plane spring stiffness at the bottom (lbs/inch) } \\
& U=\text { uniform vertical load on the wall top (lbs/inch) } \\
& W=\text { total self-weight of the wall (lbs) }
\end{aligned}
$$


For a given out-of-plane wall deflection, the following functions must be computed:

$$
\begin{gathered}
\sin (\theta)=\frac{28}{H}, \\
x_{1}=t^{\prime}[\cos (\theta)]-8, \\
x_{2}=\left[t^{\prime}-\frac{t}{2}-\frac{H[\tan (\theta)]}{4}\right] \cos (\theta), \\
T=\frac{\left(t^{\prime}+t\right)[\sin (\theta)]-H[1-\cos (\theta)]}{\frac{1}{k_{1}}+\frac{1}{k_{2}}+\frac{H\left[\cos ^{2}(\theta)\right]}{A E}+U L,} \\
q=\frac{8}{L H^{2}}\left[\left(T+\frac{W}{2}\right) x_{1}-\left(\frac{W}{2}\right) x_{2}\right] .
\end{gathered}
$$

Three criteria are used to determine if a failure has occurred;

1. instability failure $\left(x_{1}=0\right)$;

2. interface shear failure, which occurs if the reaction due to lateral pressure exceeds the frictional capacity at the interface; and

3. Compression failure, which occurs when the calculated compressive stress exceeds the ultimate value.

The predicted pressure versus deflection curve is shown in Fig. 34. The controlling failure mode was compression. A parametric study was performed to evaluate the effects of (1) normal stress, (2) offset, (3) modulus of elasticity, and (4) spring stiffness of the wall, on the ultimate strength capacity and deflection of the wall. The results of the parametric studies are plotted in Figs. 35-38.

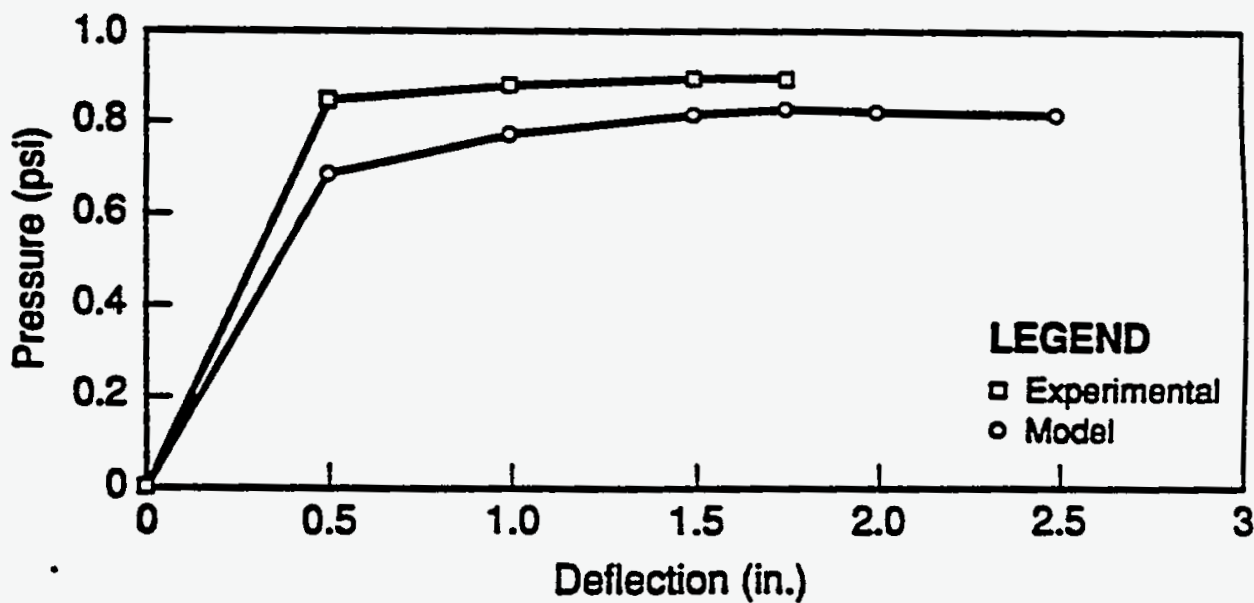

Fig. 34. Comparison of the one-way arch model with actual data from the air bag test. 


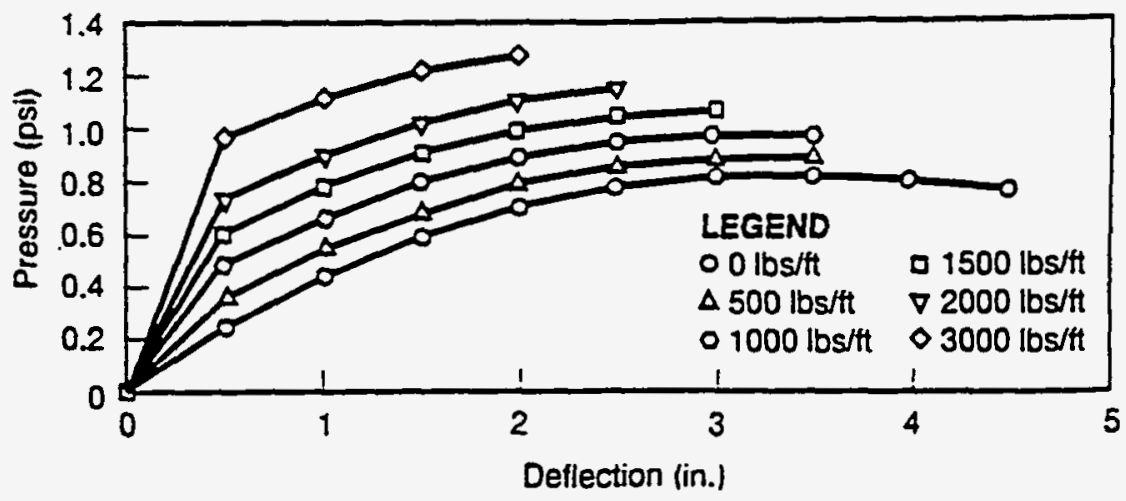

Fig. 35. The effect of normal stress on wall load deflection.

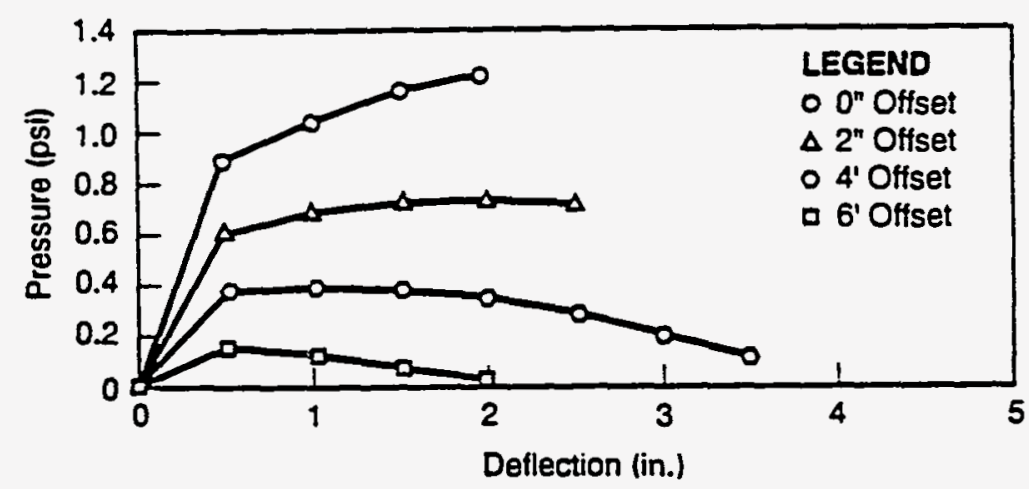

Fig. 36. The effect of wall offset on wall load deflection.

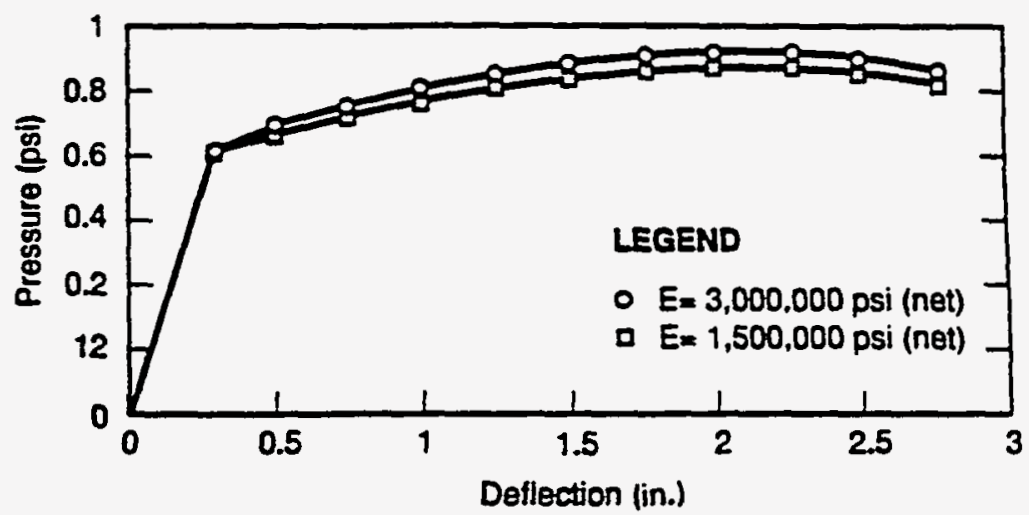

Fig. 37. The effect of elastic modulus on wall load deflection.

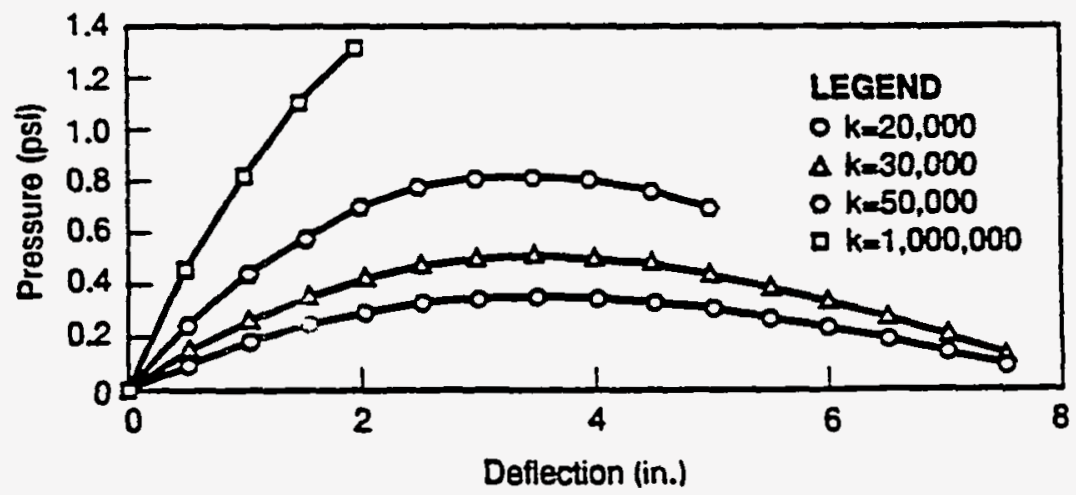

Fig. 38. The effect of spring stiffiness on wall load deflection. 


\subsection{Propped-Cantilever Model}

Another possible failure scenario is described in the following discussion, which will be more qualitative than quantitative. During the wall demolition it was noted that the bottom course of the wall fit into a shallow keyway formed into the concrete floor slab. In addition to a bed joint between the underside of the wall and the keyway, the gap between the keyway and wall was filled with mortar, thus creating a resistance to rotation and movement at the keyway. At the top, the wall was snug against the underside of the W30 beam. The W30 beam was simply supported (rivets) at the two ends and was supported against displacement (though not fully against rotation) at the middle of the span. Thus, it is possible to consider for low pressures that near its center the wall acts as a propped cantilever, fixed at its base and guided at its top. With this in mind, the following scenario is proposed (refer to Tables 3 and 4 and also to Fig. 16):

1. As the wall was initially loaded, the propped-cantilever action of the wall was active. The bottom of the wall is considered at 0.0 in. and the top at 144 in. from the floor slab. (Notice that IVDT V10 is not at the bottom, but is located about 21 in. above it, and likewise, LVTD V1 is located 14 in. below the top of the wall.) The data in Table 4 indicate that the displacement near the top of the wall, up to 1.0 psi was greater than that near the bottom by a factor of two to four. Figures 39 and 40 present plots of this data at $0.25,0.50,0.75$, and $1.00 \mathrm{psi}$. The deflected shape agrees well with the assumption of a propped cantilever, fixed at its base, and guided at its top, especially up to a pressure of $0.25 \mathrm{psi}$. To show this the curves have been extrapolated at each end with dashed lines. To get the curve back through " 0 " at the base, a reverse curvature bending takes place, which indicates an external moment exists. It might even be argued that some bending moment exists up to 0.75 psi. This moment, if it exists, would add to the compressive stress on the wall due to arching action as previously discussed. The combination of bending and arching action would produce the maximum com. pressive stress on the wall near its base on the side opposite the pressure loading (air bag). Also, tensile stress in the wall would exist on the air bag side.

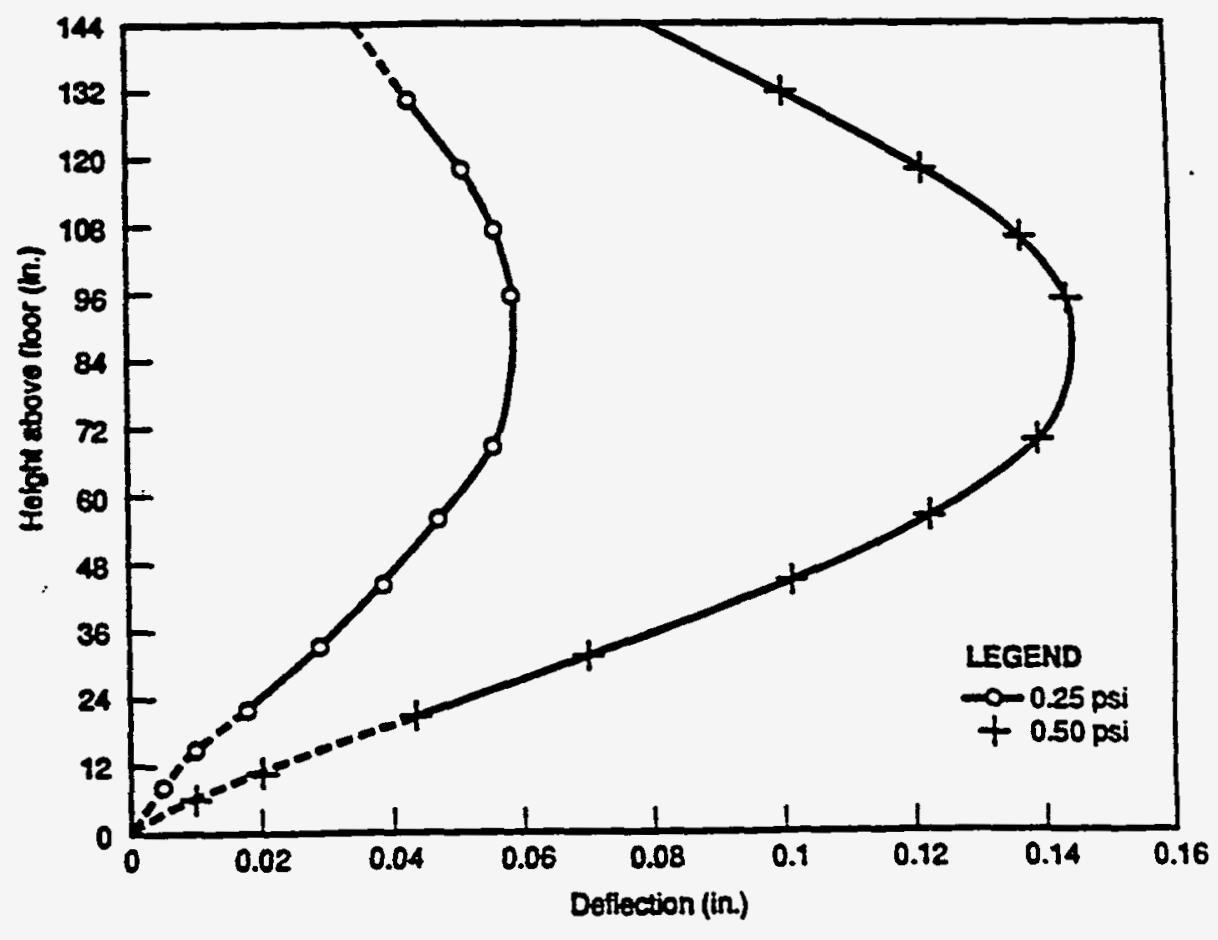

Fig. 39. Vertical defiection profiles at $0.25-$ and 0.50 psi. 
2. Once the air bag pressure attained $1.00 \mathrm{psi}$, the wall began to move outward faster at the bottom (Fig. 41) than at the top indicating a failure had occurred near the bottom. Calculations indicate that the shear created at this interface from a 1.00 psi uniform load is not large enough to fail the wall; therefore, compression was the likely driving force behind this initial failure. From this

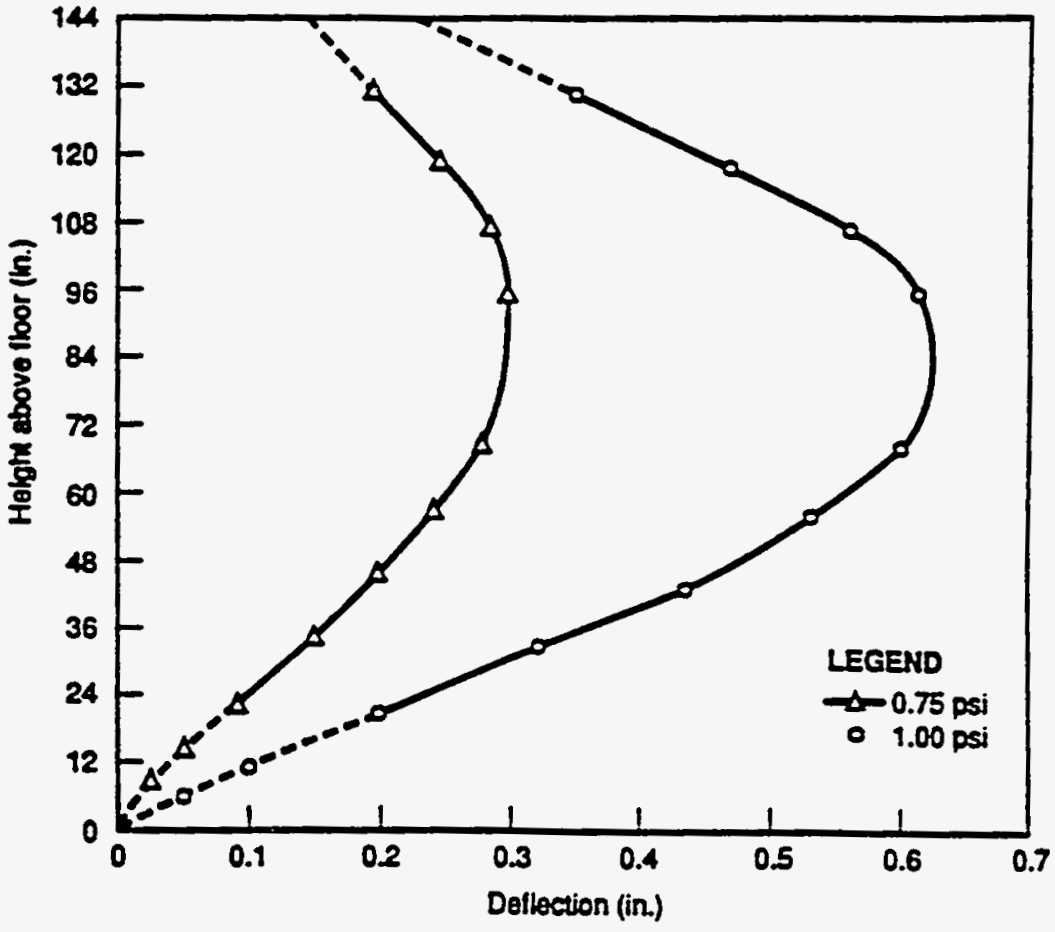

Fig. 40. Vertical deflection profiles at $0.75-$ and 1.00 psi. event on, the wall was unable to resist any increased lateral pressure loads. As can be seen in Fig. 41, the permanent set at the bottom was more than two times than that at the top of the wall.

Referring again to Figs. 27 and 28, major cracks near the bottom on both sides of the wall support the propped cantilever-arching action scenario as the mechanism that caused the final limit state of stress.

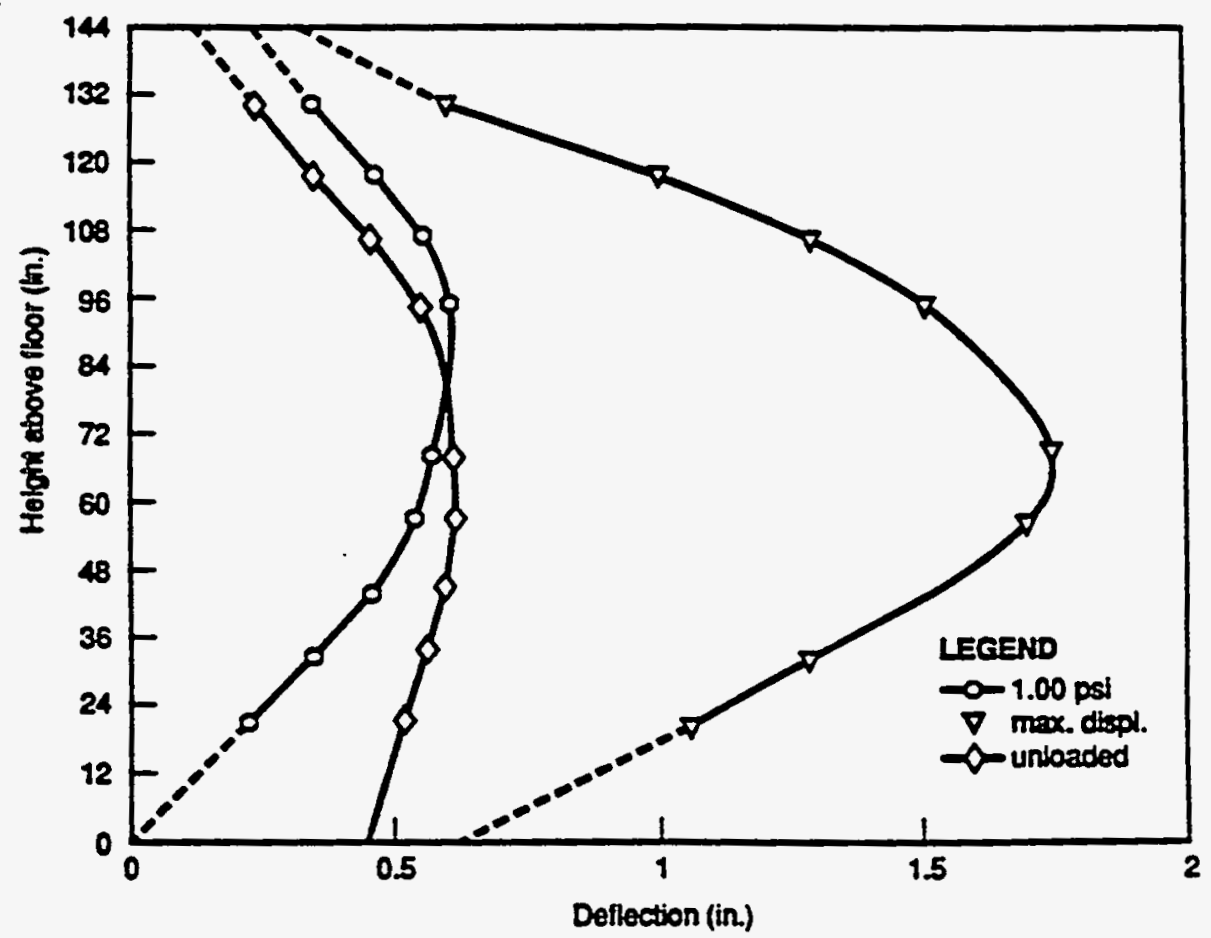

Fig. 41. Vertical deflection profiles at 1.00 psi, maximum displacement, and unioaded. 


\subsection{NATURAL FREQUENCY VERIFICATION}

Low amplitude modal tests were performed both before and after completion of the air bag test. The fundamental frequency of the infill wall prior to the test was found to be $14.43 \mathrm{~Hz}$, while after the test it was $12.97 \mathrm{~Hz}$. This section uses air bag test data to compute frequencies and to compare them with these values.

Pressure-deflection data obtained from the test can be used to compute the natural frequency of the wall at various loading stages. For low-amplitude loads, the wall is treated as if supported on all four sides. With this assumption, the natural frequency (derived from [7]) is given by the following expression:

$$
f_{1}=6.548 \sqrt{\frac{\Delta q_{c b}}{\Delta d_{b s}}},
$$

where

$q_{a b}$ is the actual air bag pressure (psi), and

$d_{v s}$ is the deflection of the center of the wall (inches).

Use of the initial slope of the test's pressure-deflection curve in this equation gives a value of around $15 \mathrm{~Hz}$ for the natural frequency of the wall. This agrees well (within 5\%) with the pretest impact hammer test result of $14.43 \mathrm{~Hz}$. However, using the final slope of the pressure-deflection curve in this equation results in a calculated frequency of around $6 \mathrm{~Hz}$, well below the impact hammer test result of $12.97 \mathrm{~Hz}$ The discrepancy is primarily due to the fact that the low-amplitude tests failed to impose a load sufficient to open cracks within the wall. Although, such cracks are in fact present during the testing, resulting in a lower stiffness; i.e., it appears that two different walls are actually being tested.

\subsection{WIND AND SEISMIC LOADS}

The ultimate out-of-plane capacity of the wall, $0.88 \mathrm{psi}$, will be used to determine equivalent wind velocities and ground accelerations for the wall in Building 9207.

\subsubsection{Wind Loading}

Wind produces a pressure loading on a surface as defined by the following equation from ASCE 7-88 [8]:

$$
q_{z}=0.00256 R_{z}(I V)^{2} \times\left[G C_{p} \pm G C_{p}\right],
$$


where $q_{z}$ is the velocity pressure (psf), $K_{z}$ is an exposure coefficient, $I$ is the importance factor of the facility, $V$ is the wind speed in miles per hour, and $G C_{p}$ and $G C_{p i}$ are cladding coefficients. Assuming an exposure wind load criteria for components and cladding, $C$, and $I=1.07$, the factored normal pressure (psf) on a ground floor wall is given by

$$
w=0.002931(V)^{2}
$$

Solving this equation for an equivalent wind velocity using the experimental ultimate capacity $(0.88 \mathrm{psi}=126.72 \mathrm{psf})$ gives

$$
V=\sqrt{\frac{126.72}{0.002931}}=208 \mathrm{mph},
$$

which simply says that the infill wall resisted the loading produced by an equivalent design wind speed of $208 \mathrm{mph}$, compared with the current worst case requirement for the Oak Ridge Reservation of $113 \mathrm{mph}$ for straight winds [9].

\section{Seismic Loading}

One of the goals of this test was to determine an equivalent static seismic capacity for the wall. Assuming that the wall accelerations are controlled by floor accelerations, and that the fundamental building mode of vibration is within the maximum amplification region of a Newmark-Hall median centered response spectrum $\left(S_{a}=1.52\right.$ maximum, assuming $12 \%$ damping for masonry shear walls), the peak ground acceleration that would produce an out-of-plane load of 0.88 psi on the tested wall is (40 psf is the approximate self-weight of the wall)

$$
P G A=\frac{144(.88)}{1.52(40)}=2.18
$$

The current worst-case criteria for the Oak Ridge Reservation is a $0.32 \mathrm{~g}$ ground acceleration corresponding to the UCRL 15910 "high-hazard" facility use category [9]. 


\section{SUMMARY AND CONCLUSIONS}

The air bag test conducted on an URM infill wall in Building 9207 has shown that the out-ofplane capacity of such infills cannot reliably be predicted by conventional linear simple-beam or plate theory. In-plane loads, which develop during the out-of-plane loading, greatly enhance the ability of the wall to resist lateral loads. Some of the factors affecting the out-of-plane strength of URM infill walls were identified as

(a) boundary conditions, (how the wall is connected to the floor and to the steel frame),

(b) size of the steel frame (stiffness),

(c) pre-existing normal stress,

(d) infill wall constitutive properties,

(e) wall eccentricity with respect to the surrounding frame, and

(f) two-way arching action

More rigorous analytic efforts should be explored to expand upon the simple, one-way arch model developed in this report to include all the effects listed above. However, despite all the variable (and rather poor) construction encountered within the test wall, it still demonstrated a remarkably high lateral-load capacity. 
Distribution

Oak Ridge National Laboratory

Central Research Library

Lab Records

DOE-OR Federal Office Building

R. W. Rucker

Oak Ridge K-25 Site
F. E. Denny
K. E. Fricke
D. K Kelly
C. T. McGloughlin

Oak Ridge Y-12 Plant

P. Adamson

J. E. Beavers

M. B. Butala

W. W. Chance

D. R. Denton

R. E. Fehling

R. D. Flanagan

M. S. Guthrie

R. C. Henderson

T. E. Huff

R. J. Hunt

W. D. Jones

V. L. Jones (RC)

A. K Lee/DOE-OSTI (2)

P. M. McCoy

T. G. Narramore

G. R. Owens

E. G. St. Clair

W. C. Stoddart

M. A. Tenbus

C. C. Wynn

A. K Zava

Y-12 Plant Records 


\section{REFERENCES}

\subsection{PUBLICATIONS}

1. Seah, Chin Kong, Out-of-Plane Behavior of Concrete Masony Infilled Frames, Master of Science in Engineering Thesis, Department of Civil Engineering, The University of New Brunswick, Fredericton, N.B., Canada, April, 1988.

2. Dawe, J. L. and Seah, C. K. "Out-of-Plane Resistance of Concrete Masonry Infilled Frames," Canadian Journal of Civil Engineering, 16, 1989.

3. Chua, Lek Song, Out-of-Plane Behavior of Unreinforced Hollow Clay Tile Masony Infilled Wall Panels, Master of Science Degree Thesis, Civil Engineering Department, The University of Tennessee, Knoxville, Tenn., May 1991.

4. Noland, J. L., Atkinson, R. H., and Schuller, M. P., "A Review of the Flatjack Method for Nondestructive Evaluation," Proceedings: Nondestructive Evaluation of Civil Structures and Materials, University of Colorado, Boulder, Colo., October, 1990.

5. HCTP-21, Test Procedure For Out-of-Plane Full Scale Air Bag Test of A Hollow Clay Tile Wall PanelAt The Y-12 Plant - Building 9207, Engineering Division, Martin Marietta Energy Systems, Inc, Oak Ridge, Tenn., September, 1991.

6. Y/EN-4124, Procedure and Analysis Reports in Support of The Hollow Clay Tile Testing Program, prepared by the University of Tennessee Civil Engineering Department, Knoxville, Tenn., for the Center For Natural Phenomena Engineering, Martin Marietta Energy Systems, Inc., Oak Ridge, Tenn., November, 1990.

7. Roark, R. J. and Young, W. C., Formulas for Stress and Strain, 5th Edition, McGraw-Hill Book Company, New York, N.Y., 1982.

8. ASCE 7-88, Minimum Design Loads for Buildings and Other Structures, American Society of Civil Engineers, New York, N.Y., 1990.

9. Kennedy, R. P., et al, Design and Evaluation Guidelines for Department of Enengy Facilities Subjected to Natural Phenomena Hazards, UCRL-15910, Prepared for the Office of the Assistant Secretary for Environment, Safety, \& Health, Office of Safety Appraisals, United States Department of Energy, June, 1990. 


\subsection{RELATED DOCUMENTS}

Y/EN-4326 (CNPE/HCT-1), Technical Overview of HCTW Program, Center for Natural Phenomena Engineering, Martin Marietta Energy Systems, Inc., Oak Ridge, Tenn., October, 1991.

Y/EN-4452 (CNPE/HCT-9), Management Overview, Hollow Clay Tile Wall Program, Center for Natural Phenomena Engineering, Martin Marietta Energy Systems, Inc., Oak Ridge, Tenn., January, 1992. 